\title{
Fundamental Aspects of Zeolite Waste Form Production by Hot Isostatic Pressing
}

Fuel Cycle Research \& Development

Approved for public release. Distribution is unlimited

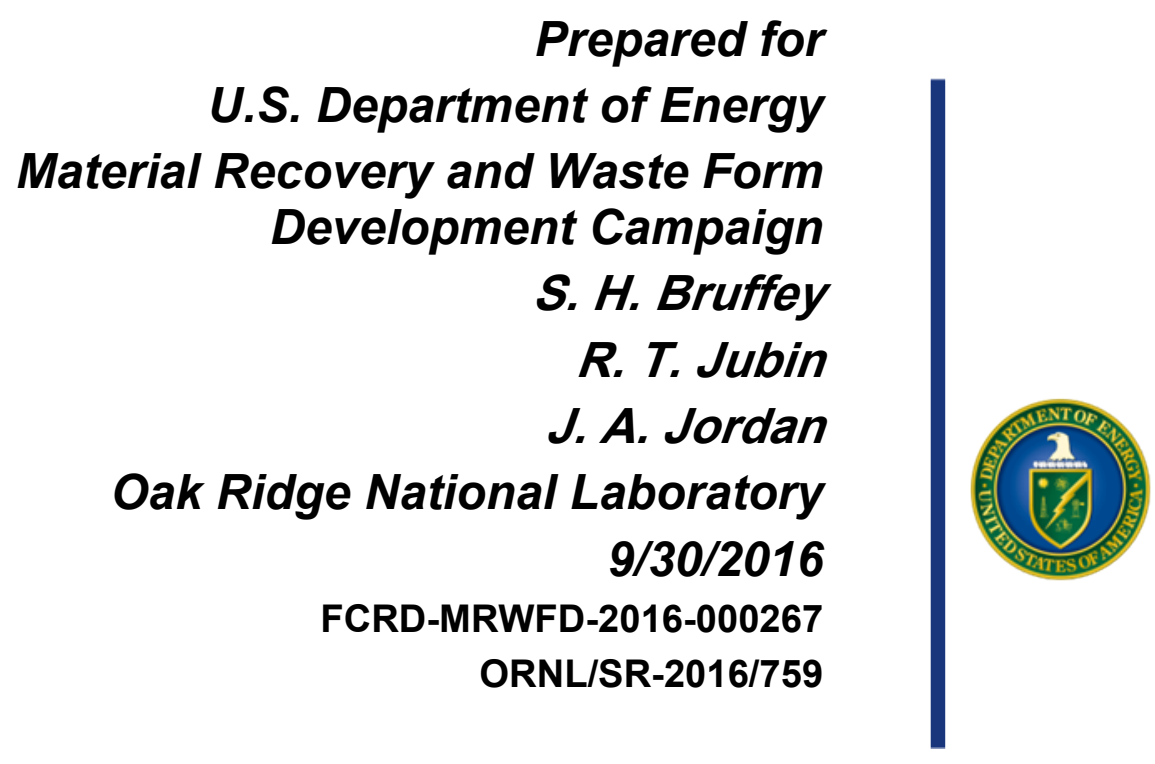





\section{DOCUMENT AVAILABILITY}

Reports produced after January 1, 1996, are generally available free via US Department of Energy (DOE) SciTech Connect.

Website http://www.osti.gov/scitech/

Reports produced before January 1, 1996, may be purchased by members of the public from the following source:

National Technical Information Service

5285 Port Royal Road

Springfield, VA 22161

Telephone 703-605-6000 (1-800-553-6847)

TDD 703-487-4639

Fax 703-605-6900

E-mail info@ntis.gov

Website http://classic.ntis.gov/

Reports are available to DOE employees, DOE contractors, Energy Technology Data Exchange representatives, and International Nuclear Information System representatives from the following source:

Office of Scientific and Technical Information

PO Box 62

Oak Ridge, TN 37831

Telephone 865-576-8401

Fax 865-576-5728

E-mail reports@osti.gov

Website http://www.osti.gov/contact.html

This report was prepared as an account of work sponsored by an agency of the United States Government. Neither the United States Government nor any agency thereof, nor any of their employees, makes any warranty, express or implied, or assumes any legal liability or responsibility for the accuracy, completeness, or usefulness of any information, apparatus, product, or process disclosed, or represents that its use would not infringe privately owned rights. Reference herein to any specific commercial product, process, or service by trade name, trademark, manufacturer, or otherwise, does not necessarily constitute or imply its endorsement, recommendation, or favoring by the United States Government or any agency thereof. The views and opinions of authors expressed herein do not necessarily state or reflect those of the United States Government or any agency thereof. 



\section{SUMMARY}

The direct conversion of iodine-bearing sorbents into a stable waste form is a research topic of interest to the US Department of Energy. The removal of volatile radioactive ${ }^{129}$ I from the off-gas of a nuclear fuel reprocessing facility will be necessary in order to comply with the regulatory requirements that apply to facilities sited within the United States (Jubin et al., 2012a), and any iodine-containing media or solid sorbents generated by this process would contain ${ }^{129} \mathrm{I}$ and would be destined for eventual geological disposal. While recovery of iodine from some sorbents is possible, a method to directly convert iodineloaded sorbents to a durable waste form with little or no additional waste materials being formed and a potentially reduced volume would be beneficial.

To this end, recent studies have investigated the conversion of iodine-loaded silver mordenite (I-AgZ) directly to a waste form by hot isostatic pressing (HIPing) (Bruffey and Jubin, 2015). Silver mordenite $(\mathrm{AgZ})$, of the zeolite class of minerals, is under consideration for use in adsorbing iodine from nuclear reprocessing off-gas streams. Direct conversion of I-AgZ by HIPing may provide the following benefits: (1) a waste form of high density that is tolerant to high temperatures, (2) a waste form that is not significantly chemically hazardous, and (3) a robust conversion process that requires no pretreatment.

One focus of the research described in this report was the potential production of iodine-bearing sodalite (I-sodalite) from I-AgZ by HIPing. There are studies showing the conversion of iodine-bearing zeolite minerals to I-sodalite, but this conversion has not been demonstrated for I-AgZ (Sheppard et al., 2006; Maddrell, 2005). Conversion to I-sodalite, a well-characterized mineral, is desirable as it could substantially decrease the amount of research required to assess the long-term stability as compared to other less-understood iodine waste forms.

Experiments were conducted to determine the effects of zeolite type, iodine loading or inclusion method, pressing conditions, and alumina addition on the HIPing of iodine-loaded zeolites. In an effort to assess the potential for production of I-sodalite from iodine-bearing zeolites, a series of experiments were designed to replicate a demonstration of zeolite conversion to I-sodalite available in the literature, and to extend that to the potential conversion of I-AgZ.

A set of 16 samples were produced, HIPed, and analyzed by X-ray diffraction (XRD). The zeolites under investigation included silver-exchanged zeolite Type A (AgA), silver-exchanged faujasite (AgX), silverexchanged mordenite (AgZ), and sodium mordenite (NaZ). HIP pressures ranged from 175 to $300 \mathrm{MPa}$. Iodine was incorporated into the zeolite material through either occlusion or chemisorption at varying iodine: zeolite ratios.

Fifteen samples were successfully compressed. This success rate is a substantial improvement over previous efforts and is a result of modifications made to the capsule design. XRD to assess the mineral phases present in the compressed samples indicated that none of the pressed samples retained the original zeolite structure. XRD analysis indicated that all I-AgA and some I-AgX samples converted to an iodinebearing sodalite phase $\left[\mathrm{Ag}_{4} \mathrm{Al}_{3}\left(\mathrm{SiO}_{4}\right)_{3} \mathrm{I}\right]$ with nepheline, a 1:1 aluminosilicate phase also present for some samples. This conversion was not observed with $\mathrm{AgZ}$. AgZ and $\mathrm{AgX}$ samples that did not convert to iodosodalite were observed to have quartz $\left(\mathrm{SiO}_{2}\right)$ and $\mathrm{AgI}$ in each sample, with mullite, a pure alumina silicate of formula $\mathrm{Al}_{2.26} \mathrm{Si}_{0.74} \mathrm{O}_{4.87}$, present in the non-converted I-AgX samples.

The experimental methodology described in this report was found to satisfactorily replicate other published studies. This provided confidence in the experimental methodology and also confirmed that iodo-sodalite formation from certain zeolitic minerals is possible. This iodo-sodalite formation had only previously been shown to result from iodine-occluded silver-exchanged zeolites A and X (faujasite). This effort demonstrated that HIPing of iodine-loaded zeolites, in which the iodine has been chemisorbed into the mineral from a gas stream, could also result in iodo-sodalite formation upon HIPing. Several differences were observed between iodine-loaded samples produced by chemisorption and iodine-loaded samples produced by occlusion. 
One of the most significant observations from the completed work was that no iodo-sodalite formation was observed for any of the I-AgZ samples, either chemisorbed or occluded. This is likely tied to the relative amounts of silicon and aluminum present in $\mathrm{AgZ}$ as compared to $\mathrm{AgA}$ and $\mathrm{AgX}$. The silicon-toaluminum ratio ( $\mathrm{Si}: \mathrm{Al}$ ) for the mordenite unit cell is five times that of $\mathrm{AgX}$ and $\mathrm{AgA}$. The importance of this characteristic was first identified by Sheppard et al. (2006) and has been reinforced through this study.

Throughout the course of the testing described in this report, and through previous efforts, attention has been given to optimizing the pressing conditions for Ag-zeolite samples. Temperatures have ranged from 525- $1100^{\circ} \mathrm{C}$, and pressures have ranged from $75-300 \mathrm{MPa}$. This work used pressures of 175 , 190, and $300 \mathrm{MPa}$. No difference (either visually or through XRD) was identified that could be correlated to pressure conditions. Further characterization, such as through waste form durability testing, would be required to fully describe the effect of pressure on HIPing of iodine-loaded zeolite minerals.

The HIP process continues to demonstrate promise as a method for the direct consolidation of I-AgZ to a waste form. In envisioning a large-scale waste form conversion effort, the lack of chemical pretreatment required for the sorbent prior to waste form manufacture, the mechanical stability, and the relatively low chemical hazards associated with the sorbent material suggest that this could be a very desirable process for waste form creation from I-AgZ. 


\section{CONTENTS}

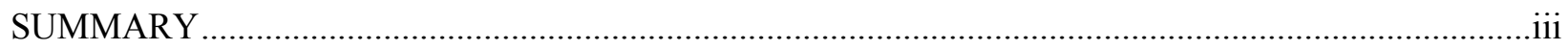

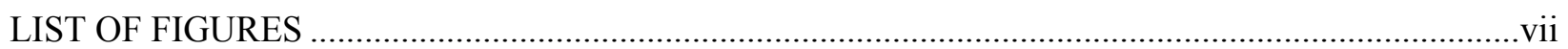

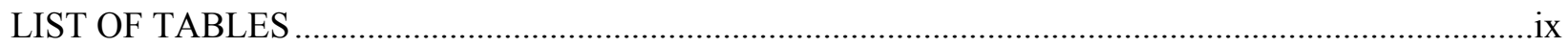

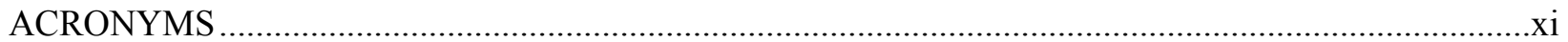

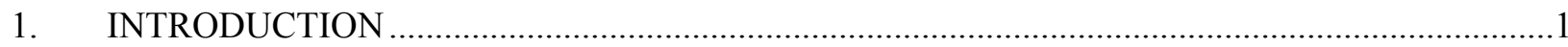

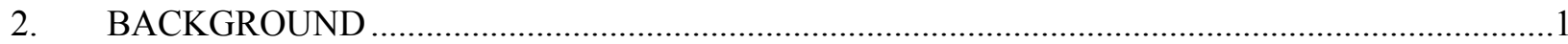

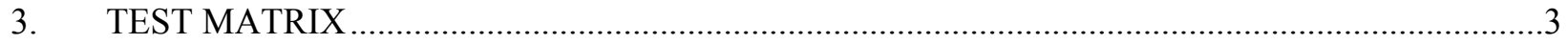

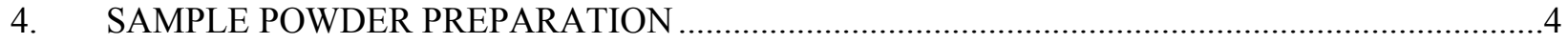

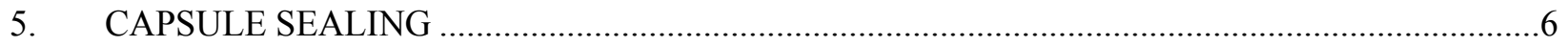

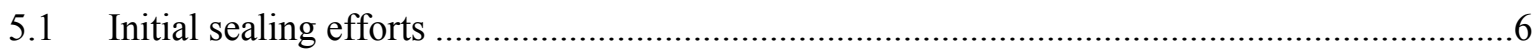

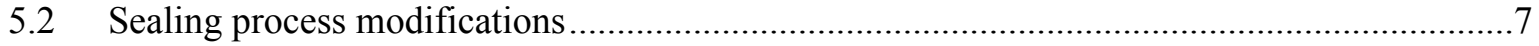

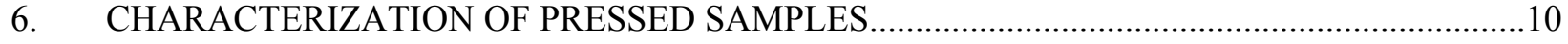

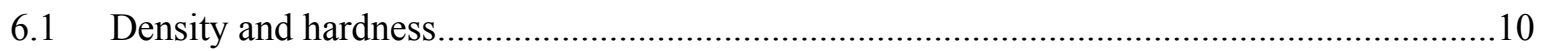

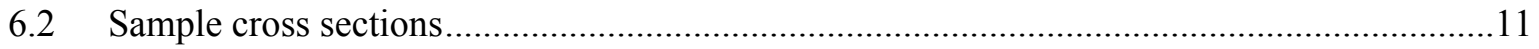

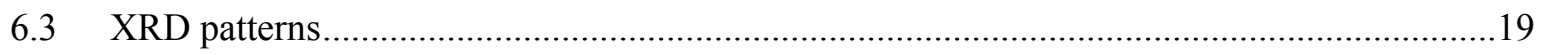

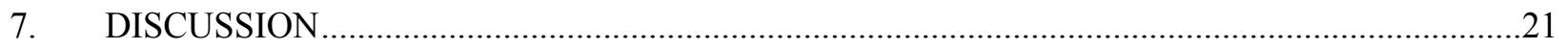

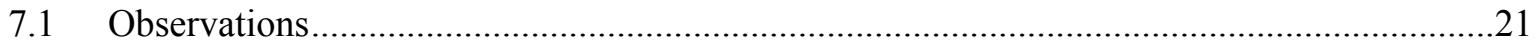

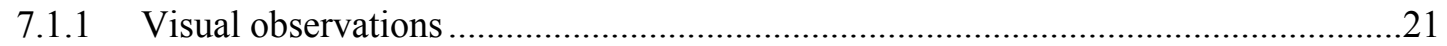

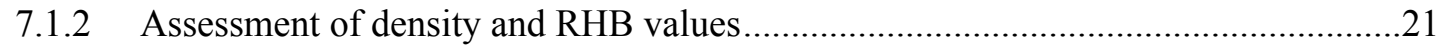

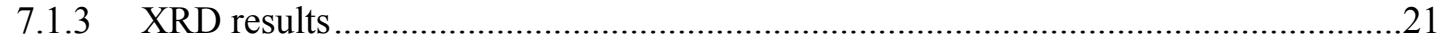

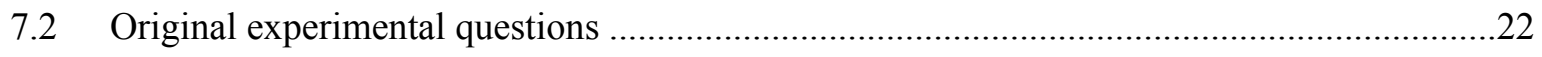

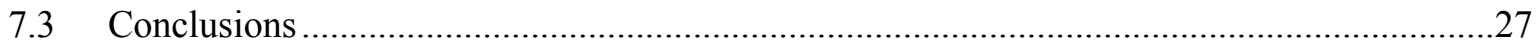

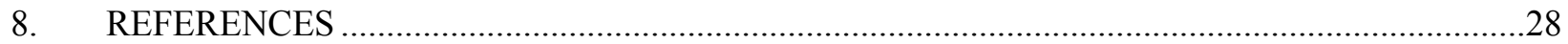

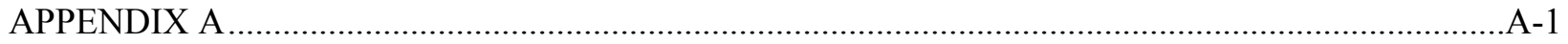


This page is intentionally left blank. 


\section{LIST OF FIGURES}

Figure 1. Sealed sample capsule.

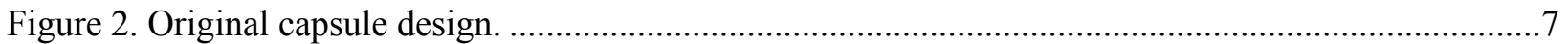

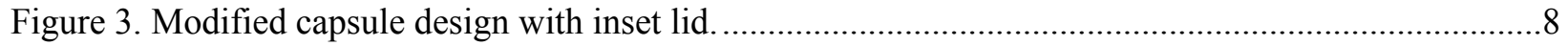

Figure 4. Modified capsule design with inset vacuum port lid..............................................................

Figure 5. Capsule lid modifications (L to R: original, inset cap, inset vacuum port lid)...........................9

Figure 6. Cross section of Sample 1 (AgA | Occluded | 1:2 | 190 MPa). .................................................12

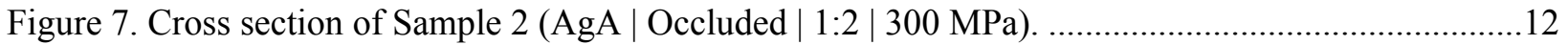

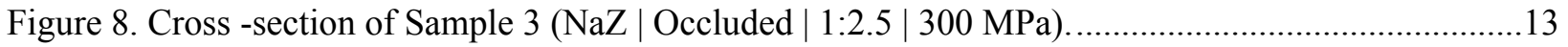

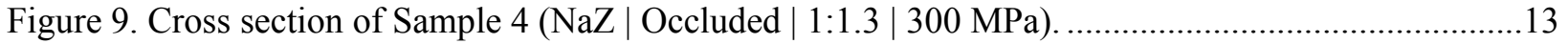

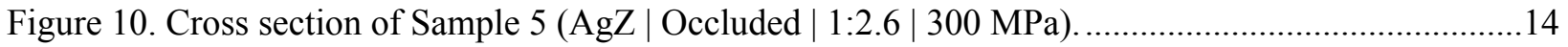

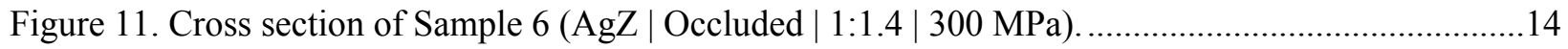

Figure 12. Cross section of Sample 7 (AgX | Occluded | 1:14.7 | $300 \mathrm{MPa})$.........................................15

Figure 13. Cross section of Sample 8 (AgX | Occluded | 1:14.8 | $300 \mathrm{MPa})$..........................................15

Figure 14. Cross section of Sample 9 (AgA | Chemisorbed | 1:0.2 | $175 \mathrm{MPa})$......................................16

Figure 15. Cross section of Sample 10 (AgA | Chemisorbed | 1:0.2 | $300 \mathrm{MPa})$...................................16

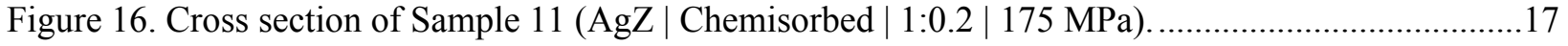

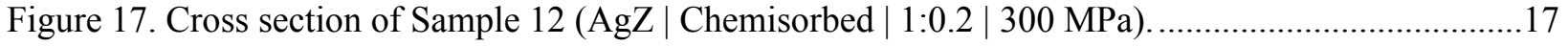

Figure 18. Cross section of Sample 13 (AgX | Chemisorbed | 1:2.8 | $175 \mathrm{MPa})$....................................18

Figure 19. Cross section of Sample $14(\mathrm{AgX} \mid$ Chemisorbed | 1:2.8 | $300 \mathrm{MPa})$....................................18

Figure 20. Cross section of Sample $16\left(\mathrm{AgX} \mid\right.$ Chemisorbed | 1:2.8 | $\left.300 \mathrm{MPa} \mid \mathrm{Al}_{2} \mathrm{O}_{3}\right)$.......................19

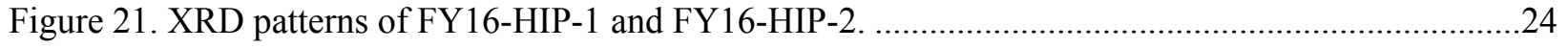

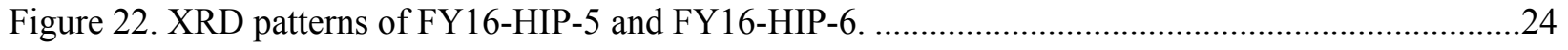

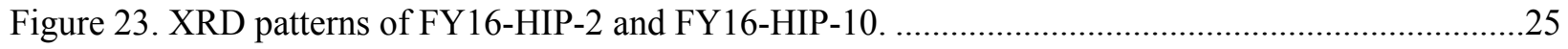

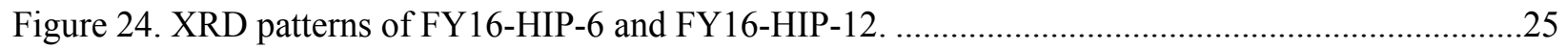

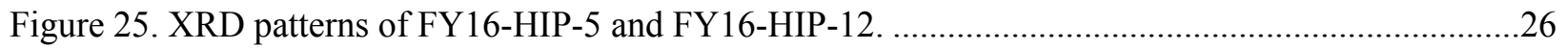

Figure 26. XRD patterns of FY16-HIP-14 and FY16-HIP-16. .............................................................26

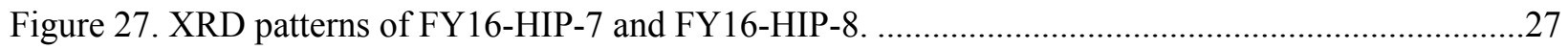


This page intentionally left blank. 


\section{LIST OF TABLES}

Table 1. Chemical composition of selected zeolite minerals ................................................................2

Table 2. $\mathrm{SiO}_{2}$-to-sodalite ratio for selected conversions .........................................................................

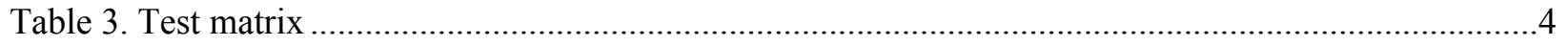

Table 4. Zeolite : AgI molar ratios for occluded samples........................................................................

Table 5. Iodine loading of silver-exchanged zeolites ...............................................................................

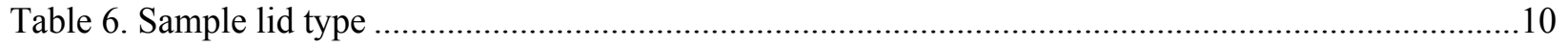

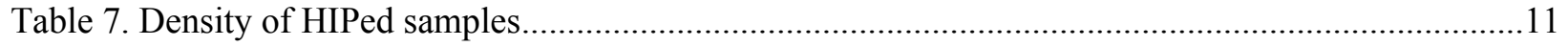

Table 8. Hardness of HIPed samples ...............................................................................................

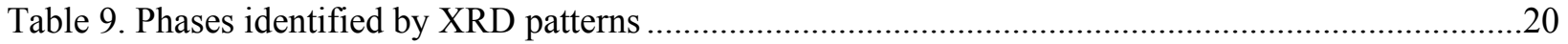


This page is intentionally left blank. 


\section{ACRONYMS}

$\operatorname{AgA}$

$\operatorname{AgX}$

$\operatorname{AgZ}$

ASTM

I-AgZ

HIP

HUP

ORNL

PCT

RHA

RHB

SEM

XRD
Silver-exchanged zeolite A

Silver-exchanged faujasite

Silver-exchanged mordenite

American Society for Testing and Materials

Iodine-loaded silver-exchange mordenite

hot isostatic press

hot uniaxial press

Oak Ridge National Laboratory

Product Consistency Testing

Rockwell hardness A

Rockwell hardness B

scanning electron microscopy

X-ray diffraction 
This page is intentionally left blank. 


\section{FUNDAMENTAL ASPECTS OF ZEOLITE WASTE FORM PRODUCTION BY HOT ISOSTATIC PRESSING}

\section{INTRODUCTION}

The direct conversion of iodine-bearing sorbents into a stable waste form is a research topic of interest to the US Department of Energy. The removal of volatile radioactive ${ }^{129}$ I from the off-gas of a nuclear reprocessing facility will be necessary in order to comply with the regulatory requirements that apply to facilities sited within the United States (Jubin et al., 2012a). Efforts in iodine removal from these gas streams have focused on adsorption of iodine by silver-containing sorbents, which will result in the formation of AgI, a relatively insoluble mineral with a high melting point (Matyáš, 2011; Jubin et al., $2012 b)$. Sorbents containing ${ }^{129}$ I would be destined for geological disposal, but the location and repository conditions are currently indeterminate, and the specific waste form has not yet been selected. While recovery of iodine from these sorbents is possible, a method to directly convert the iodine-loaded sorbents to a durable waste form with little or no additional waste materials being formed and potentially reduced volume would be beneficial.

To this end, recent studies have investigated the conversion of iodine-loaded silver mordenite (I-AgZ) directly to a waste form by hot isostatic pressing (HIPing) (Bruffey and Jubin, 2015). Silver mordenite $(\mathrm{AgZ})$, of the zeolite class of minerals, is under consideration for use in adsorbing iodine from nuclear reprocessing off-gas streams, and a substantial amount of research has been reported on the iodine adsorption characteristics of AgZ (Jubin and Strachan, 2015). AgZ is commercially available in pellet form with silver concentrations of $\approx 10 \mathrm{wt} \%$ and maximum iodine loadings of $10-12 \mathrm{wt} \%$.

A waste form and the process by which it is produced can be evaluated by a number of metrics (Jubin et al., 2016). Direct conversion of I-AgZ may provide the following benefits: (1) a waste form of high density that is tolerant to high temperatures, (2) a waste form that is not significantly chemically hazardous, and (3) a robust conversion process that requires no pretreatment. Waste form performance evaluation metrics include quantification of the dissolution or release rate of the radionuclide from the waste form and the interaction of the waste form with canister materials.

One focus of the research described here focused on the potential production of iodine-bearing sodalite (I-sodalite) from I-AgZ as one of the products formed by HIPing. There are studies showing the conversion of iodine-bearing zeolite minerals to I-sodalite, but this conversion has not been demonstrated for I-AgZ (Sheppard et al., 2006; Maddrell, 2005). Conversion to I-sodalite, a well-characterized mineral, is desirable as it could substantially decrease the amount of research required to assess the long-term stability as compared to other less-understood iodine waste forms.

The work described in this report aimed to determine the effects that zeolite type, method and quantity of iodine inclusion, pressing conditions, and alumina addition would have on the HIPing of iodine-loaded zeolites. In an effort to assess the potential for production of I-sodalite from iodine-bearing zeolites, a series of experiments were designed to replicate a demonstration of zeolite conversion to I-sodalite available in the literature, and to extend that to the potential conversion of I-AgZ.

\section{BACKGROUND}

Direct conversion of iodine-bearing zeolites into a waste form by HIPing has been investigated by several researchers. Zeolite minerals refer to those hydrated aluminosilicate minerals with a specific tetrahedral layered $\mathrm{AlO}_{4} / \mathrm{SiO}_{4}$ structure. Specific chemical compositions for the zeolites of interest to this work are shown in Table 1. 
Table 1. Chemical composition of selected zeolite minerals

\begin{tabular}{|c|c|}
\hline Zeolite & Chemical composition \\
\hline $\mathrm{A}$ & $\mathrm{M}_{12}^{+}\left(\mathrm{Al}_{12} \mathrm{Si}_{12} \mathrm{O}_{48}\right) \cdot 27 \mathrm{H}_{2} \mathrm{O}$ \\
\hline $\mathrm{X}$ & $\mathrm{M}_{86}^{+}\left(\mathrm{Al}_{86} \mathrm{Si}_{106} \mathrm{O}_{384}\right) \cdot 264 \mathrm{H}_{2} \mathrm{O}$ \\
\hline $\mathrm{Y}$ & $\mathrm{M}_{56}^{+}\left(\mathrm{Al}_{56} \mathrm{Si}_{136} \mathrm{O}_{384}\right) \cdot 264 \mathrm{H}_{2} \mathrm{O}$ \\
\hline $\mathrm{Z}$ & $\mathrm{M}_{8}^{+}\left(\mathrm{Al}_{8} \mathrm{Si}_{40} \mathrm{O}_{96}\right) \cdot 24 \mathrm{H}_{2} \mathrm{O}$ \\
\hline
\end{tabular}

HIPing of iodine-loaded silver zeolite or silver silica gel with a metal is described in a Japanese and US patent (Fukumoto, 1998). These studies mixed either iodine-loaded faujasite or iodine-loaded silverimpregnated silica gel with 50 vol\% copper powder and pressed the samples at $860^{\circ} \mathrm{C}$ at $195 \mathrm{MPa}$ for $3 \mathrm{~h}$. This resulted in confinement of AgI particles to the adsorbent and the encapsulation of the adsorbent within a sintered metallic matrix. A second Japanese study HIPed silver nitrate-impregnated alumina at $1200^{\circ} \mathrm{C}$ and $175 \mathrm{MPa}$ for $3 \mathrm{~h}$. The resulting product had a density greater than $4.0 \times 10^{3} \mathrm{~kg} / \mathrm{m}^{3}$ (Tanabe, 2010).

There are two reported conversions of zeolites to sodalite by HIP. In 2005, the National Nuclear Laboratory in the United Kingdom demonstrated HIPing of A and X zeolites at $900^{\circ} \mathrm{C}$, converting them to a sodalite (Maddrell, 2005). Sheppard et al. (2006) investigated the conversion of various iodinebearing silver zeolites to form I-sodalite. These included the silver-exchanged zeolites of structural type $\mathrm{A}, \mathrm{X}$, and $\mathrm{Y}$. These tests were conducted with powdered zeolites occluded with powdered AgI. HIP conditions were $900^{\circ} \mathrm{C}$ at $190 \mathrm{MPa}$ for $2 \mathrm{~h}$. Silver zeolite Y was not observed to form sodalite, while silver-exchanged zeolites $\mathrm{A}$ and $\mathrm{X}$ appear to form monolithic sodalities.

ORNL has recently performed several studies focused on the hot pressing of $\mathrm{AgZ}$, ranging from initial scoping tests with hot uniaxial pressing to more systematic studies identifying pressing conditions, the mineral phases produced during HIPing, and the homogeneity of iodine distribution within the pressed mineral (Bruffey and Jubin, 2016; Jubin and Bruffey, 2015). The most recent experimental study conducted by ORNL on the HIPing of I-AgZ focused upon multiple mordenite forms, including sodium mordenite (NaZ), pure AgZ, and engineered AgZ that includes a clay binder material (Bruffey and Jubin, 2015). The variables investigated included the pressure and temperature of pressing, the ratio of mineral to iodine, and the form of iodine (NaI vs. AgI). In this study, the minerals and iodide forms were ground together by mortar and pestle and then pressed using the desired pressing conditions. The pressed samples were characterized according to their densities, analyzed by x-ray diffraction (XRD) to ascertain mineral phases, and tested by product consistency testing (PCT) protocol to determine their durability. The resultant waste forms had densities two to three times greater than the bulk density of the unconsolidated material. Of the 12 samples tested by PCT, six had no measureable release of iodine. The initial tests showed these favorable PCT results at a HIP temperature of $900^{\circ} \mathrm{C}$, with no improvement observed at higher temperatures. No correlations between iodine release and HIP pressure were observed in this work. The findings resulted in the selection of $900^{\circ} \mathrm{C}$ for future HIP testing. XRD revealed that after pressing, the sample material was largely amorphous, with some $\mathrm{SiO}_{2}$ and $\mathrm{AgI}$ phases distinct within the sample.

These results indicate that HIP of I-AgZ is likely to produce a durable, densified waste form. The conversion of mordenite to sodalite has not been observed in ORNL efforts to date. Thus, one objective of this work was to more systematically confirm whether this conversion was possible through replication of the work by Sheppard and extension to minerals of interest to this particular application. The following conversion pathways for I-AgA and I-AgX were proposed by Sheppard (Equations 1 and 2), and the conversion of AgZ was proposed by Jubin and Bruffey (Equation 3) (2015) as

\section{Zeolite A}




$$
M_{12}^{+}\left(\mathrm{Al}_{12} \mathrm{Si}_{12} \mathrm{O}_{48}\right) \cdot 27 \mathrm{H}_{2} \mathrm{O}+4 \mathrm{AgI} \rightarrow 2\left[\mathrm{M}_{6}^{+}\left(\mathrm{Al}_{6} \mathrm{Si}_{6} \mathrm{O}_{24}\right) \cdot 2(\mathrm{AgI})\right]+27 \mathrm{H}_{2} \mathrm{O}
$$

Zeolite X

$$
3\left[\mathrm{M}_{86}^{+}\left(\mathrm{Al}_{86} \mathrm{Si}_{106} \mathrm{O}_{384}\right) \cdot 264 \mathrm{H}_{2} \mathrm{O}\right]+86 \mathrm{AgI} \rightarrow 43\left[\mathrm{M}_{6}^{+}\left(\mathrm{Al}_{6} \mathrm{Si}_{6} \mathrm{O}_{24}\right) \cdot 2(\mathrm{AgI})\right]+60 \mathrm{SiO}_{2}+792 \mathrm{H}_{2} \mathrm{O},
$$

and

\section{Zeolite Z}

$$
3\left[\mathrm{M}_{8}^{+}\left(\mathrm{Al}_{8} \mathrm{Si}_{40} \mathrm{O}_{96}\right) \cdot 24 \mathrm{H}_{2} \mathrm{O}\right]+8 \mathrm{AgI} \rightarrow 4\left[\mathrm{M}_{6}^{+}\left(\mathrm{Al}_{6} \mathrm{Si}_{6} \mathrm{O}_{24}\right) \cdot 2(\mathrm{AgI})\right]+96 \mathrm{SiO}_{2}+72 \mathrm{H}_{2} \mathrm{O} .
$$

Notable differences between conversion of $\mathrm{AgZ}$ and zeolites $\mathrm{A}$ and $\mathrm{X}$ are the ratios of silicon to aluminum ( $\mathrm{Si}: \mathrm{Al}$ ) in the starting zeolite form and the ratios of $\mathrm{SiO}_{2}$ product to sodalite product, as shown in Table 2. While zeolites A and $\mathrm{X}$ both have ratios close to 1, mordenite has a 5:1 Si: Al ratio and substantially more $\mathrm{SiO}_{2}$ would be produced during a potential conversion to sodalite.

Table 2. $\mathrm{SiO}_{2}$-to-sodalite ratio for selected conversions

\begin{tabular}{|c|c|c|}
\hline Precursor to sodalite & $\begin{array}{c}\mathbf{S i}: \mathbf{A l} \\
\text { in starting zeolite }\end{array}$ & $\begin{array}{c}\mathbf{S i O}_{2}: \text { sodalite } \\
\text { in product }\end{array}$ \\
\hline $\mathrm{A}$ & $1: 1$ & $0: 1$ \\
\hline $\mathrm{X}$ & $53: 43$ & $1: 1$ \\
\hline Mordenite $(\mathrm{Z})$ & $5: 1$ & $24: 1$ \\
\hline
\end{tabular}

This $\mathrm{SiO}_{2}$ production was also observed in previous research, which showed that $\mathrm{SiO}_{2}$ was the dominant phase present after HIPing of I-AgZ (Bruffey and Jubin, 2015). In order to facilitate the conversion, it was proposed that additional aluminum as alumina be added to selected $\mathrm{AgZ}$ samples in order to potentially reduce the excess $\mathrm{Si}$ or $\mathrm{SiO}_{2}$ in the final product.

An area of interest, as part of this effort, was to assess the impact of the iodine incorporation method on the produced waste form. In previous published studies, iodine was generally added to the zeolite samples through mixing or occlusion by heating of the iodine and zeolite mixture to high temperature to promote diffusion of AgI into the zeolite pores. This iodine addition method may not be representative of the current application of interest and could potentially result in a different HIPed product than if the iodine was incorporated into the zeolite by diffusion from gaseous streams followed by chemisorption on the silver previously incorporated into the zeolite via ion exchange.

Finally, previous research on HIPing of zeolites suffered a high capsule failure rate during pressing. Each sample is tamped into a stainless steel capsule that is then sealed by electron beam welding and is under vacuum. This sealed sample capsule is necessary for the HIP process, but at the high temperatures and pressures of pressing, pinhole leaks or failed welds can prevent capsule consolidation. The high capsule failure rates experienced during previous studies resulted in a loss of the data from the failed capsules and significantly hampered project progress. Improvement of the capsule manufacture, lid welding, and leak testing of the individual capsules were judged to be critical not only to the successful completion of this research effort but also for any future scale-up efforts should the HIPing of AgZ be determined to be a viable method for durable iodine waste form production.

\section{TEST MATRIX}

Building upon previous efforts, the experiments performed in this study were intended to answer a series of questions through the completion of a designed test matrix (Table 3). These questions are as follows: 
1) Can the results of Sheppard et al. for the conversion of zeolite A to iodine-loaded sodalite be replicated by the test methods used here? (Sample \#1)

2) Is this conversion also effected at $300 \mathrm{MPa}$, the HIP pressure used in previous ORNL research? (comparison of Samples \#1, 2)

3) Can mordenite (as either $\mathrm{NaZ}$ or $\mathrm{AgZ}$ ) be converted to iodine-loaded sodalite through methods analogous to those used by Sheppard et al. in their reported conversion of zeolite A to iodine-loaded sodalite? (Samples \#3, \#4, \#5, \#6)

4) What is the effect of iodine concentration on the potential conversion? (Samples \#3, \#4, \#5, \#6)

5) Can the conversion of $\mathrm{AgX}$ to iodine-loaded sodalite as described by Sheppard et al. be effected at the higher pressure of $300 \mathrm{MPa}$ (Samples \#7, \#8)

6) How does the iodine inclusion method impact the potential conversion? (Samples \#9-\#14)

7) What is the effect of pressing pressure? (Samples \#9-\#14)

8) Can alumina addition facilitate the conversion of $\mathrm{AgX}$ and $\mathrm{AgZ}$ to iodine-loaded sodalite? (Samples \#15, \#16)

9) How reproducible are the methods tested in this study? (Samples \#7, \#8)

10) What are the physical properties of the resultant waste form (i.e., homogeneity of the surface, density of the samples, pitting or bubble formation within the waste form, durability of the waste form during sample processing will all be considered)?

Table 3. Test matrix

\begin{tabular}{|c|c|c|c|c|c|}
\hline Sample ID & Mineral form & $\begin{array}{c}\text { Method of } \\
\text { iodine inclusion }\end{array}$ & $\begin{array}{c}\text { Molar ratio } \\
\text { (Zeolite }: \text { AgI })\end{array}$ & Alumina & $\begin{array}{c}\text { Pressure } \\
\text { (MPa) }\end{array}$ \\
\hline FY16-HIP-1 & $\mathrm{AgA}$ & Occlusion & $1: 2.0$ & No & 190 \\
\hline FY16-HIP-2 & $\mathrm{AgA}$ & Occlusion & $1: 2.0$ & No & 300 \\
\hline FY16-HIP-3 & $\mathrm{NaZ}$ & Occlusion & $1: 2.5$ & No & 300 \\
\hline FY16-HIP-4 & $\mathrm{NaZ}$ & Occlusion & $1: 1.3$ & No & 300 \\
\hline FY16-HIP-5 & $\mathrm{AgZ}$ & Occlusion & $1: 2.6$ & No & 300 \\
\hline FY16-HIP-6 & $\mathrm{AgZ}$ & Occlusion & $1: 1.4$ & No & 300 \\
\hline FY16-HIP-7 & $\mathrm{AgX}$ & Occlusion & $1: 14.7$ & No & 300 \\
\hline FY16-HIP-8 & $\mathrm{AgX}$ & Occlusion & $1: 14.8$ & No & 300 \\
\hline FY16-HIP-9 & $\mathrm{AgA}$ & Chemisorption & $1: 0.2$ & No & 175 \\
\hline FY16-HIP-10 & $\mathrm{AgA}$ & Chemisorption & $1: 0.2$ & No & 300 \\
\hline FY16-HIP-11 & $\mathrm{AgZ}$ & Chemisorption & $1: 0.2$ & No & 175 \\
\hline FY16-HIP-12 & $\mathrm{AgZ}$ & Chemisorption & $1: 0.2$ & No & 300 \\
\hline FY16-HIP-13 & $\mathrm{AgX}$ & Chemisorption & $1: 2.8$ & No & 175 \\
\hline FY16-HIP-14 & $\mathrm{AgX}$ & Chemisorption & $1: 2.8$ & No & 300 \\
\hline FY16-HIP-15 & $\mathrm{AgZ}$ & Chemisorption & $1: 0.2$ & Yes & 300 \\
\hline FY16-HIP-16 & $\mathrm{AgX}$ & Chemisorption & $1: 2.8$ & Yes & 300 \\
\hline
\end{tabular}

\section{SAMPLE POWDER PREPARATION}

The silver-exchanged zeolites used in this test matrix were prepared by ion exchange of commercially available sodium forms. Zeolite A (Sigma-Aldrich) was obtained in $3.2 \mathrm{~mm}$ pellet form containing a 
mixture of calcium and sodium as the metal ion. Zeolite 13X (Sigma-Aldrich) was obtained from Sigma-Aldrich in $3.2 \mathrm{~mm}$ pellet form containing $14 \%$ by weight sodium. Sodium mordenite was obtained from Sud-Chemie in a powder form. The sodium form of mordenite (NaZ) was used as received for Samples FY16-HIP-3 and FY16-HIP-4, which did not require Ag exchange. Crystalline $\mathrm{AgNO}_{3}(99.9+\%$ pure, metals basis), alumina $\left(\mathrm{Al}_{2} \mathrm{O}_{3}\right.$, gamma powder, $99.5 \%$ pure, metals basis), and AgI powder (99.999\% pure, metals basis) were purchased from Alfa Aesar.

The silver exchange was performed by contacting each zeolite with $0.13 \mathrm{M} \mathrm{AgNO}_{3}$ for 7 days with occasional shaking to agitate the solid in the solution as the zeolite solids sedimented to the container bottom. Although silver was present in excess during the exchange, it is unlikely that $100 \%$ of the $\mathrm{M}^{+}$ cation was exchanged for silver. The exchange procedure was not intended to provide $100 \%$ cation exchange but rather to produce starting materials similar to those referenced in the literature. An incomplete exchange would result in some retention of the metal cations present in the original zeolite starting material. The exchanged zeolite solids were vacuum filtered to remove any residual $\mathrm{AgNO}_{3}$ solution and then rinsed with water at least five times. The solids were stored in a furnace at $90^{\circ} \mathrm{C}$ for 2 months for drying.

Iodine was incorporated into the samples by either occlusion or chemisorption. For occlusion, AgI was ground together with zeolite powder by mortar and pestle. The amount of zeolite and AgI used for each sample is shown in Table 4.

The unhydrated unit cell of each zeolite (shown in Table 4) is calculated assuming that $100 \%$ of the $\mathrm{M}^{+}$ cation was exchanged for silver. This assumption may be revisited upon receipt of silver assay postexchange as the assay is likely to reflect an exchange rate lower than $100 \%$.

Table 4. Zeolite : AgI molar ratios for occluded samples

\begin{tabular}{|c|c|c|c|}
\hline Sample ID & $\begin{array}{c}\text { Zeolite } \\
\text { type }\end{array}$ & $\begin{array}{c}\text { Molecular weight } \\
\text { (g/mol) }\end{array}$ & $\begin{array}{c}\text { Zeolite : AgI } \\
\text { (mol : mol) }\end{array}$ \\
\hline FY16-HIP-1 & AgA & 2723 & $1: 2.0$ \\
\hline FY16-HIP-2 & AgA & 2723 & $1: 2.0$ \\
\hline FY16-HIP-3 & NaZ & 3059 & $1: 2.5$ \\
\hline FY16-HIP-4 & $\mathrm{NaZ}$ & 3059 & $1: 1.3$ \\
\hline FY16-HIP-5 & $\mathrm{AgZ}$ & 3738 & $1: 2.6$ \\
\hline FY16-HIP-6 & $\mathrm{AgZ}$ & 3738 & $1: 1.4$ \\
\hline FY16-HIP-7 & $\mathrm{AgX}$ & 20718 & $1: 14.7$ \\
\hline FY16-HIP-8 & $\mathrm{AgX}$ & 20718 & $1: 14.8$ \\
\hline
\end{tabular}

Incorporation of iodine by chemisorption into the silver-exchanged zeolites (to form $\mathrm{AgI}$ ) was performed by contacting each zeolite with a 50 ppmv $\mathrm{I}_{2}$ stream (balance dry air) with a gas velocity of $10 \mathrm{~m} / \mathrm{min}$. The zeolites were contained within a tube furnace at $150^{\circ} \mathrm{C}$ during iodine loading. After loading of each zeolite with iodine, the material was then purged with dry air to remove any physisorbed iodine. The amount of iodine adsorbed by the samples is shown in Table 5. The amount of unreacted silver remaining in the material will be assessed upon receipt of silver assay results.

Table 5. Iodine loading of silver-exchanged zeolites

\begin{tabular}{|c|c|}
\hline Mineral & $\begin{array}{c}\text { Average iodine loading } \\
\text { (mg I/g zeolite) }\end{array}$ \\
\hline $\mathrm{AgA}$ & 7.6 \\
\hline $\mathrm{AgX}$ & 16.9 \\
\hline $\mathrm{AgZ}$ & 6.7 \\
\hline
\end{tabular}


As noted earlier, if it is assumed that sodalite is formed during the HIPing process, there will also be an excess of silicon and oxygen. In an attempt to reduce this excess silicon-to-aluminum ratio and potentially promote sodalite formation, alumina was added to several of the samples. Alumina was incorporated into $\mathrm{AgX}$ and $\mathrm{AgZ}$ by grinding alumina $\left(\mathrm{Al}_{2} \mathrm{O}_{3}\right)$ in mortar and pestle. The ratios for mixing by grinding were $0.028 \mathrm{~g} / \mathrm{g}$ for $\mathrm{AgX}$ and $0.31 \mathrm{~g} / \mathrm{g}$ for $\mathrm{AgZ}$.

After each sample material was prepared, the sample powders were tamped into capsules and sealed. Capsule sealing is discussed in Section 5. After sealing, the samples were HIPed at $900^{\circ} \mathrm{C}$ and pressures as specified in Table 3 by American Isostatic Presses, Inc.

\section{CAPSULE SEALING}

After the prepared sample material was tamped into open capsules, a thin $0.02 \mathrm{~mm} 304$ stainless steel lid was attached by electron beam welding. This operation is performed under vacuum in a glove box, which results in evacuation of the sample chambers, as required for the HIP process.

The sample capsules were constructed of 304 stainless steel tubing. The wall thickness of the tubing and the end cap was 0.020 in., and the internal volume was measured to be $6.3 \mathrm{~cm}^{3}$. A sealed capsule is shown in Figure 1.

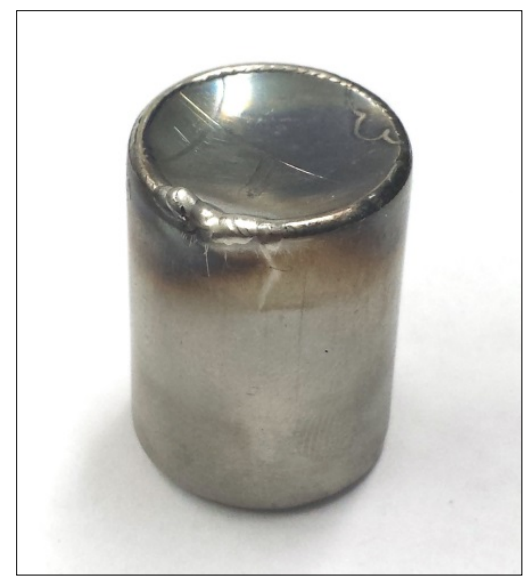

Figure 1. Sealed sample capsule.

\subsection{Initial sealing efforts}

Previous HIP experiments used a capsule design in which a flat lid was welded directly onto the upper edge of the capsule wall, as shown in Figure 2.

Over the past several years, the capsule sealing operation has incurred a number of failed welds and required excessive time to complete the welding process. Many capsules were never successfully sealed, but of the capsules that were assumed to be fully welded closed, $32 \%$ were found to leak during the HIP operation, which resulted in failure of the samples to compress and loss of the sample data that HIPed capsules would have provided.

The welding and machining personnel identified the extremely thin capsule and lid as being difficult to weld without breaking through the stainless steel. The caution and precision required to avoid breakthrough increased the time needed to seal each capsule. Even with a high degree of attention, the welds were not always leak tight as the sealing edge (a $90^{\circ}$ angle), the thin material, and potential contamination of the sealing edge with sample material combined to make the sealing of the capsule a very difficult operation. Initial sealing efforts for the 16-sample test matrix resulted in a substantial amount of breakthrough, and only three of the original 16 samples described in the test matrix were successfully sealed. This was an abnormally high failure rate compared to previous efforts. 


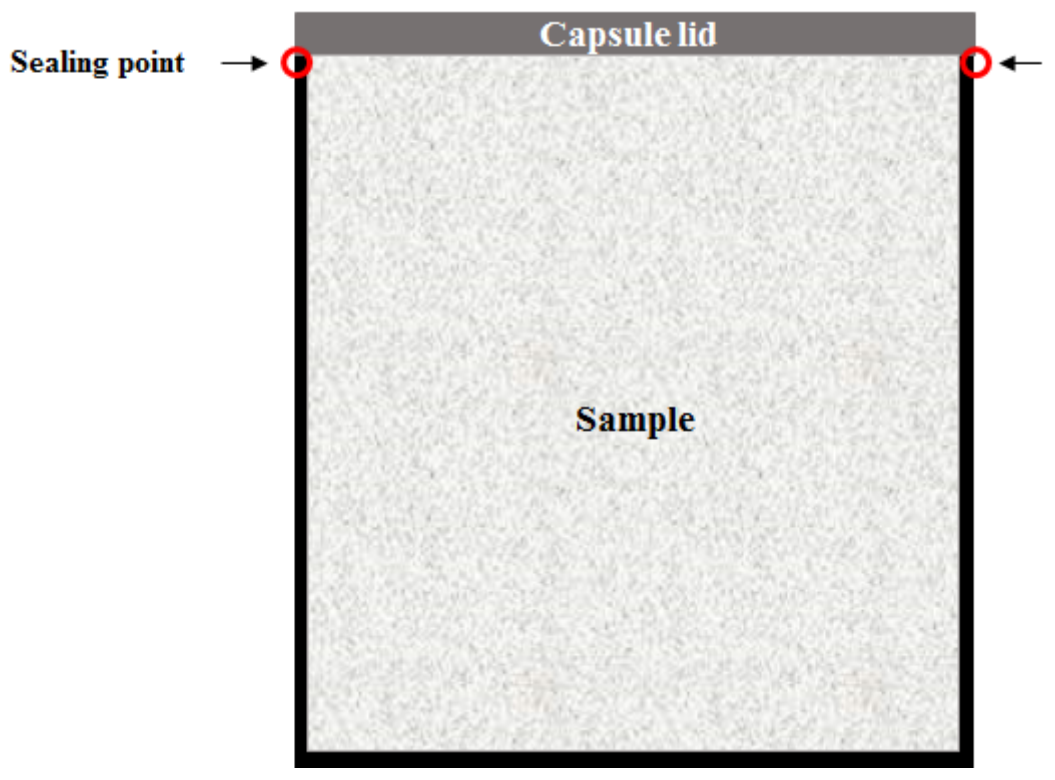

Figure 2. Original capsule design.

\subsection{Sealing process modifications}

The increased difficulty in sealing prompted discussions with welding and machining personnel. It appeared that the direct contact of the capsule lid with the sample surface was preventing high-quality welds due to sample powders interfering with the weld between the lid and the capsule. Previous experiments had used both pellet and powder forms of zeolite. The current test matrix is exclusively composed of mineral powders, amplifying the issue of powder contamination on the weld surface.

To resolve this issue, an inset lid was designed (Figure 3). Rather than being a single plate, the lid was inset with a lip above it. This prevented the sample from contacting the weld surface, as the lip served as the sealing point with the capsule body. This modification enabled the sealing of 10 additional capsules, bringing the total number of capsules sealed to 13 of 16 . 


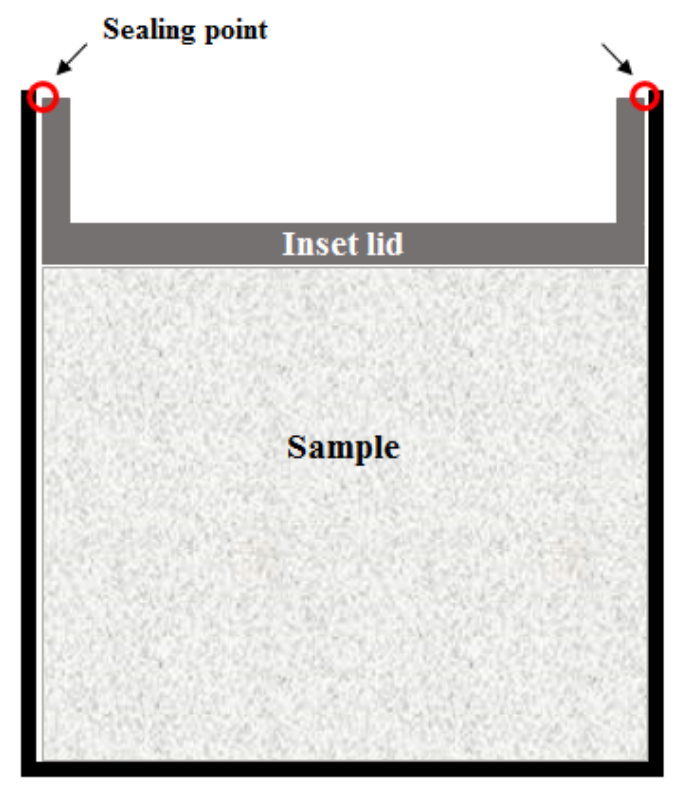

Figure 3. Modified capsule design with inset lid.

The inset lid did have the unintended consequence of decreasing the strength of vacuum that could be pulled over the sample itself during welding, resulting in longer evacuation times required prior to completion of welding. A subsequent improvement to the lid was the addition of a small open tube in the center of the lid that could serve as a vacuum port and increase the ability to pull a strong vacuum (Figure 4).

The modified inset lid with vacuum port resulted in an additional benefit. The inset lids could now be traditionally welded onto the capsule body outside of the electron beam vacuum glove box and then briefly transferred in to achieve vacuum and tack the vacuum port closed. This greatly decreased the amount of time required to seal a capsule. The remaining three samples were sealed with this lid modification, completing the 16-sample set. The samples with this vacuum tube lid were sealed at a pace 10 times that of the previous methods. The three types of capsule lids are shown sealed in Figure 5. 


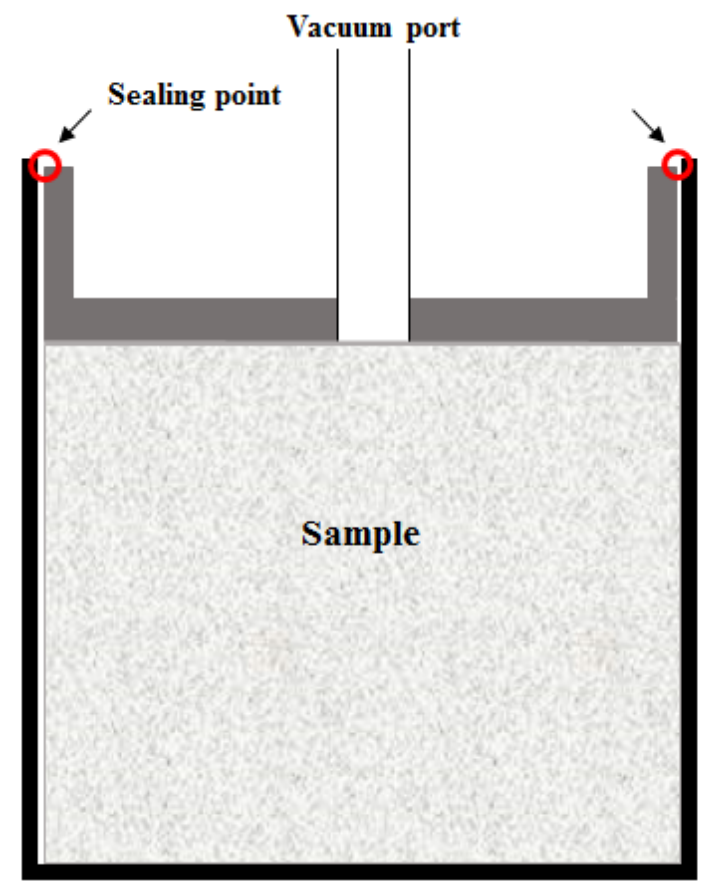

Figure 4. Modified capsule design with inset vacuum port lid.

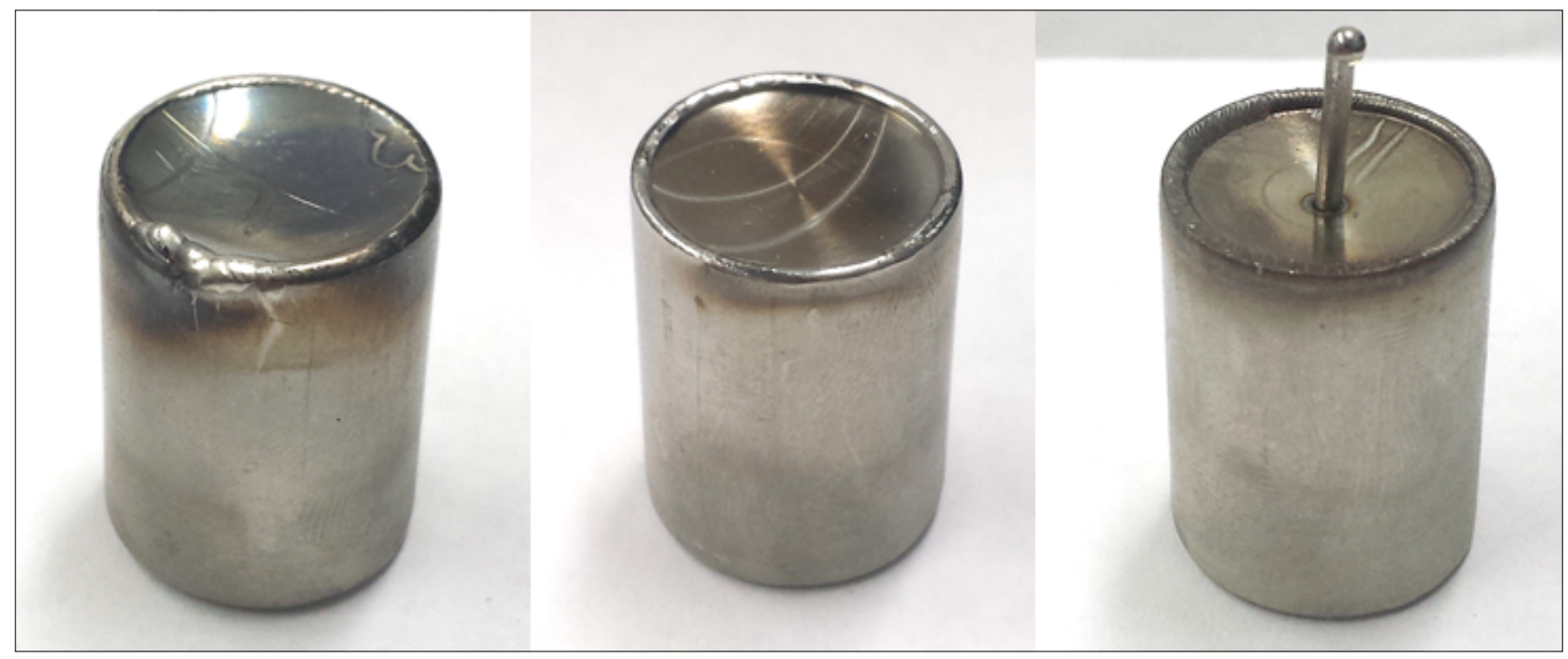

Figure 5. Capsule lid modifications ( $L$ to $R$ : original, inset cap, inset vacuum port lid).

Throughout the sealing process, the capsules were hydrostatically leak checked to verify the integrity of the welds. The samples were placed in a bell jar and pressurized to $1450 \mathrm{psi}$. An increase in weight of the capsule after pressurization indicated in-leakage of water. Any capsules that did not seal were discarded and a replacement capsule containing fresh sample material was produced and subsequently sealed using one of the lid modifications described. The final lid type for each sample is shown in Table 6.

The combination of capsule lid modifications and hydrostatic leak checking prior to HIPing resulted in a substantial decrease in failure rate during the HIP process: of the 16 samples sent for HIPing, 15 were compressed. The Sample FY16-HIP-15 failed to compress. 
Table 6. Sample lid type

\begin{tabular}{|l|l|}
\hline \multicolumn{1}{|c|}{ Sample ID } & \multicolumn{1}{c|}{ Lid type } \\
\hline FY16-HIP-1 & Original \\
\hline FY16-HIP-2 & Original \\
\hline FY16-HIP-3 & Inset/Vacuum Port \\
\hline FY16-HIP-4 & Inset \\
\hline FY16-HIP-5 & Original \\
\hline FY16-HIP-6 & Inset \\
\hline FY16-HIP-7 & Inset \\
\hline FY16-HIP-8 & Inset \\
\hline FY16-HIP-9 & Inset \\
\hline FY16-HIP-10 & Inset \\
\hline FY16-HIP-11 & Inset \\
\hline FY16-HIP-12 & Inset \\
\hline FY16-HIP-13 & Inset \\
\hline FY16-HIP-14 & Inset/Vacuum Port \\
\hline FY16-HIP-15 & Inset \\
\hline FY16-HIP-16 & Inset/Vacuum Port \\
\hline
\end{tabular}

\section{CHARACTERIZATION OF PRESSED SAMPLES}

After HIPing, the density of each sample was determined by a pycnometer. Initial efforts to measure the density of each capsule using water as the fill liquid in the pycnometer were inconsistent due to air bubbles on the surface on the metal. The density measurements were repeated using isopropyl alcohol as the fill liquid to improve precision by reducing the surface tension. Sample 15 was not successfully pressed due to a small leak not identified in the hydrostatic leak check and is not included in any characterization results.

Following the density measurements, the capsules were cross sectioned and visually examined, and onehalf was mounted in epoxy for analysis by XRD. The second half was used in hardness testing. The Rockwell Hardness was determined using an Instron Wilson Rockwell Series 20000 and was reported in Rockwell Hardness B (RHB) values. This is the Rockwell hardness range associated with copper alloys, soft steels, aluminum alloys, and malleable iron (ASTM, 2003).

XRD analysis was performed with continuous $\theta-2 \theta$ scans on the Panalytical X'pert diffractometer from nominally 5 to $90^{\circ} 2 \theta$ using $\mathrm{CuK} \alpha$ radiation $\left(\lambda=1.540598 \AA\right.$ ). All scans used $14^{\circ}$ fixed slits, $1 / 2^{\circ}$ anti-scatter slit, 0.04 soller slits coupled with a $10 \mathrm{~mm}$ mask (beam length). For the phase identification procedure, a search match was conducted using the Jade software (2012) and the ICDD database (2015).

\subsection{Density and hardness}

The density of each sample is reported in Table 7. These measurements were performed in triplicate, and the average and standard deviation for each sample is provided.

Hardness measurements are provided in Table 8. In some cases, the measurement was performed in duplicate and both numbers are reported. In other cases, the sample surface cracked during hardness testing, and in these cases, either the hardness could not be determined or a duplicate measurement could not be performed. 
Table 7. Density of HIPed samples

\begin{tabular}{|c|c|c|l|c|}
\hline Sample ID & $\begin{array}{c}\text { Density } \\
\mathbf{( g / m L}\end{array}$ & $+/-$ & \multicolumn{1}{|c|}{ Description } & $\begin{array}{c}\text { Pressure } \\
\text { (MPa) }\end{array}$ \\
\hline FY16-HIP-1 & 3.980 & 0.014 & $\mathrm{AgA} \mid$ Occlusion $\mid 1: 2.0$ & 190 \\
\hline FY16-HIP-2 & 3.917 & 0.020 & $\mathrm{AgA} \mid$ Occlusion $\mid 1: 2.0$ & 300 \\
\hline FY16-HIP-3 & 2.364 & 0.012 & $\mathrm{NaZ} \mid$ Occlusion $\mid 1: 2.5$ & 300 \\
\hline FY16-HIP-4 & 2.518 & 0.021 & $\mathrm{NaZ} \mid$ Occlusion $\mid 1: 1.3$ & 300 \\
\hline FY16-HIP-5 & 2.964 & 0.023 & $\mathrm{AgZ} \mid$ Occlusion $\mid 1: 2.6$ & 300 \\
\hline FY16-HIP-6 & 3.065 & 0.022 & $\mathrm{AgZ} \mid$ Occlusion $\mid 1: 1.4$ & 300 \\
\hline FY16-HIP-7 & 3.785 & 0.035 & $\mathrm{AgX} \mid$ Occlusion $\mid 1: 14.7$ & 300 \\
\hline FY16-HIP-8 & 4.079 & 0.045 & $\mathrm{AgX} \mid$ Occlusion $\mid 1: 14.8$ & 300 \\
\hline FY16-HIP-9 & 3.376 & 0.008 & $\mathrm{AgA} \mid$ Chemisorbed & 175 \\
\hline FY16-HIP-10 & 3.654 & 0.008 & $\mathrm{AgA} \mid$ Chemisorbed & 300 \\
\hline FY16-HIP-11 & 2.811 & 0.015 & $\mathrm{AgZ} \mid$ Chemisorbed & 175 \\
\hline FY16-HIP-12 & 2.897 & 0.009 & $\mathrm{AgZ} \mid$ Chemisorbed & 300 \\
\hline FY16-HIP-13 & 3.503 & 0.008 & $\mathrm{AgX} \mid$ Chemisorbed & 175 \\
\hline FY16-HIP-14 & 3.145 & 0.000 & $\mathrm{AgX} \mid$ Chemisorbed & 300 \\
\hline FY16-HIP-16 & 2.309 & 0.004 & $\mathrm{AgX} \mid$ Chemisorbed $\mid$ Alumina & 300 \\
\hline
\end{tabular}

Table 8. Hardness of HIPed samples

\begin{tabular}{|c|c|c|l|c|}
\hline Sample ID & \multicolumn{2}{|c|}{$\begin{array}{c}\text { Hardness } \\
\text { (HRB) }\end{array}$} & \multicolumn{1}{|c|}{ Description } & $\begin{array}{c}\text { Pressure } \\
\text { (MPa) }\end{array}$ \\
\hline FY16-HIP-1 & 100 & 111 & $\mathrm{AgA} \mid$ Occlusion $\mid 1: 2.0$ & 190 \\
\hline FY16-HIP-2 & 97 & 97 & $\mathrm{AgA} \mid$ Occlusion $\mid 1: 2.0$ & 300 \\
\hline FY16-HIP-3 & 108 & $n / p$ & $\mathrm{NaZ} \mid$ Occlusion $\mid 1: 2.5$ & 300 \\
\hline FY16-HIP-4 & cracked & $n / p$ & $\mathrm{NaZ} \mid$ Occlusion $\mid 1: 1.3$ & 300 \\
\hline FY16-HIP-5 & cracked & $n / p$ & $\mathrm{AgZ} \mid$ Occlusion $\mid 1: 2.6$ & 300 \\
\hline FY16-HIP-6 & 75 & $n / p$ & $\mathrm{AgZ} \mid$ Occlusion $\mid 1: 1.4$ & 300 \\
\hline FY16-HIP-7 & 70 & 115 & $\mathrm{AgX} \mid$ Occlusion $\mid 1: 14.7$ & 300 \\
\hline FY16-HIP-8 & 89 & 87 & $\mathrm{AgX} \mid$ Occlusion $\mid 1: 14.8$ & 300 \\
\hline FY16-HIP-9 & 88 & 110 & $\mathrm{AgA} \mid$ Chemisorbed & 175 \\
\hline FY16-HIP-10 & cracked & $n / p$ & $\mathrm{AgA} \mid$ Chemisorbed & 300 \\
\hline FY16-HIP-11 & 95 & $n / p$ & $\mathrm{AgZ} \mid$ Chemisorbed & 175 \\
\hline FY16-HIP-12 & 113 & 112 & $\mathrm{AgZ} \mid$ Chemisorbed & 300 \\
\hline FY16-HIP-13 & 77 & 92 & $\mathrm{AgX} \mid$ Chemisorbed & 175 \\
\hline FY16-HIP-14 & 72 & $n / p$ & $\mathrm{AgX} \mid$ Chemisorbed & 300 \\
\hline FY16-HIP-16 & 85 & $n / p$ & $\mathrm{AgX} \mid$ Chemisorbed $\mid$ Alumina & 300 \\
\hline
\end{tabular}

$n / p=$ duplicate measurement not performed

\subsection{Sample cross sections}

Pictures of each sample cross section are shown in Figures 6-20. 


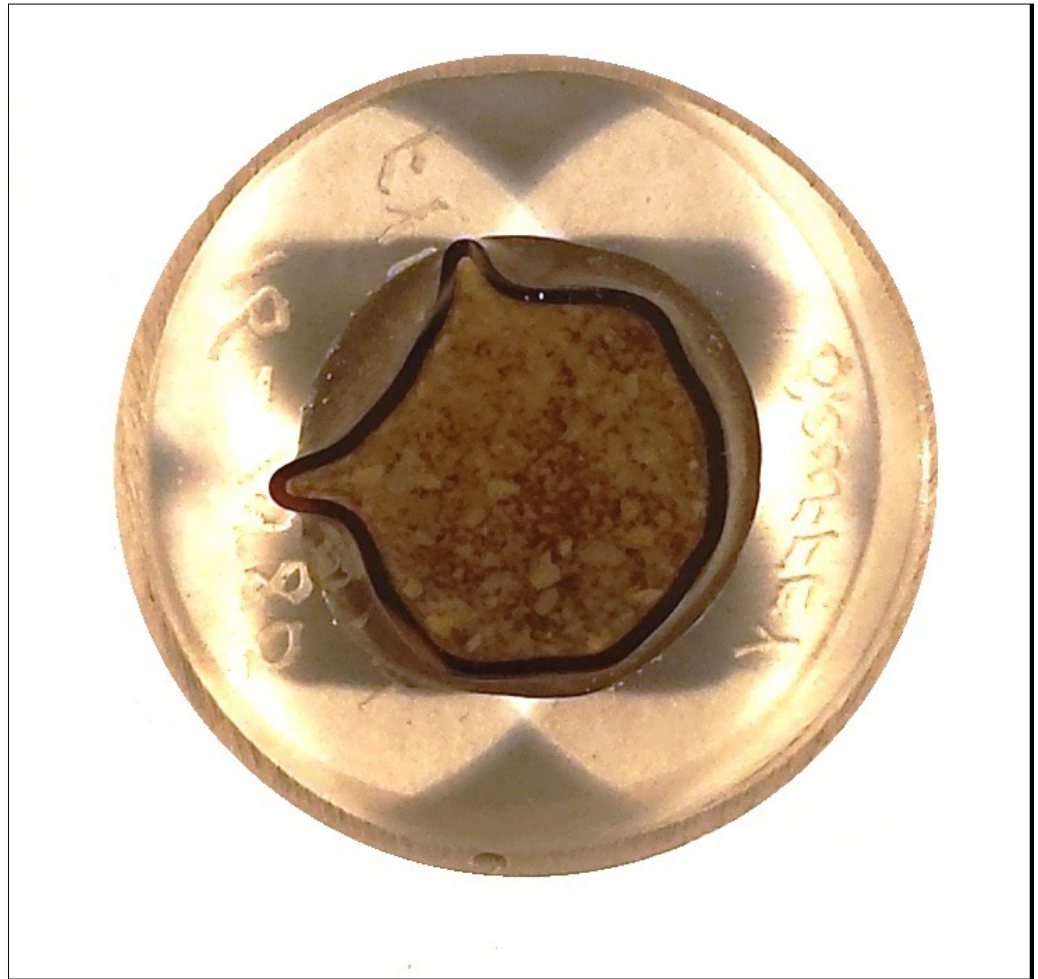

Figure 6. Cross section of Sample 1 (AgA | Occluded | 1:2 | 190 MPa).

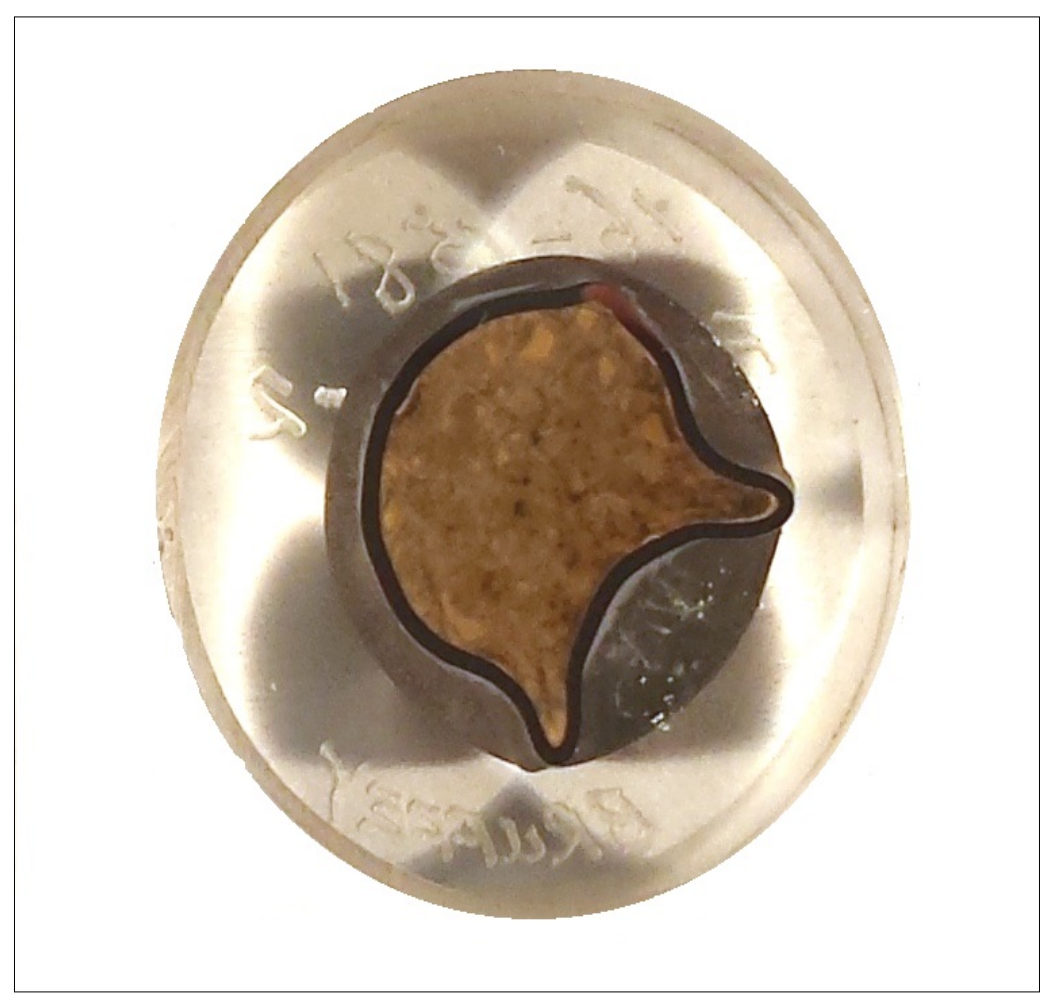

Figure 7. Cross section of Sample 2 (AgA | Occluded | 1:2 | 300 MPa). 


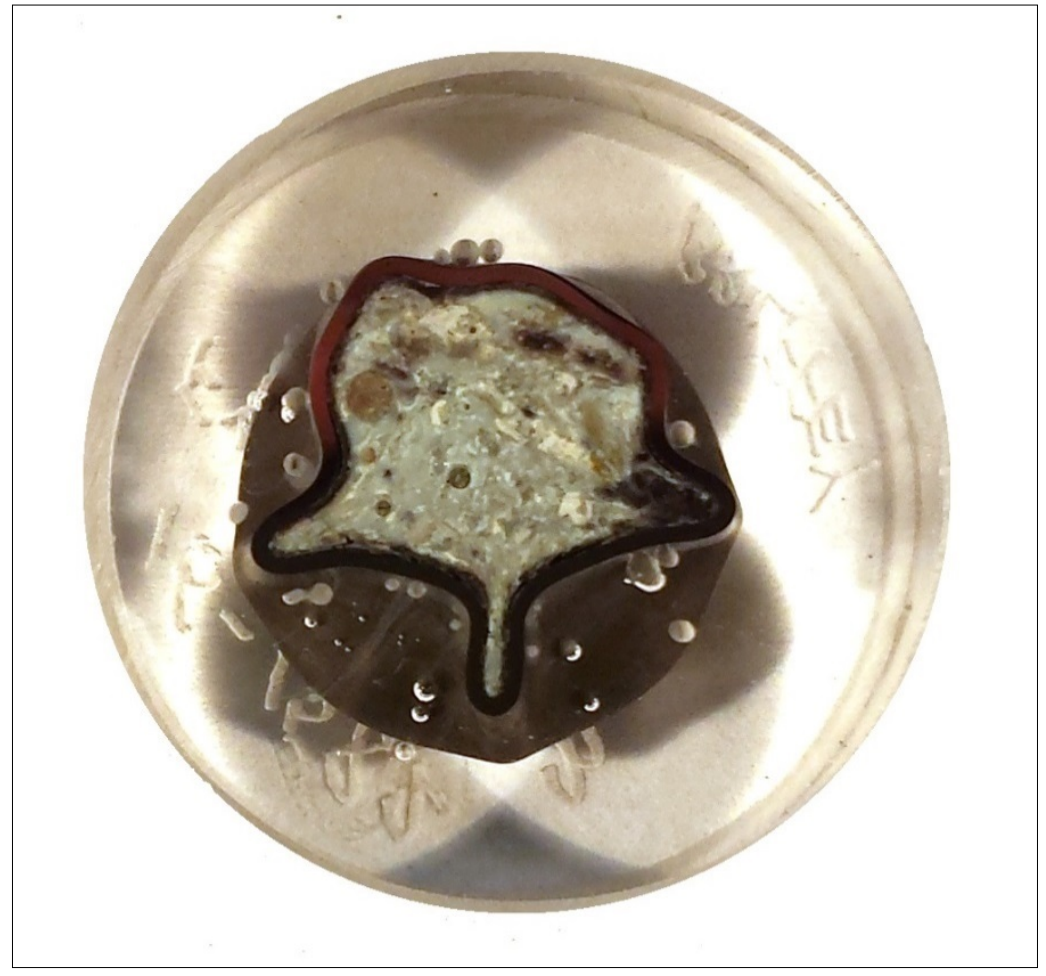

Figure 8. Cross -section of Sample 3 (NaZ | Occluded | 1:2.5 | 300 MPa).

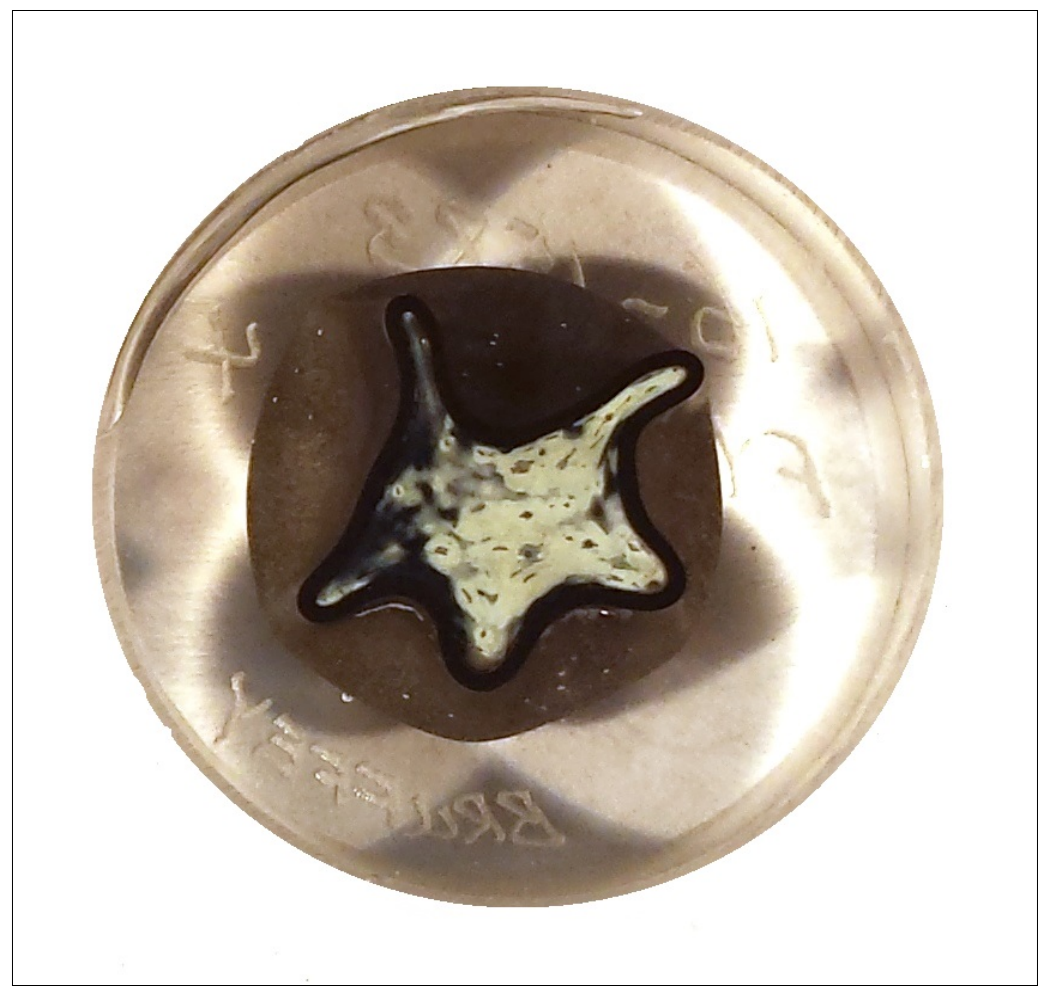

Figure 9. Cross section of Sample 4 (NaZ | Occluded | 1:1.3 | 300 MPa). 


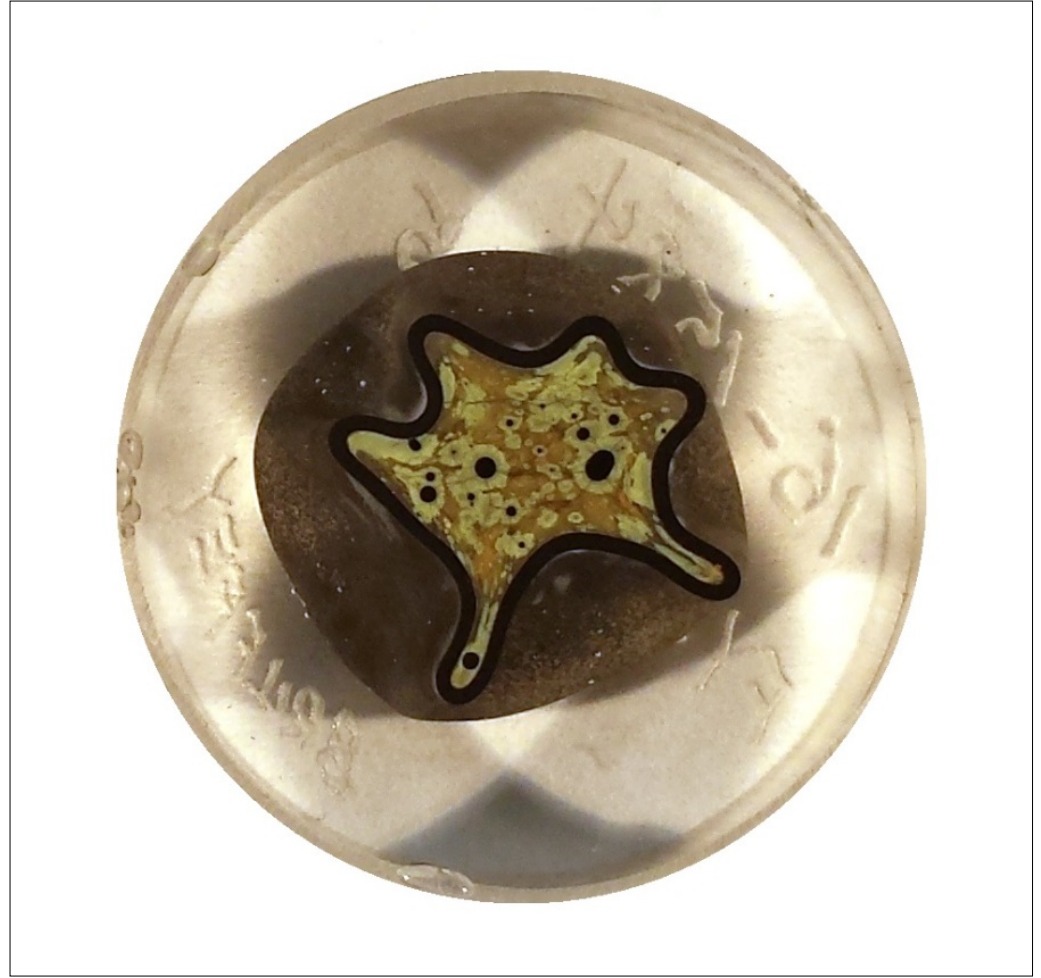

Figure 10. Cross section of Sample 5 (AgZ | Occluded | 1:2.6 | 300 MPa).

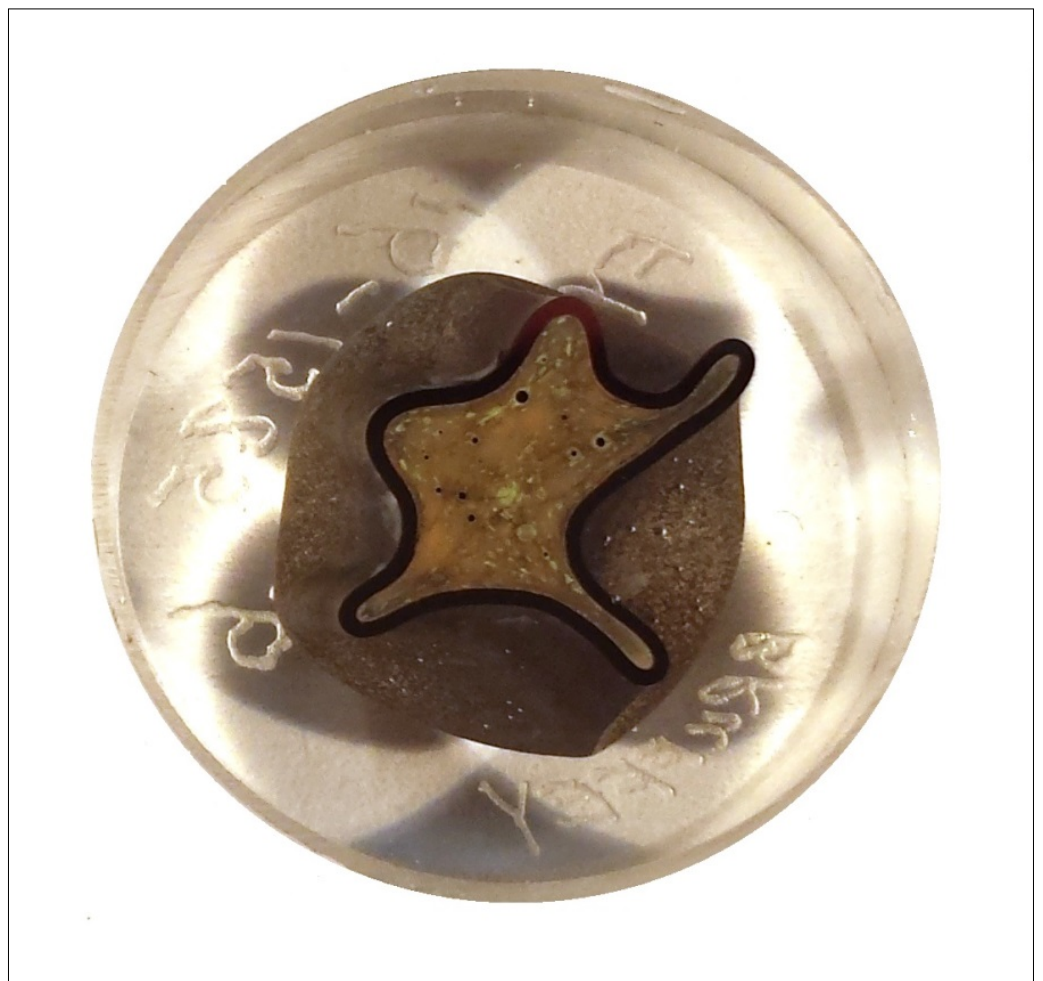

Figure 11. Cross section of Sample 6 (AgZ | Occluded | 1:1.4 | 300 MPa). 


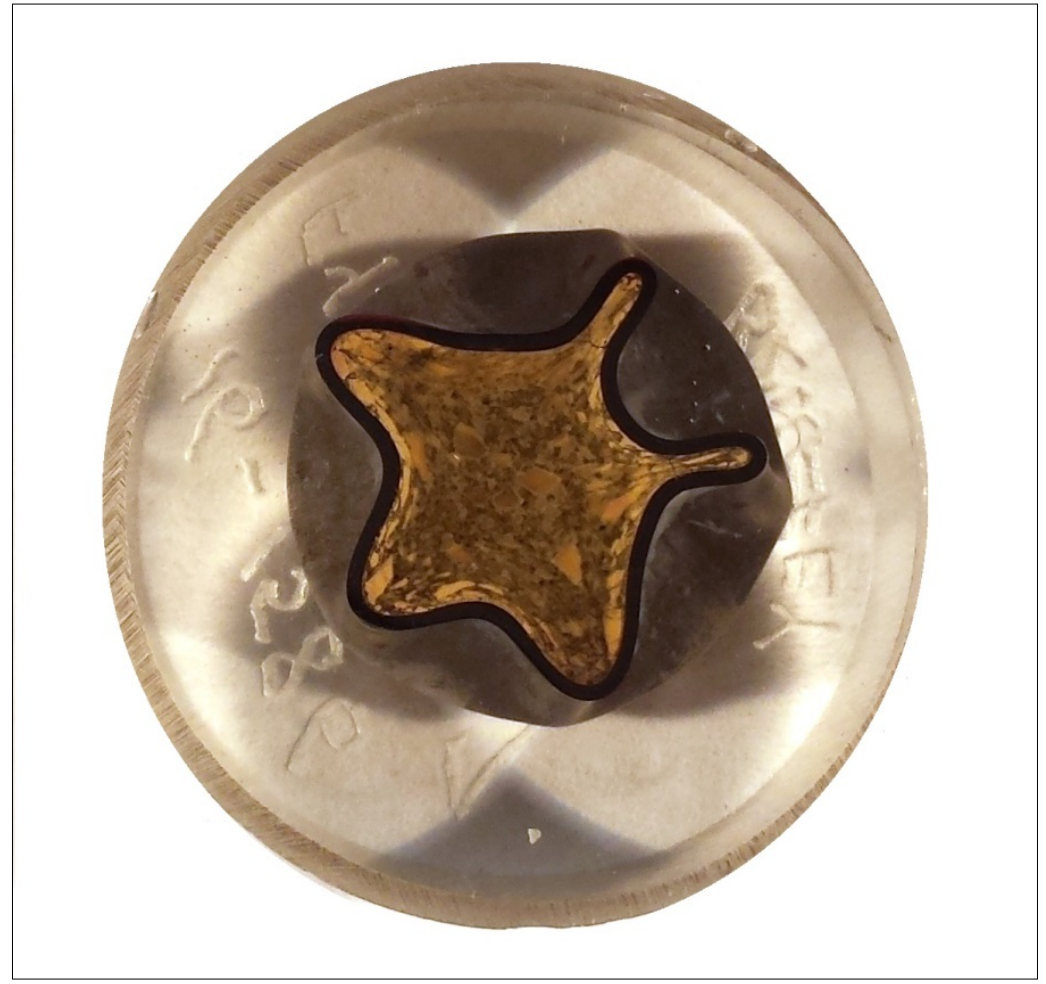

Figure 12. Cross section of Sample 7 (AgX | Occluded | 1:14.7 | 300 MPa).

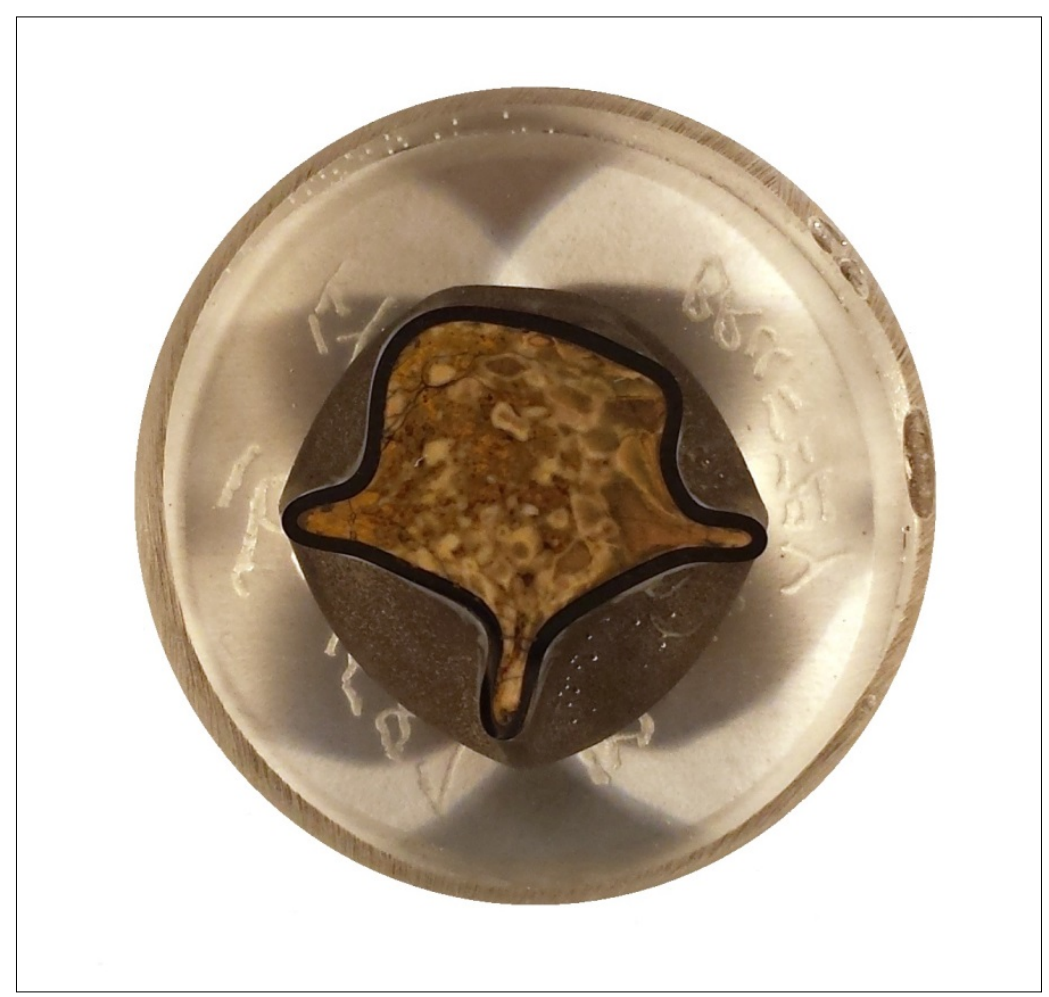

Figure 13. Cross section of Sample 8 (AgX | Occluded | 1:14.8 | 300 MPa). 


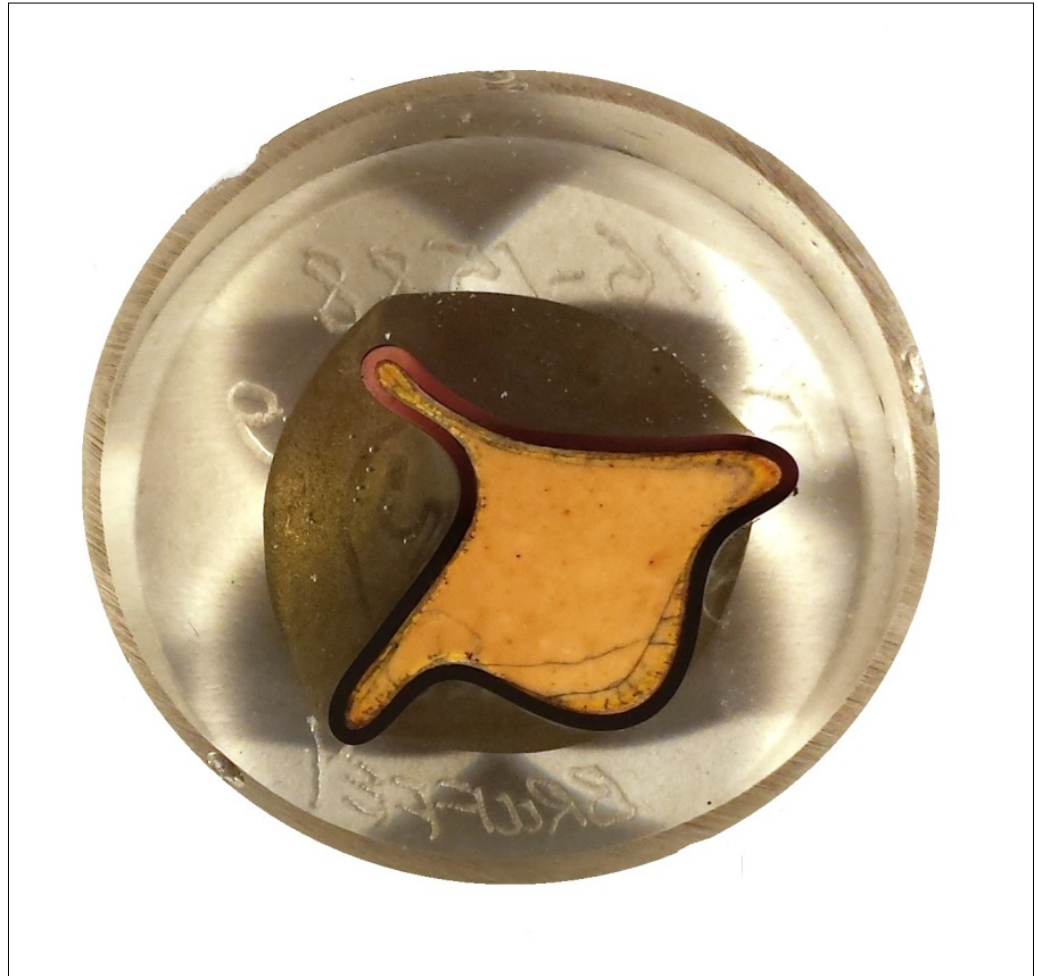

Figure 14. Cross section of Sample 9 (AgA | Chemisorbed | 1:0.2 | 175 MPa).

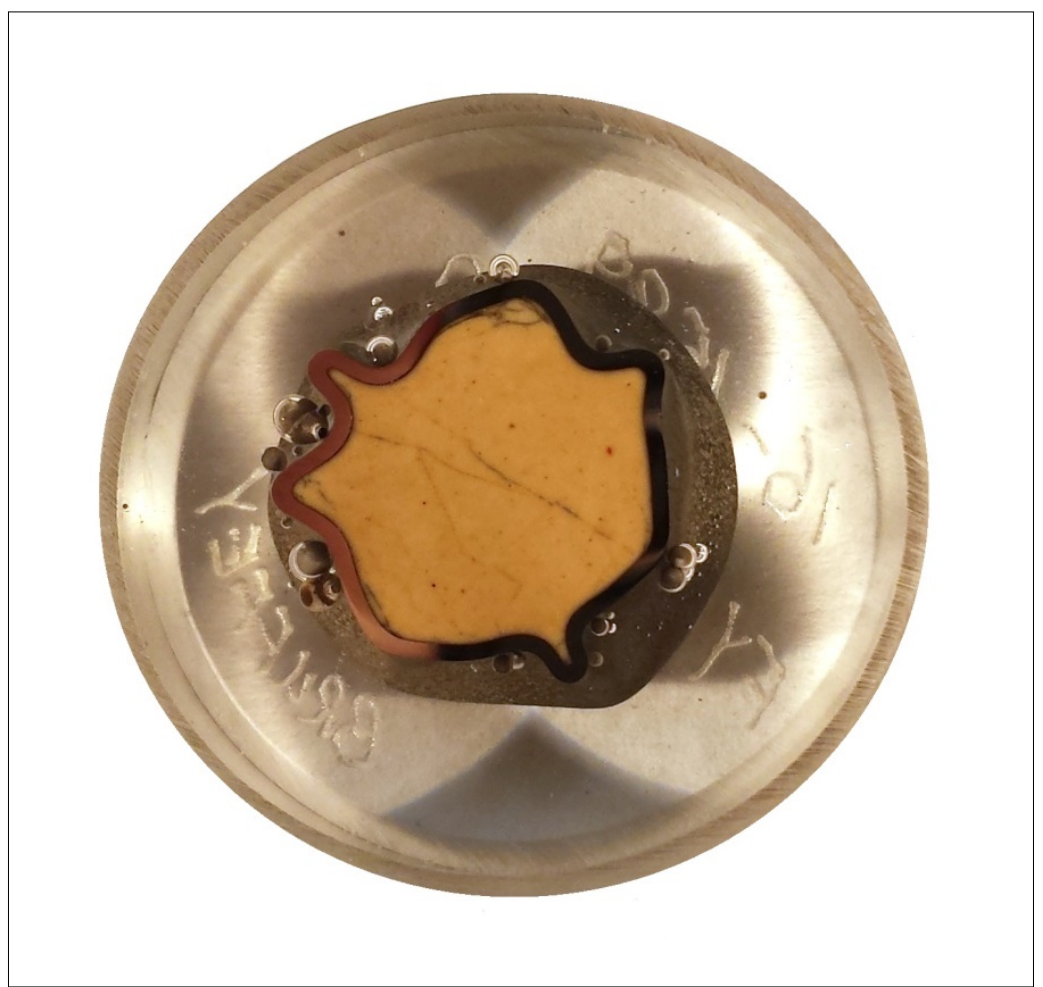

Figure 15. Cross section of Sample 10 (AgA | Chemisorbed | 1:0.2 | 300 MPa). 


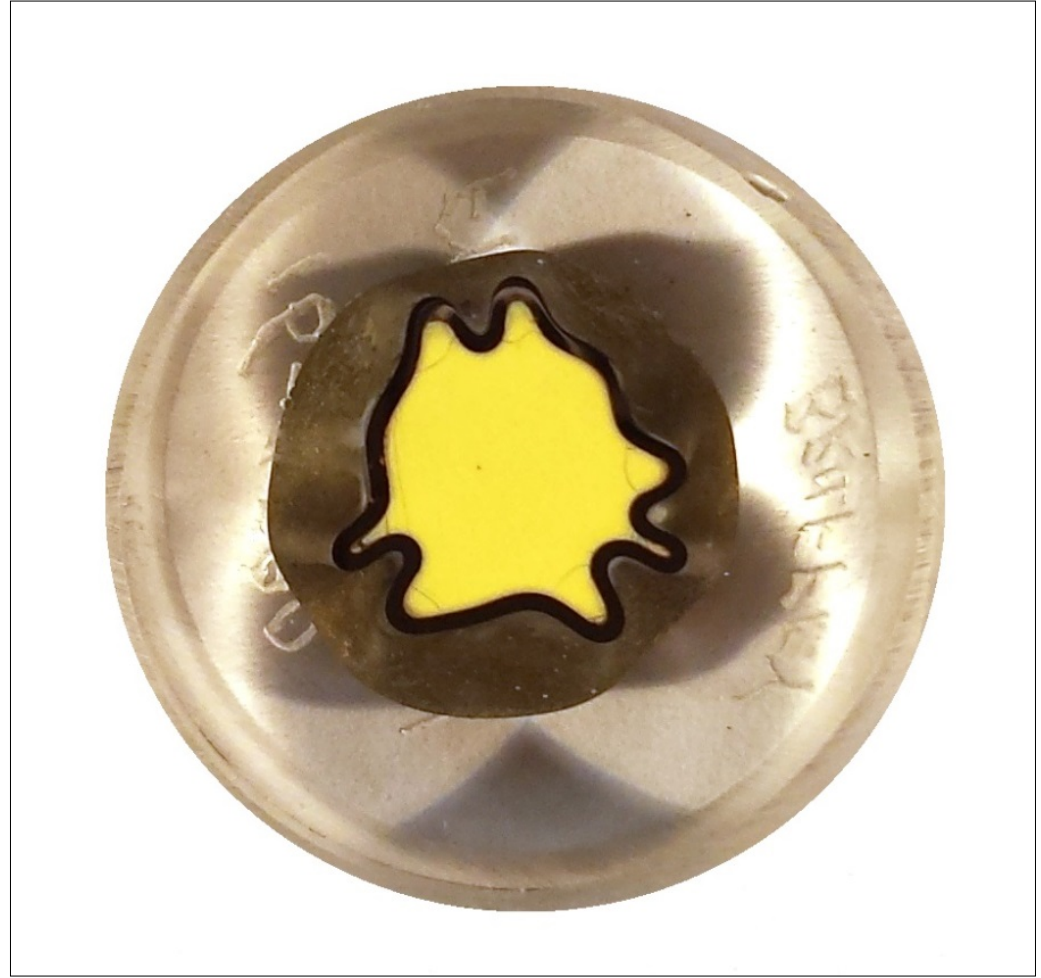

Figure 16. Cross section of Sample 11 (AgZ | Chemisorbed | 1:0.2 | 175 MPa).

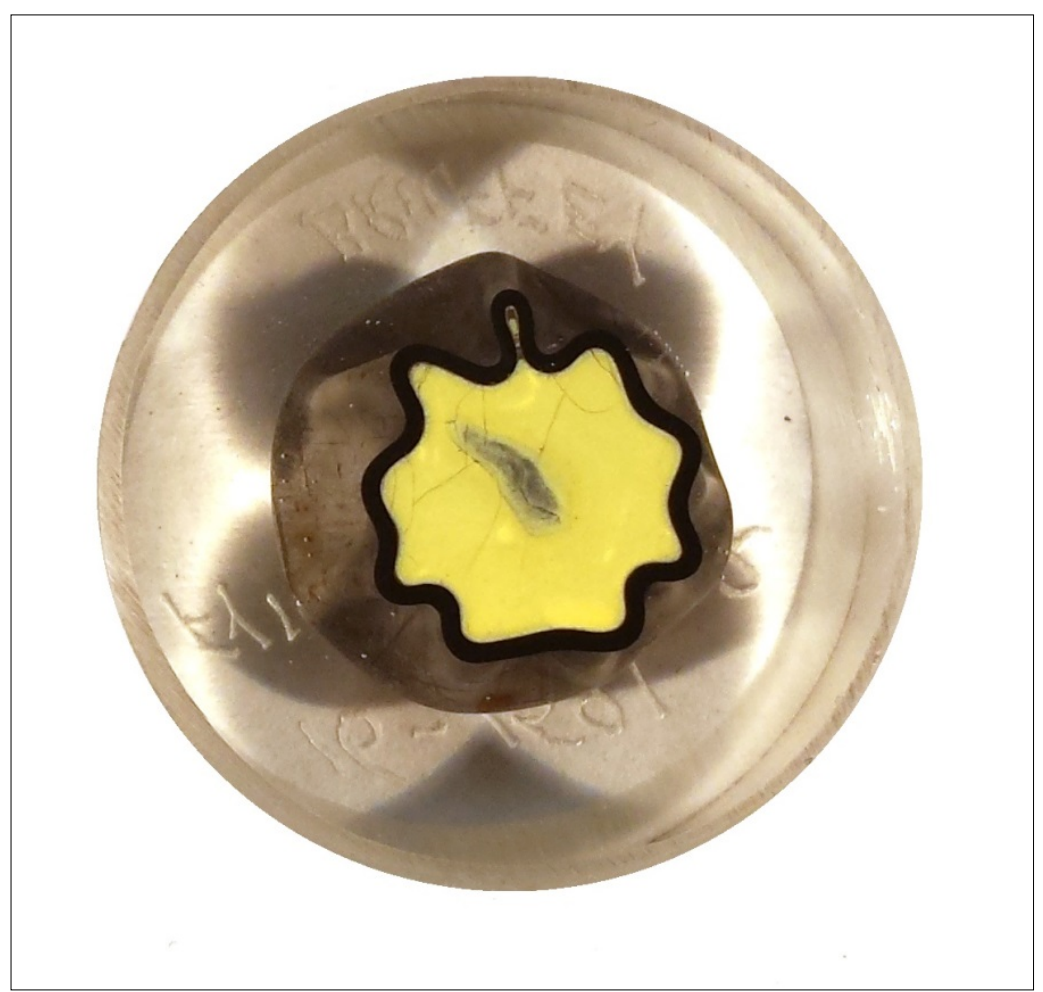

Figure 17. Cross section of Sample 12 (AgZ | Chemisorbed | 1:0.2 | 300 MPa). 


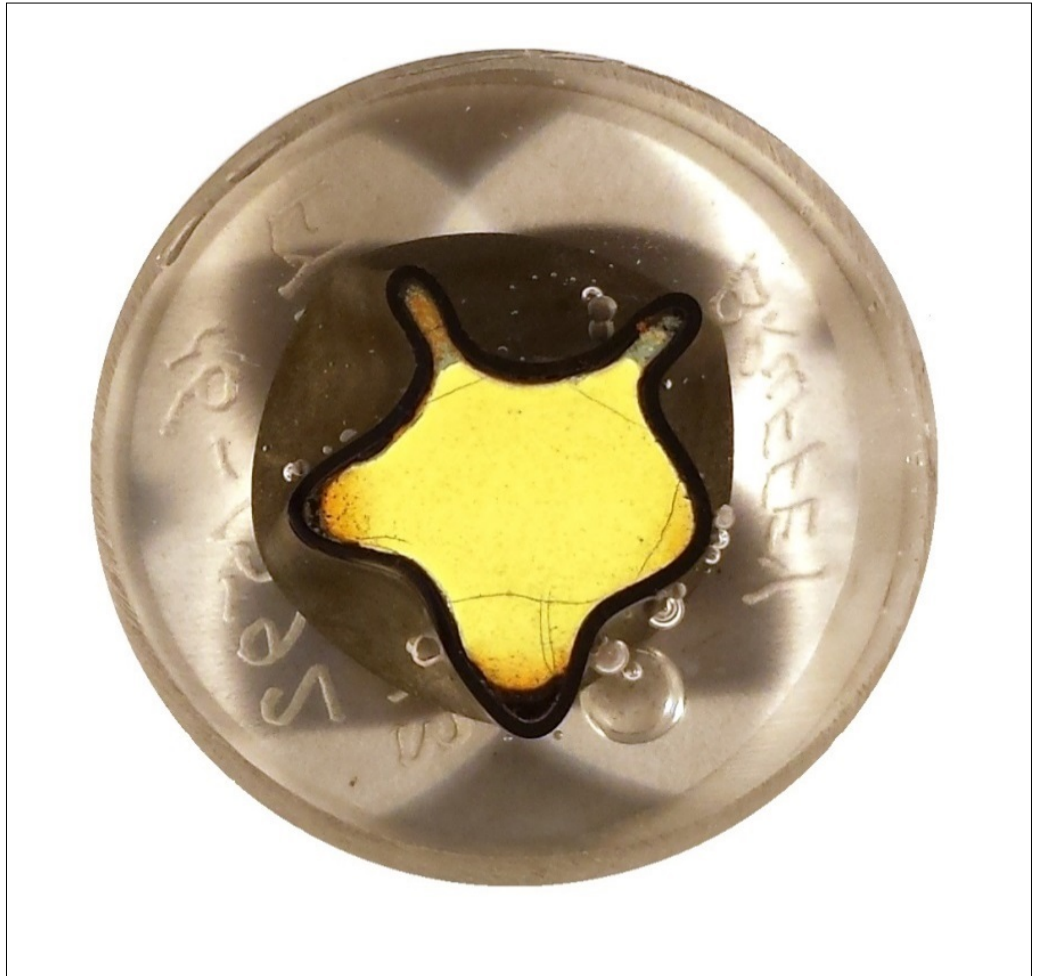

Figure 18. Cross section of Sample 13 (AgX | Chemisorbed | 1:2.8 | $175 \mathrm{MPa})$.

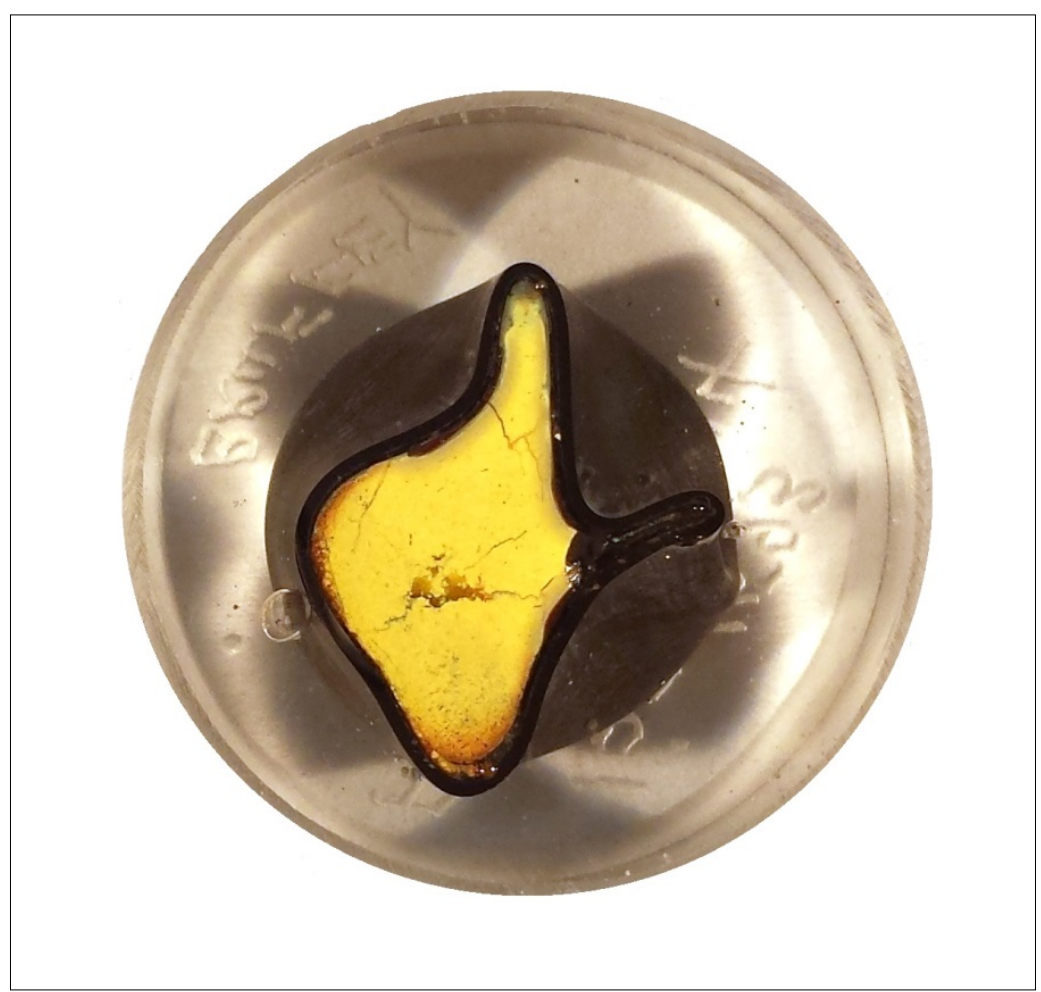

Figure 19. Cross section of Sample 14 (AgX | Chemisorbed | 1:2.8 | $300 \mathrm{MPa})$. 


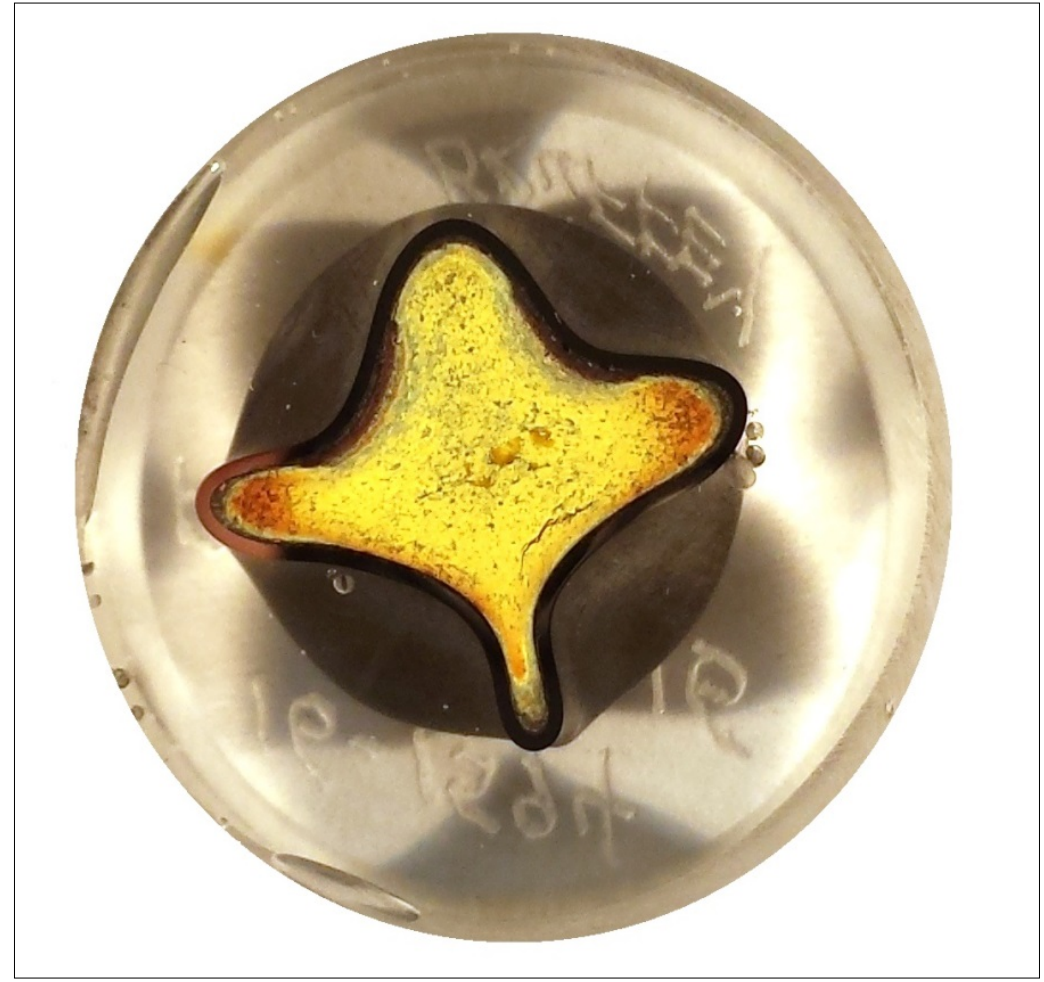

Figure 20. Cross section of Sample $16\left(\mathrm{AgX} \mid\right.$ Chemisorbed | 1:2.8 | $\left.300 \mathrm{MPa} \mid \mathrm{Al}_{2} \mathrm{O}_{3}\right)$.

\subsection{XRD patterns}

XRD patterns are shown in Appendix A for each sample. None of the pressed samples retained the original zeolite crystalline structure. The phases identified for each sample are shown in Table 9. Diffraction of the X-ray beam by the capsule wall causes taenite, an iron nickel alloy, to appear as an identified phase in the diffraction patterns. 
Table 9. Phases identified by XRD patterns

\begin{tabular}{|c|c|c|c|c|c|c|c|}
\hline $\begin{array}{c}\text { Sample } \\
\text { ID }\end{array}$ & Zeolite & $\begin{array}{c}\mathrm{Ag}_{4} \mathrm{Al}_{3}\left(\mathrm{SiO}_{4}\right)_{3} \mathbf{I} \\
\text { (Sodalite) }\end{array}$ & $\begin{array}{c}\mathrm{K}_{1.2} \mathrm{Na}_{2.8} \mathrm{Fe}_{0.1} \mathrm{Al}_{3.9} \mathrm{Si}_{4} \mathrm{O}_{16} \\
\text { (Nepheline) }\end{array}$ & $\begin{array}{c}\text { AgI } \\
\text { (Iodargyrite) }\end{array}$ & $\begin{array}{c}\text { AgI } \\
\text { (Miersite) }\end{array}$ & $\begin{array}{c}\mathrm{SiO}_{2} \\
\text { (Quartz) }\end{array}$ & Other phases \\
\hline HIP-1 & $\mathrm{AgA}$ & $\bullet$ & $\bullet$ & & & & \\
\hline HIP-2 & $\mathrm{AgA}$ & - & $\bullet$ & & & & \\
\hline HIP-3 & $\mathrm{NaZ}$ & & & $\bullet$ & & $\bullet$ & \\
\hline HIP-4 & $\mathrm{NaZ}$ & & & $\bullet$ & $\bullet$ & $\bullet$ & \\
\hline HIP-5 & $\mathrm{AgZ}$ & & & & $\bullet$ & $\bullet$ & $\begin{array}{l}\mathrm{K}_{0.7} \mathrm{Na}_{0.3} \mathrm{Cl} \\
\text { (Sylvite) }\end{array}$ \\
\hline HIP-6 & $\mathrm{AgZ}$ & & & $\bullet$ & $\bullet$ & $\bullet$ & \\
\hline HIP-7 & $\operatorname{AgX}$ & $\bullet$ & $\bullet$ & & & & \\
\hline HIP-8 & $\operatorname{AgX}$ & $\bullet$ & $\bullet$ & & & & \\
\hline HIP-9 & $\mathrm{AgA}$ & $\bullet$ & & & & & \\
\hline HIP-10 & $\mathrm{AgA}$ & $\bullet$ & & & & & \\
\hline HIP-11 & $\mathrm{AgZ}$ & & & $\bullet$ & $\bullet$ & $\bullet$ & $\begin{array}{c}\mathrm{K}_{0.7} \mathrm{Na}_{0.3} \mathrm{Cl} \\
\text { (Sylvite) }\end{array}$ \\
\hline HIP-12 & $\mathrm{AgZ}$ & & & $\bullet$ & $\bullet$ & $\bullet$ & $\begin{array}{l}\mathrm{K}_{0.7} \mathrm{Na}_{0.3} \mathrm{Cl} \\
\text { (Sylvite) }\end{array}$ \\
\hline HIP-13 & $\operatorname{AgX}$ & & & $\bullet$ & $\bullet$ & & $\begin{array}{c}\mathrm{K}_{0.7} \mathrm{Na}_{0.3} \mathrm{Cl} \\
(\text { Sylvite) } \\
\mathrm{Al}_{2.26} \mathrm{Si}_{0.74} \mathrm{O}_{4.87} \\
\text { (Mullite) }\end{array}$ \\
\hline HIP-14 & $\operatorname{AgX}$ & & & $\bullet$ & $\bullet$ & & $\begin{array}{c}\mathrm{K}_{0.7} \mathrm{Na}_{0.3} \mathrm{Cl} \\
(\text { Sylvite) } \\
\mathrm{Al}_{2.26} \mathrm{Si}_{0.74} \mathrm{O}_{4.87} \\
\text { (Mullite) }\end{array}$ \\
\hline HIP-16 & $\operatorname{AgX}$ & & & $\bullet$ & $\bullet$ & & $\begin{array}{c}\mathrm{K}_{0.7} \mathrm{Na}_{0.3} \mathrm{Cl} \\
\quad \text { Sylvite) } \\
\mathrm{Al}_{2.26} \mathrm{Si}_{0.74} \mathrm{O}_{4.87} \\
\text { (Mullite) }\end{array}$ \\
\hline
\end{tabular}




\section{DISCUSSION}

\subsection{Observations}

\subsubsection{Visual observations}

Visual observation of the capsule cross sections reveals several interesting features. There is a clear difference between occluded and chemisorbed samples. The occluded samples display a lesshomogeneous surface, and voids across the surface are easily observed. A clear example of this is Sample 5 (Figure 10). In contrast, the chemisorbed samples appear more homogenous. All chemisorbed samples have small hairline fractures within the surface and do not have voids. A close inspection of the surface of chemisorbed samples reveals that while the sample surface is not flecked throughout, as seen in the occluded samples, it instead has a segregated outside layer towards the edges of the capsule. This is most clearly seen in Sample 14 (Figure 19). Analysis by scanning electron microscopy-electron dispersive spectroscopy (SEM-EDS) could potentially resolve the chemical composition of each of these layers.

\subsubsection{Assessment of density and RHB values}

The creation of duplicate samples (FY16-HIP-7 and FY16-HIP-8) was intended to evaluate the reproducibility of the HIP process. The density measurements for these two samples were 3.785 and 4.079 , respectively. This difference of $0.3 \mathrm{~g} / \mathrm{mL}$ is statistically significant in comparison to the error of the measurement itself $(\sim 0.03 \mathrm{~g} / \mathrm{mL})$. The origin of the density differences is unknown. Unfortunately, as the two replicate samples displayed a density difference, it was not possible to establish what magnitude of density variation could be a result of the experimental variables studied. Thus, the density measurements reported could be useful in waste volume assessments, for example, but could not be used to assess the original questions posed in Section 3.

Similarly, the RHB measurement was determined to be unsuccessful in determining the hardness of the sample surface. "Hardness" is not a property that would be included in a waste acceptance criteria document, but the measurement was performed as a potential way to gauge some of the mechanical properties of the manufactured waste form. As was demonstrated in Table 8, some of the duplicate measurements varied widely. Other measurements cracked the sample surface. These outcomes indicate that RHB measurements are not appropriate for this waste form. It may be more appropriate to pursue other hardness standard measurements, such as the Knoop Indentation Hardness for Advanced Ceramics (ASTM C1326). Alternatively, other factors such as fine formation or resistance to stress and strains could be judged more valuable than a hardness measurement in evaluating the waste form potential.

\subsubsection{XRD results}

All I-AgA samples were shown to convert to $\mathrm{Ag}_{4} \mathrm{Al}_{3}\left(\mathrm{SiO}_{4}\right)_{3} \mathrm{I}$, an iodine-bearing sodalite phase. For I-AgA samples that were prepared by iodine occlusion, a nepheline phase was also identified. This was not present for chemisorbed I-AgA samples. Nepheline is an aluminosilicate with a 1:1 Si:Al ratio (M$\mathrm{AlSiO}_{4}$ ). Nepheline is found in nature with a mixture of sodium, potassium, and calcium as the interstitial metal cation. Synthetic nepheline contains predominately sodium with potassium in smaller amounts than that of natural samples; calcium is generally not incorporated in synthetic samples (Tait, 2003). The nepheline diffraction pattern used for this sample was collected from a sample with formula $\mathrm{K}_{1.2} \mathrm{Na}_{2.8} \mathrm{Fe}_{0.1} \mathrm{Al}_{3.9} \mathrm{Si}_{4} \mathrm{O}_{16}$.

Sodalite and nepheline phases were also identified for I-AgX samples prepared by occlusion. I-AgX prepared by chemisorption did not convert to sodalite, with HIPing of chemisorbed I-AgX resulting in the formation of quartz $\left(\mathrm{SiO}_{2}\right)$. Sodalite was not observed in FY16-HIP-16, which had additional alumina added. Mullite, a pure alumina silicate of formula $\mathrm{Al}_{2.26} \mathrm{Si}_{0.74} \mathrm{O}_{4.87}$, was found in each of the I-AgX samples prepared by chemisorption. 
The presence of sodalite was not observed for any of the mordenite samples, either sodium or silver exchanged. The dominate phases observed for $\mathrm{NaZ}$ and $\mathrm{AgZ}$ samples were quartz $\left(\mathrm{SiO}_{2}\right), \mathrm{AgI}$ (miersite) and AgI (iodargyrite), along with an amorphous phase.

Sylvite, a mineral phase with chemical composition $\mathrm{K}_{0.7} \mathrm{Na}_{0.3} \mathrm{Cl}$, was found in one I-AgZ sample prepared by occlusion and in both I-AgZ samples prepared by chemisorption. It was also present in I-AgX samples prepared by chemisorption. Both sylvite and nepheline, identified in I-AgA and I-AgX samples that converted to sodalite, had potassium metal cations present in the mineral structure. The origin of potassium in these samples is unknown but could be attributed to impurities in the zeolite starting material, as all other reagents were of high purity. Additionally, any metal cations that did not participate in the silver ion exchange, whether sodium, calcium, or impurities, would be retained by the zeolite material and available for incorporation into these phases during the HIP process. It was not possible to obtain a minor impurity assay for the $\mathrm{NaZ}, \mathrm{NaX}$, and Zeolite A starting material. Zeolite A did contain a mixture of calcium and sodium as the metal cation in the starting material (as stated by the manufacturer), and this could have contributed to the formation of nepheline.

\subsection{Original experimental questions}

As was described in Section 3, the sample set was intended to investigate specific questions. These are revisited here. In many cases, the concerns with density and hardness measurements obscured clear answers to these questions. In an effort to qualitatively answer these questions using XRD patterns, the XRD patterns of selected samples were overlaid.

1) Is the work of Sheppard et al. on the conversion of zeolite A to iodine-loaded sodalite replicated by the test methods used here? (Sample \#1) - Yes, sodalite was confirmed in the HIPed product for sample FY16-HIP-1.

2) Is this conversion also effected at $300 \mathrm{MPa}$, the HIP pressure used in previous ORNL research? (comparison of Samples \#1, 2) -Yes, XRD patterns for both samples FY16-HIP-1 and FY16-HIP-2 are very similar (Figure 21).

3) Can mordenite (as either NaZ or AgZ) be converted to iodine-loaded sodalite through methods analogous to those used by Sheppard et al. in their reported conversion of zeolite A to iodine-loaded sodalite? (Samples \#3, \#4, \#5, \#6) - No, as shown by XRD analysis of samples FY16-HIP-3 through FY16-HIP-6. $\mathrm{SiO}_{2}$ and $\mathrm{AgI}$ (as either iodargyrite or miersite) were observed in all four samples. Sample \#5 also included sylvite.

4) What is the effect of iodine concentration on the potential conversion? (Samples \#3, \#4, \#5, \#6) Unknown, as XRD patterns did not show a clear difference in samples prepared with varying iodine concentration (Figure 22).

5) Can the conversion of AgX to iodine-loaded sodalite as described by Sheppard et al. be effected at the higher pressure of 300MPa (Samples \#7, \#8) - Yes, as seen in the associated XRD patterns (Figure 27).

6) How does the iodine inclusion method impact the potential conversion? (Samples \#9-\#14) - First, there is a difference in the phases that formed from samples prepared by chemisorption or occlusion. In comparing AgA samples (\#1, \#2,\#9, and \#10), it is observed that all form sodalite, but the samples starting with the occluded form also appear to form a nepheline phase. In the case of the faujasite samples (\#7, \#8,\#13, and \#14), the samples starting with the occluded iodine form (\#7 and \#8) result in the formation of sodalite and nepheline, but neither phase is observed for the samples beginning with the chemisorbed iodine.

Second, in comparing the XRD patterns of samples prepared by chemisorption and occlusion (Figures 23-25), the chemisorbed starting material appears to provide a more crystalline pattern. This 
could be due to more even distribution of iodine within the sample. This is observed for I-AgA material, which converted to sodalite, and for I-AgZ material, which did not convert.

These patterns do indicate that the method of iodine inclusion could impact zeolite conversion to sodalite. It is important to note that chemisorbed material contained iodine at lower molar ratios than that of occluded material, as the experiments were not designed to control the iodine concentration of the chemisorbed material. Thus, attribution of additional crystallinity or varied phase formation to solely iodine inclusion method is not possible using the data collected during this study.

7) What is the effect of pressing pressure? (Samples \#9-\#14) - XRD patterns did not show substantial difference as a result of pressure variation (Figure 21). There is likely little effect within the pressure range studied.

8) Can alumina addition facilitate the conversion of $\mathrm{AgX}$ and $\mathrm{AgZ}$ to iodine-loaded sodalite? (Samples $\# 15$, \#16) - Sample 15 (AgZ) was not evaluated due to capsule failure. In the case of AgX, this particular sample (\#16) was created with chemisorbed I-AgX and alumina and was not found to convert to iodosodalite. From AgX-based Samples \#7, \#8, \#13, and \#14, it is clear that the method of iodine inclusion impacted the phases that were observed in pressed AgX samples, with occluded I-AgX converting to iodosodalite while chemisorbed I-AgX did not convert to sodalite. It is thus difficult to distinguish the effects of the alumina addition from the effects of iodine inclusion method. XRD patterns and identified phases did not display significant differences between chemisorbed AgX samples with and without alumina (Figure 26). During the course of analysis, it was determined that the equations provided in Section 2 do not fully account for the role of metal cations present in the precursor materials and that the addition of alumina may not promote iodosodalite formation without also including a metal cation additive.

9) Will the methods described here be reproducible? (Samples \#7, \#8) - Unknown, as is discussed in Section 7.1.2. The XRD patterns of both samples are similar (Figure 27).

10) What are the physical properties of the resultant waste form? - This question merits further investigation. Each type of zeolite produced a distinctive surface. Chemisorbed samples were observed to have hairline fractures throughout the material. Occluded samples were observed to have small voids in the cross-sectioned surface. 


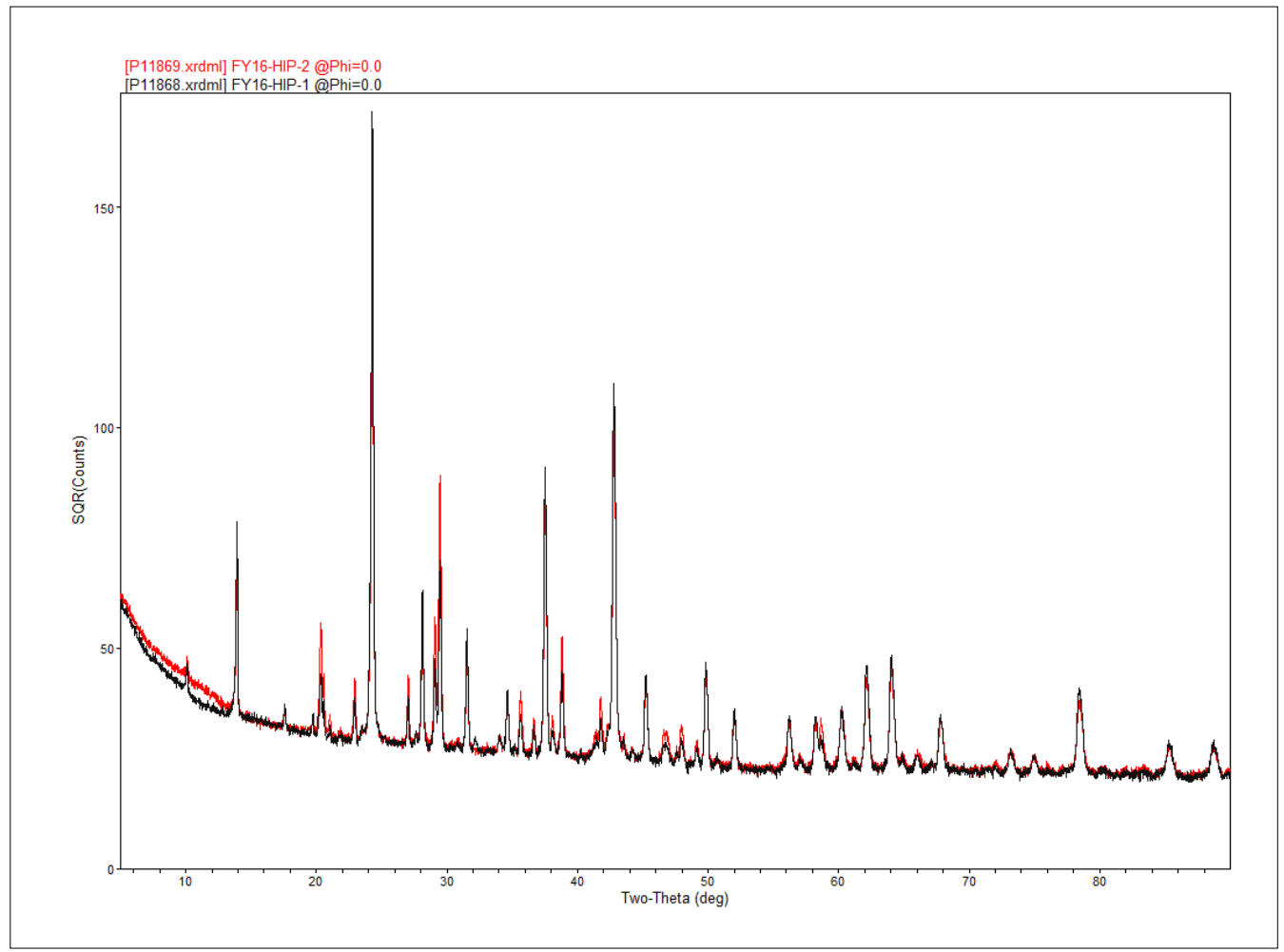

Figure 21. XRD patterns of FY16-HIP-1 and FY16-HIP-2.

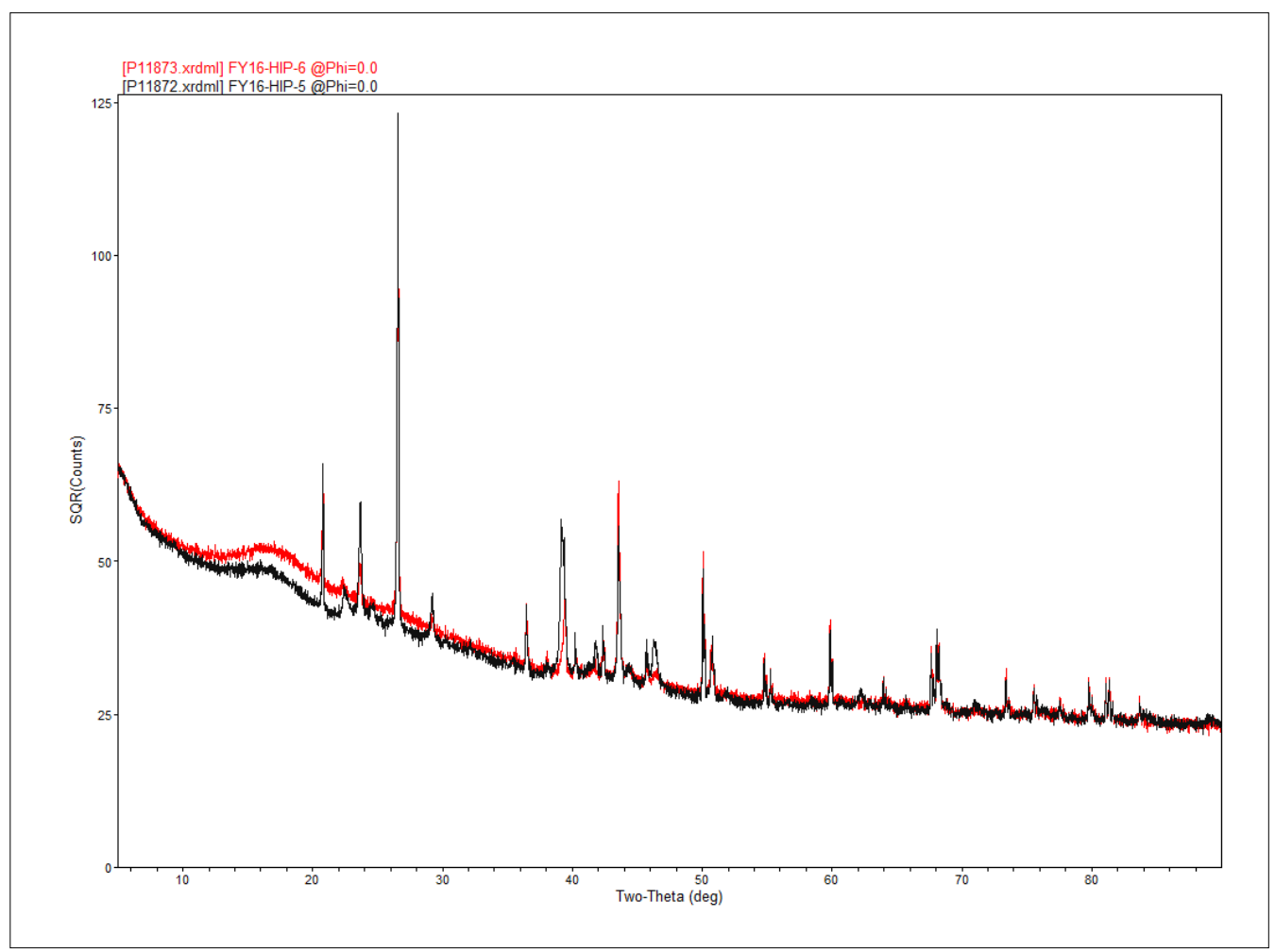

Figure 22. XRD patterns of FY16-HIP-5 and FY16-HIP-6. 


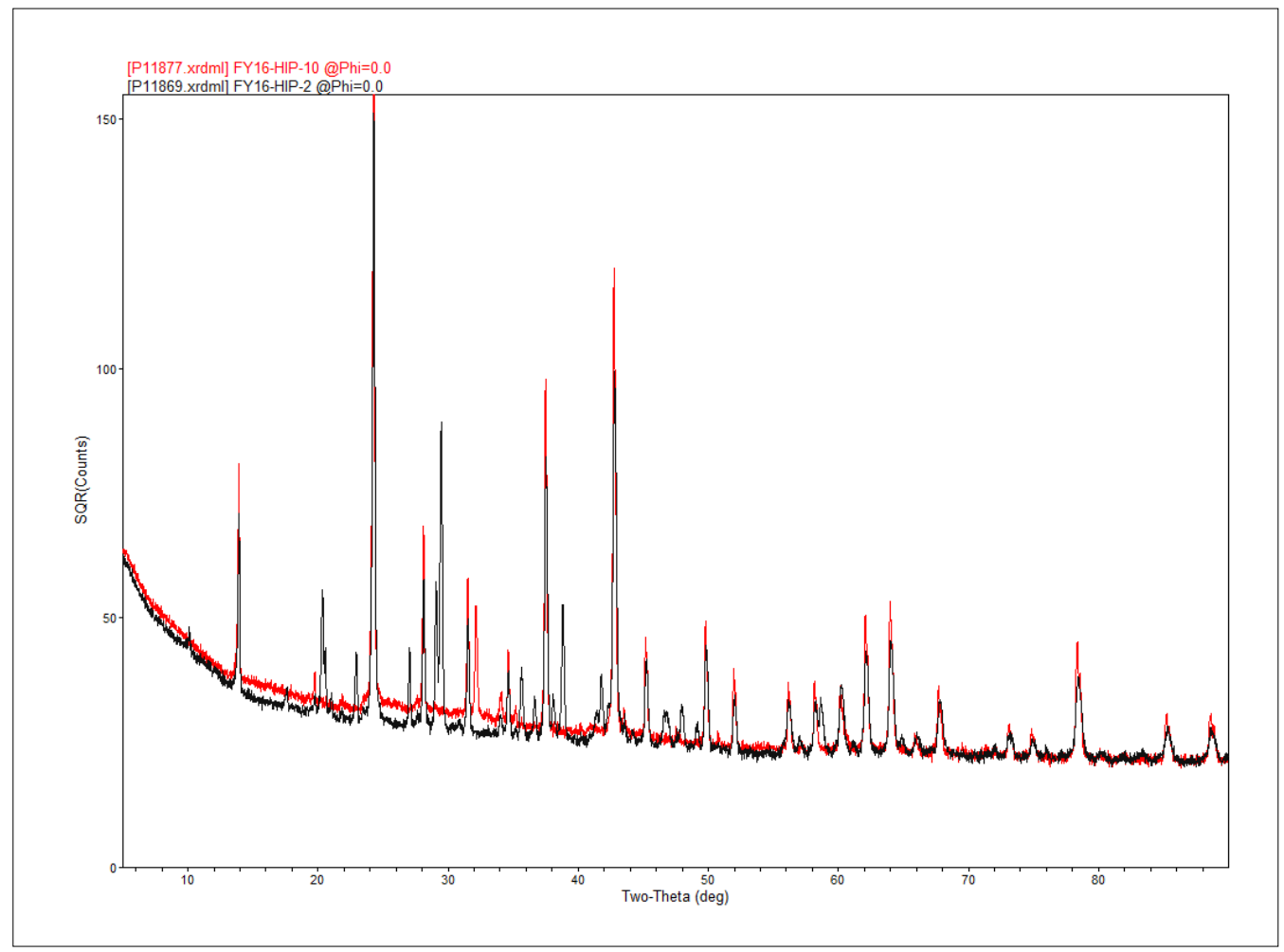

Figure 23. XRD patterns of FY16-HIP-2 and FY16-HIP-10.

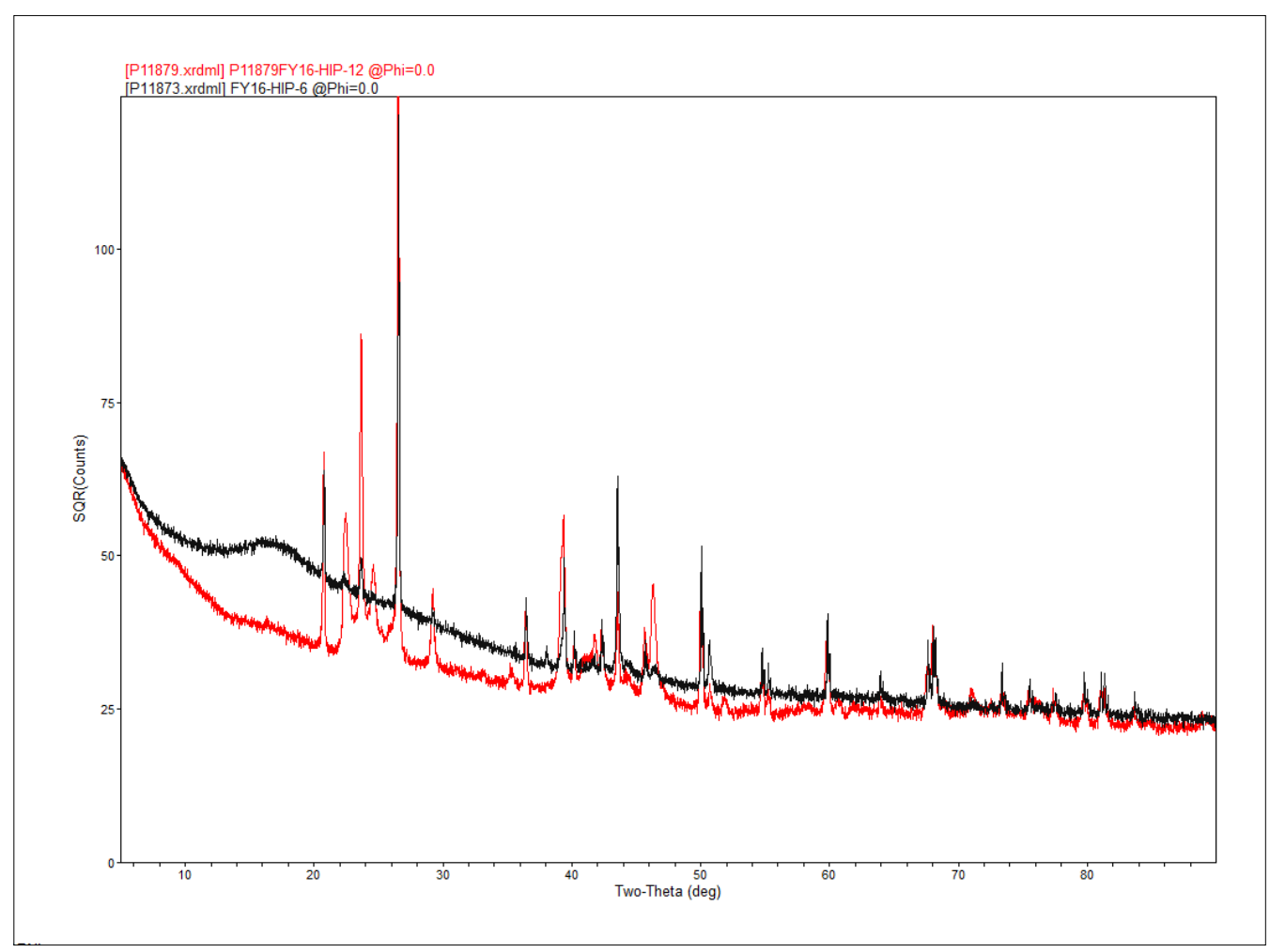

Figure 24. XRD patterns of FY16-HIP-6 and FY16-HIP-12. 


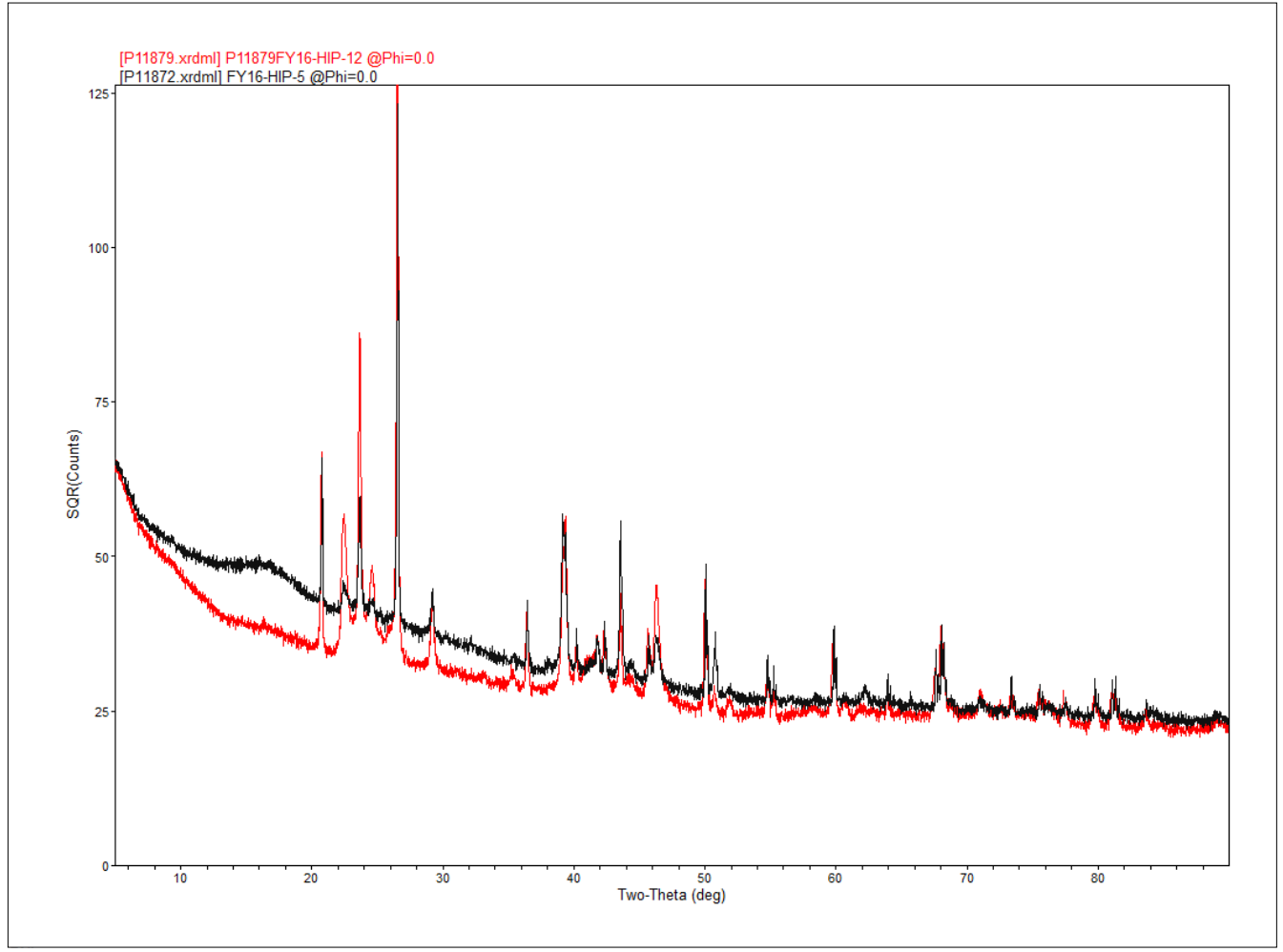

Figure 25. XRD patterns of FY16-HIP-5 and FY16-HIP-12.

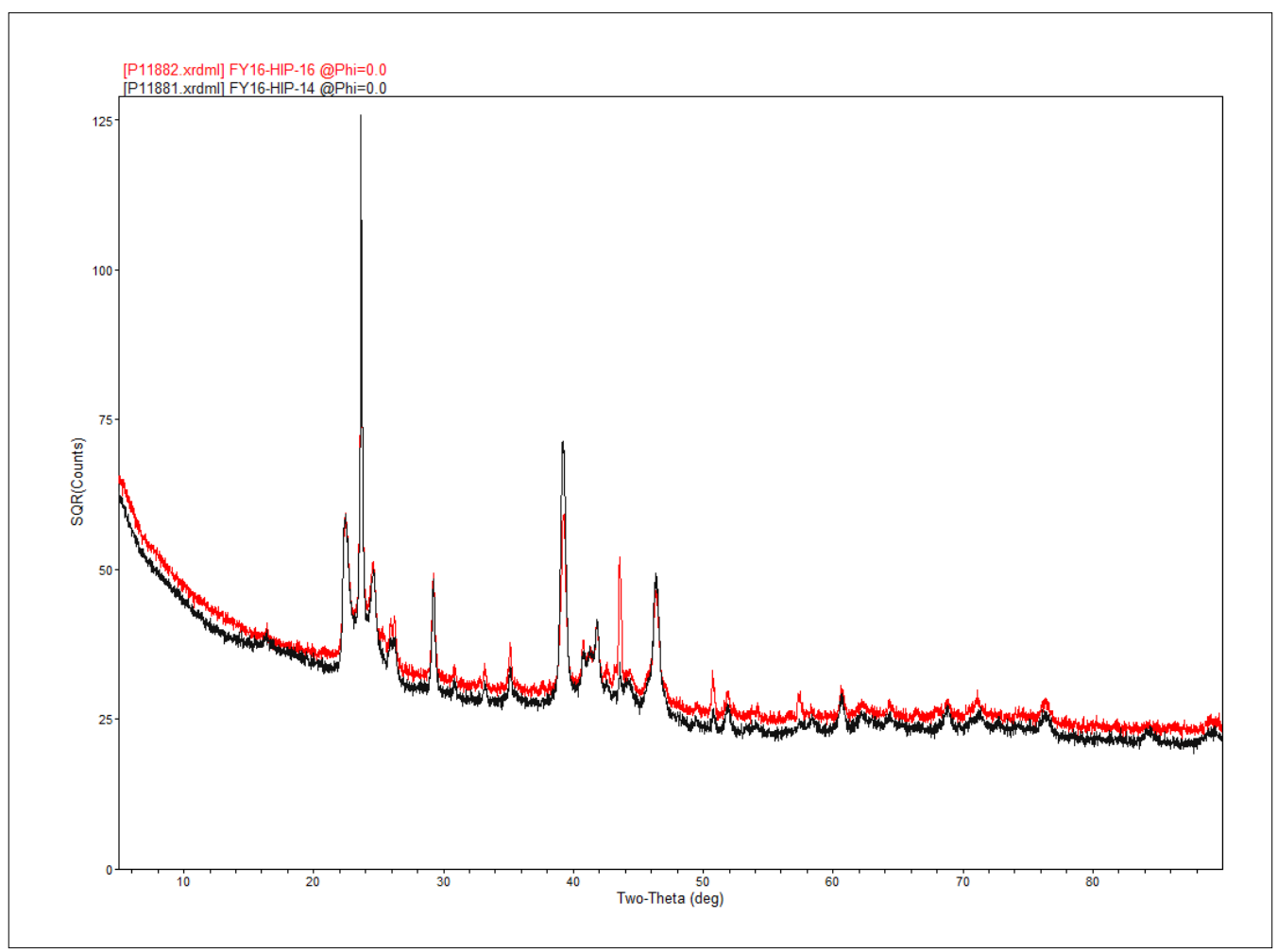

Figure 26. XRD patterns of FY16-HIP-14 and FY16-HIP-16. 


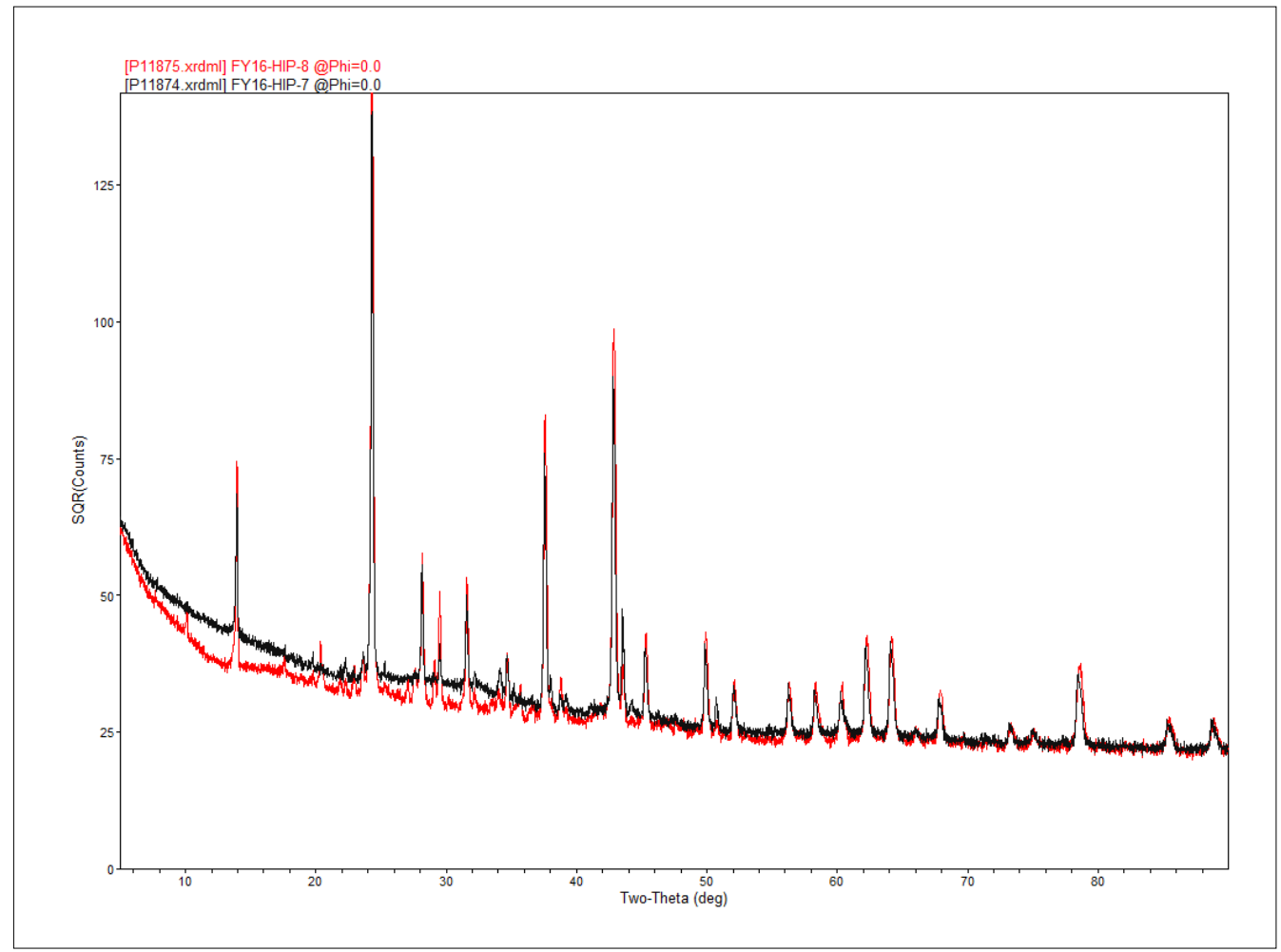

Figure 27. XRD patterns of FY16-HIP-7 and FY16-HIP-8.

\subsection{Conclusions}

Investigation of iodine-bearing waste forms created by HIPing of silver-exchanged zeolites was conducted. Improvements to the capsule design and sealing operation resulted in a substantial decrease in failure rate of capsules during the HIP process. The failure rate for this test matrix was $6 \%$, as compared to $32 \%$ in previous efforts. This success was critical in determining that the HIP process merits continued consideration as potential process for iodine waste form production.

The experimental methodology described in this report was found to satisfactorily replicate other published studies. Iodine-loaded sodalite was produced by the HIPing of AgA occluded with AgI, as was first reported by Sheppard (2006). In addition to providing confidence in the described methodology, it also confirmed that iodo-sodalite formation is possible from certain zeolitic minerals.

This iodo-sodalite formation had only previously been shown to result from iodine-occluded silverexchanged zeolites A and X (faujasite). Occlusion is not representative of likely operations in an off-gas treatment stream, in which iodine will be incorporated into zeolites through chemisorption. This effort demonstrated that HIPing of iodine-loaded zeolites, in which the iodine has been adsorbed into the mineral from a gas stream, could also result in iodo-sodalite formation upon HIPing. However, this iodosodalite formation occurred only for iodine-loaded silver exchanged zeolite A. This was an unexpected finding and it is not yet clear why chemisorption would prevent iodo-sodalite formation for zeolite X.

It is of interest to compare the occluded and chemisorbed I-AgA XRD patterns. The XRD patterns for these samples both contain iodo-sodalite, but the occluded appears to be more amorphous. Even in the cases where iodo-sodalite is not formed (for example, with I-AgZ samples), the samples appear to be less amorphous through XRD analysis. Visually, all occluded samples appear more heterogenous than their chemisorbed counterparts, which is unsurprising as chemisorption is likely to result in more homogenously distributed iodine within the sample. 
It was also observed that the occluded samples were more likely to have voids in the cross-sectioned surface, while the chemisorbed samples were more likely to have hairline fractures. In previous efforts, voids had been observed, but it was unclear whether they were arising from the sectioning and polishing process or from HIPing itself. The fact that chemisorbed samples do not show these voids now indicates that the sectioning and polishing process does not create these voids. The fundamental cause of void or fracture formation remains unclear. A non-exhaustive list of potential factors impacting the physical appearance of the sample could include the behavior of water during the pressing process, the homogeneity of the sample prior to HIP, the thermal expansion coefficients of the sample material, the thermal expansion coefficients of the capsule, or other technical unknowns.

One of the most significant observations from the completed work was that no iodo-sodalite formation was observed for any of the I-AgZ samples, either chemisorbed or occluded. This provides further confirmation of the importance of the Al:Si ratio for zeolite mineral behavior during HIPing. This characteristic was first identified by Sheppard and has now been expanded to the mordenite structure by this effort. This is interesting information in terms of sorbent characterization, for the Al:Si ratio is also a critical factor in the improved acid resistance of $\mathrm{AgZ}$ over $\mathrm{AgX}$ or AgA. An important aspect of this work was to assess whether alumina addition could promote iodo-sodalite formation in AgX and AgZ. Unfortunately, this hypothesis could not be investigated for AgZ due to capsule failure during the HIP process. For $\mathrm{AgX}$, it remains unclear whether the alumina addition was beneficial, as alumina was added to a chemisorbed sample and chemisorbed I-AgX samples did not convert to iodo-sodalite under the pressing conditions used.

Throughout the course of the testing described in this report, and through previous efforts, attention has been given to optimizing the pressing conditions for Ag-zeolite samples. Temperatures have ranged from $525-1100^{\circ} \mathrm{C}$, and pressures have ranged from $75-300 \mathrm{MPa}$. PCT testing identified $900^{\circ} \mathrm{C}$ as a pressing temperature for which no measurable iodine was released from the subsequent waste form. This work used pressures of 175, 190, and 300. No distinctive difference (either visually or through XRD) was found that could be correlated to pressure conditions. Further characterization, such as through waste form durability testing, would be required to fully describe the effect of pressure on HIPing of iodineloaded zeolite minerals.

In conclusion, the HIP process continues to demonstrate promise as a method for the direct consolidation of I-AgZ to a waste form. Future research into this process will attempt to resolve outstanding questions regarding the mechanical properties of the HIPed waste form and ideal pressing conditions Collaborations with other institutions to perform novel experiments testing waste form durability will be pursued, as the heterogeneous nature of the waste form can pose a unique challenge to traditional waste form durability methodology. In envisioning a large-scale waste form manufacture effort, the lack of required pretreatment, the mechanical stability and relatively low chemical hazards associated with the material, and other factors suggest that this could be a very desirable process for waste form creation from I-AgZ, should that technology be selected for iodine removal from gaseous streams.

\section{REFERENCES}

ASTM International, Standard Test Methods for Rockwell Hardness and Rockwell Superficial Hardness of Metallic Material, ASTM E18-03, June, 2003.

Bruffey, SH and RT Jubin. Recommend HIP Conditions for AgZ. ORNL/SPR-2015/503. UT-Battelle, LLC, Oak Ridge National Laboratory, 2015.

Bruffey, SH and RT Jubin. "Product Consistency Testing of a Hot Isostatically Pressed Iodine-Containing Waste Form." Transactions of the American Nuclear Society Vol. 115, Las Vegas, NV. November 6-10, 2016. pp 233-235. 
Fukumoto, M. Method for Solidifying Waste Containing Radioactive Iodine. US Patent No. 5826203, 1998.

ICDD, PDF-4+ 2015, International Centre for Diffraction Data, Newtown Square, PA.

Jade (2012), version 9.4.5 (computer software), Materials Data Inc., Livermore, CA 94550, USA.

Jubin, R, N Soelberg, D Strachan, and G Ilas. 2012a. Fuel Age Impacts on Gaseous Fission Product Capture During Separations. Report No. FCRD-SWF-2012-000089, PNNL-22550, Oak Ridge National Laboratory, Oak Ridge, TN.

Jubin, RT, DW Ramey, BB Spencer, KK Anderson, and SM Robinson. 2012b. "Impact of Pretreatment and Aging on the Iodine Capture Performance of Silver Exchanged Mordenite -12314." Presented at Waste Management 2012, WM Symposia, Tempe, AZ.

Jubin, RT and SH Bruffey. "Initial Evaluation of a Hot Isostatic Pressed Waste Form from Iodine-Loaded Silver-Exchanged Mordenite." In Proceedings of Global 2015, in publication.

Jubin, RT and DM Strachan. 2015. Assessments and Options for Removal and Immobilization of Volatile Radionuclides from the Processing of Used Nuclear Fuel. Report No. MRWFD-2015-000429

(ORNLSPR-2015/115), Oak Ridge National Laboratory, Oak Ridge, TN.

Jubin, RT and SH Bruffey, DM Strachan, NR Soelberg, BB Spencer, BJ Riley. Performance Criteria for Capture and/or Immobilization Technologies. ORNL/TM-2016/73. February 2016.

Maddrell, E. "Capture and Immobilization of Iodine," National Nuclear Laboratory, November 2, 2005.

Matyáš, J, GE Fryxell, BJ Busche, K Wallace, and LS Fifield. 2011. "Functionalized Silica Aerogels: Advanced Materials to Capture and Immobilize Radioactive Iodine." In Ceramic Materials for Energy Applications, pp. 21-32. American Ceramic Society, Westerville, OH.

Sheppard, G P, and JA Hriljac, ER Maddrell, and NC Hyatt. "Silver Zeolites: Iodide Occlusion and Conversion to Sodalite-A Potential I-129 Waste Form?" In Scientific Basis for Nuclear Waste Management XXIX, ed. P Van Iseghem, Vol. 932, pp. 775-82. Materials Research Society, Warrendale, Penn., 2006.

Tait, K, E Sokolova, FC Hawthorne. "The Crystal Chemistry of Nepheline." Canadian Mineralogist, vol. 41, pp. 61-70, 2003.

Tanabe, H.; T. Sakuragi, K. Yamaguchi, T. Sato. "Development of New Waste Forms to Immobilize Iodine-129 Released from a Spent Fuel Reprocessing Plant." Advances in Science and Technology, vol. 73, pp. 158-170, 2010. 
This page is intentionally left blank. 


\section{APPENDIX A}

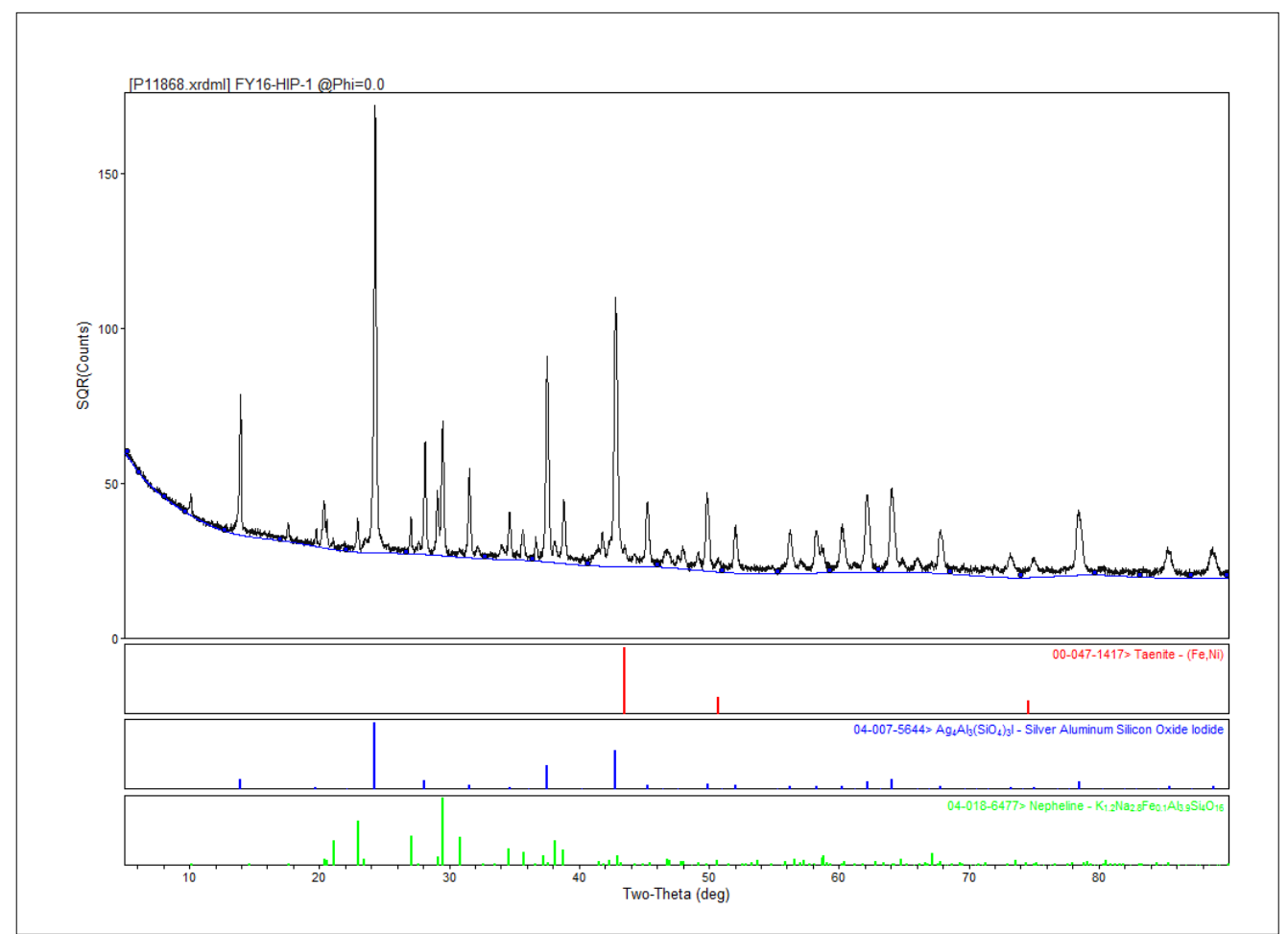

Figure A.1. The XRD pattern obtained from the sample FY16-HIP-1 (AgA Occluded | 1:2 | 190 MPa).

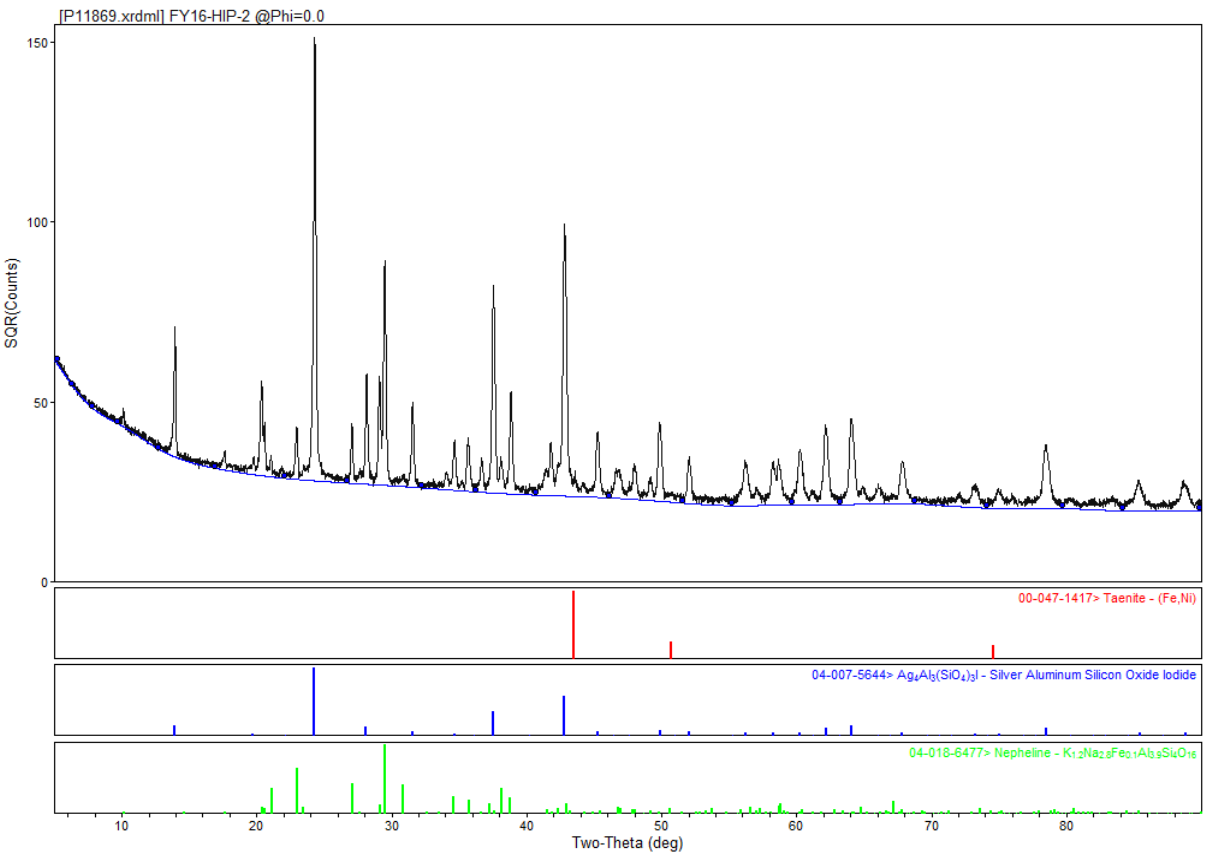

Figure A.2. The XRD pattern obtained from the sample FY16-HIP-2 (AgA | Occluded | 1:2 | 300 MPa). 


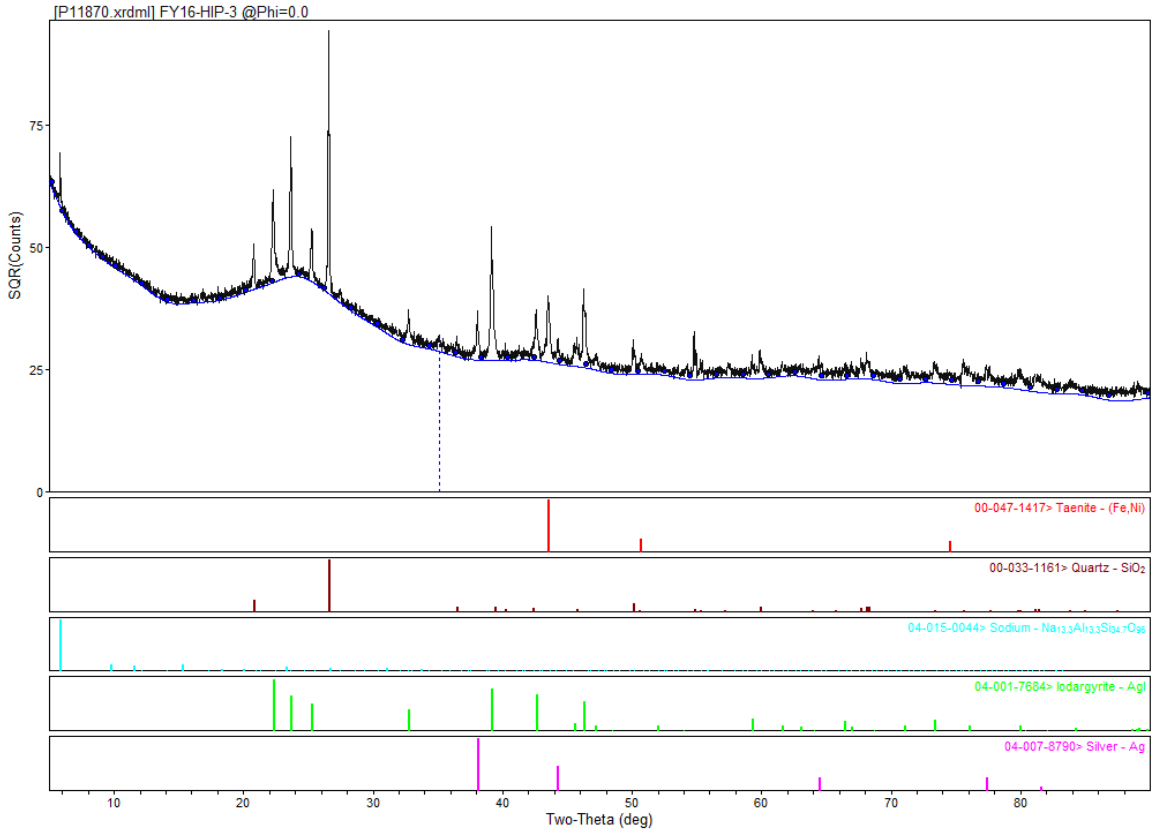

Figure A.3. The XRD pattern obtained from the sample FY16-HIP-3 (NaZ | Occluded | 1:2.5 |300 MPa).

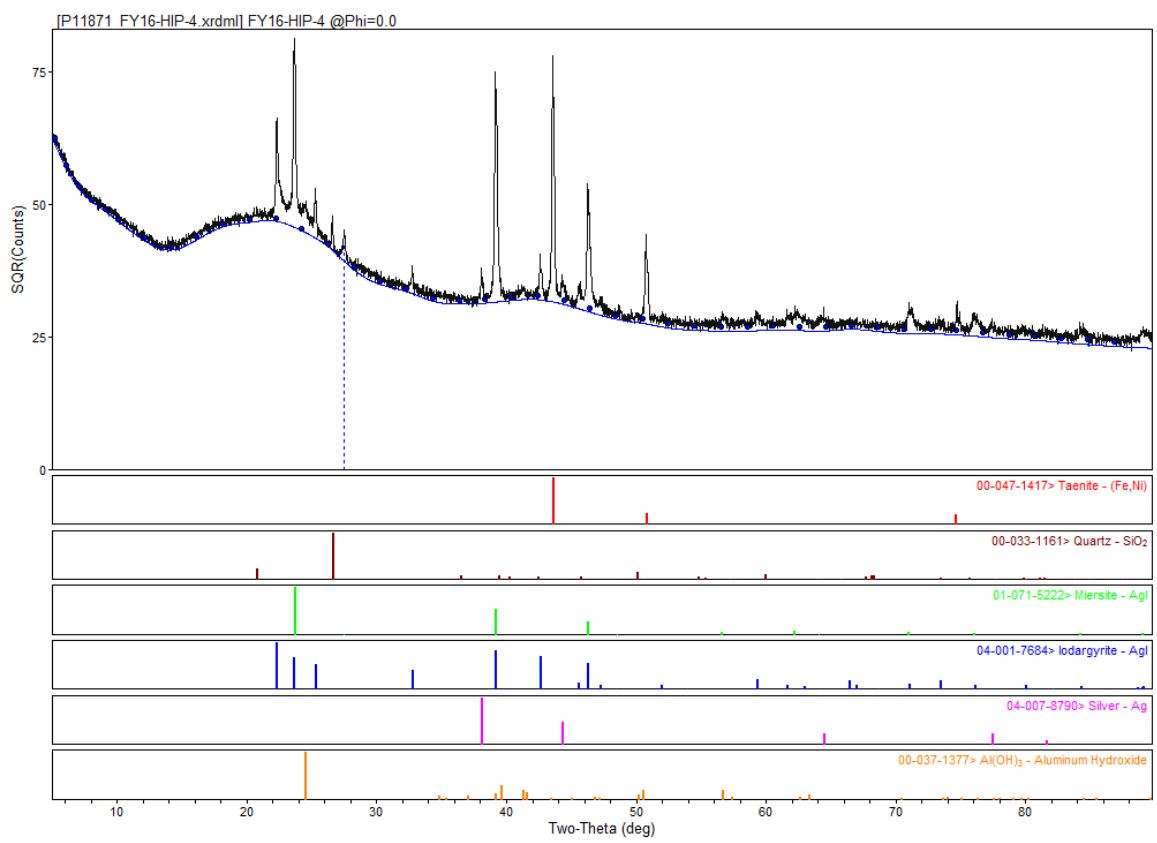

Figure A.4. The XRD pattern obtained from the sample FY16-HIP-4 (NaZ | Occluded | 1:1.3 | 300 MPa). 


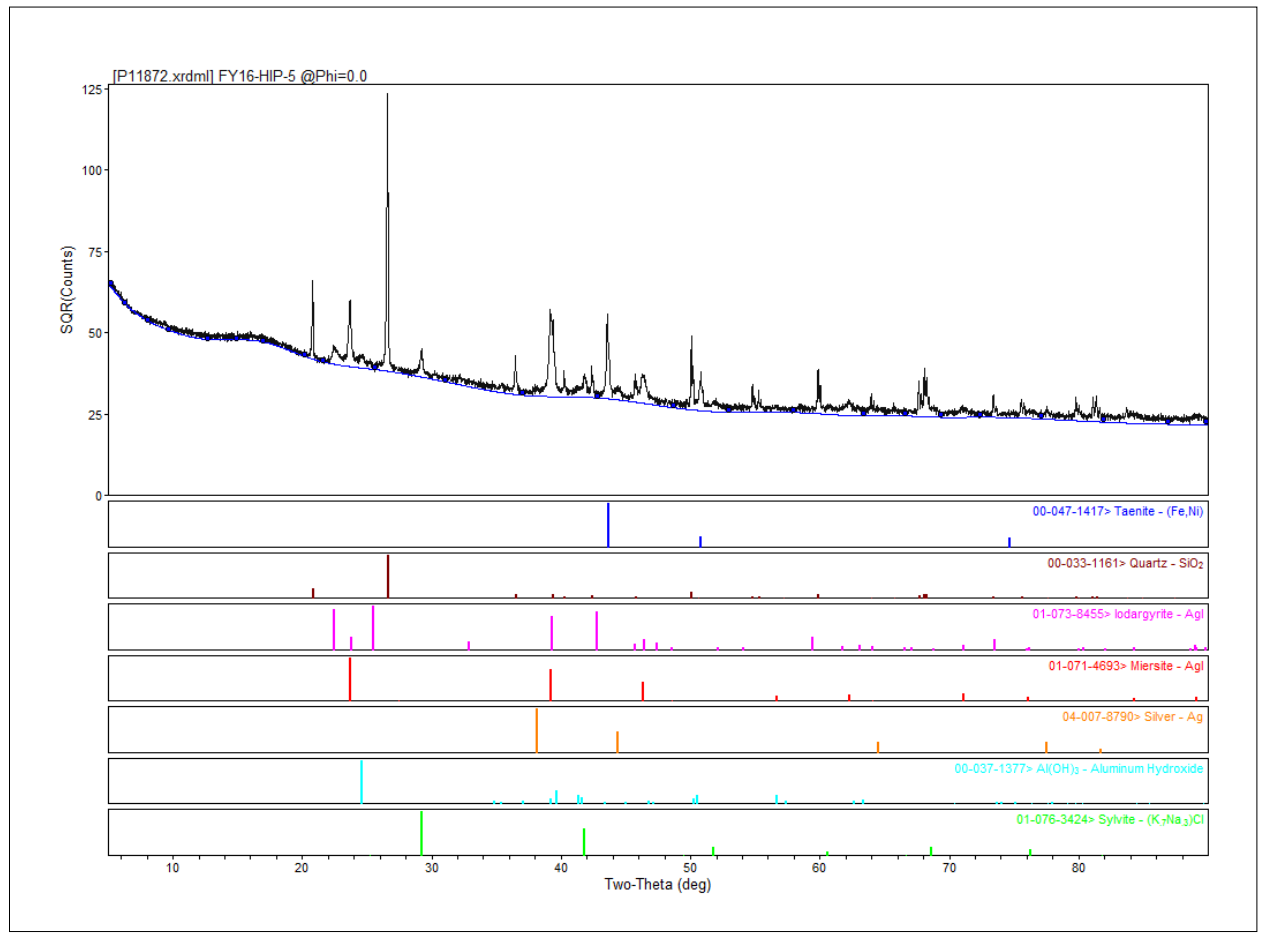

Figure A.5. The XRD pattern obtained from the sample FY16-HIP-5 (AgZ | Occluded | 1:2.6 |300 MPa).

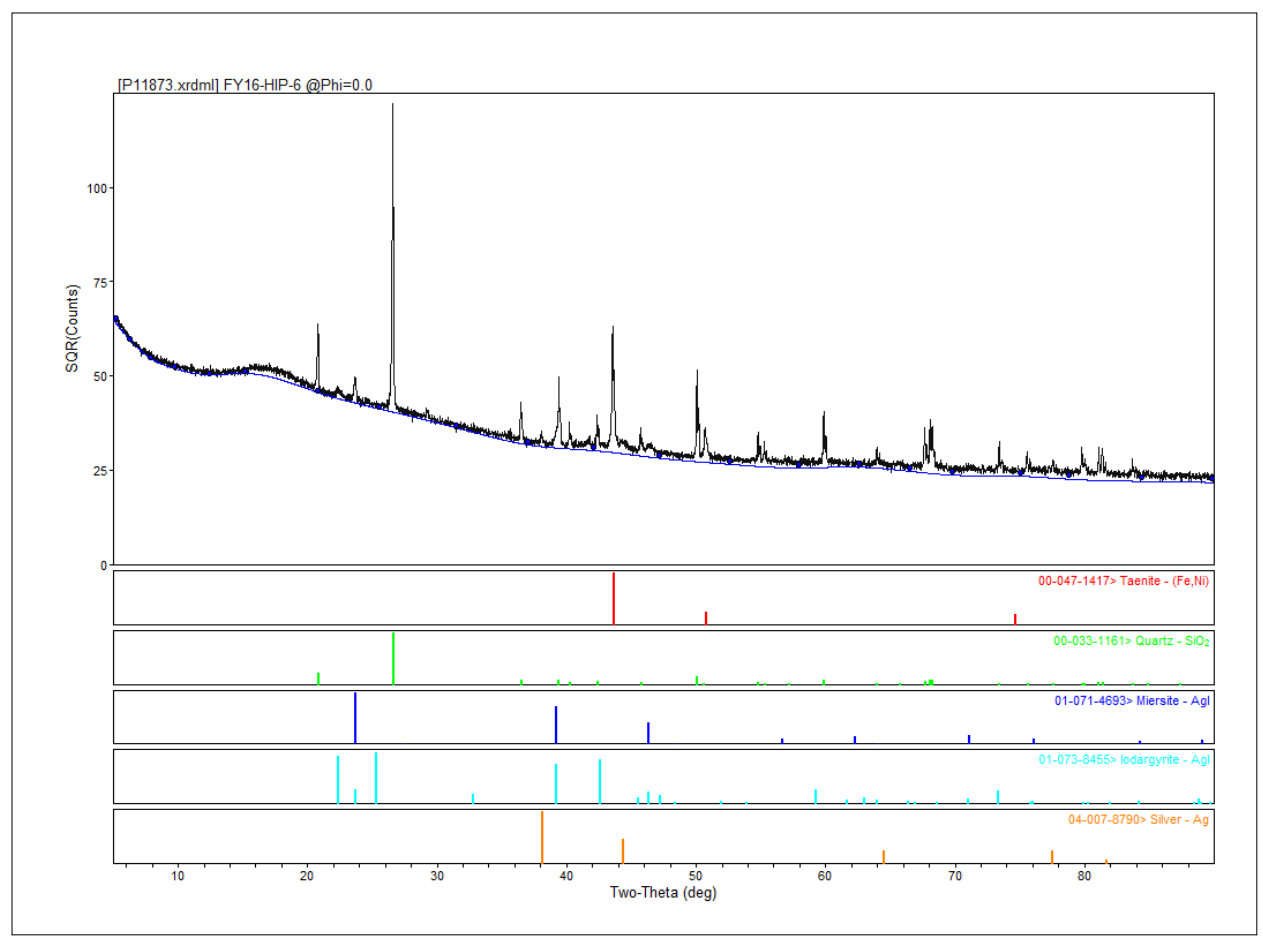

Figure A.6. The XRD pattern obtained from the sample FY16-HIP-6 (AgZ | Occluded | 1:1.4 |300 MPa). 


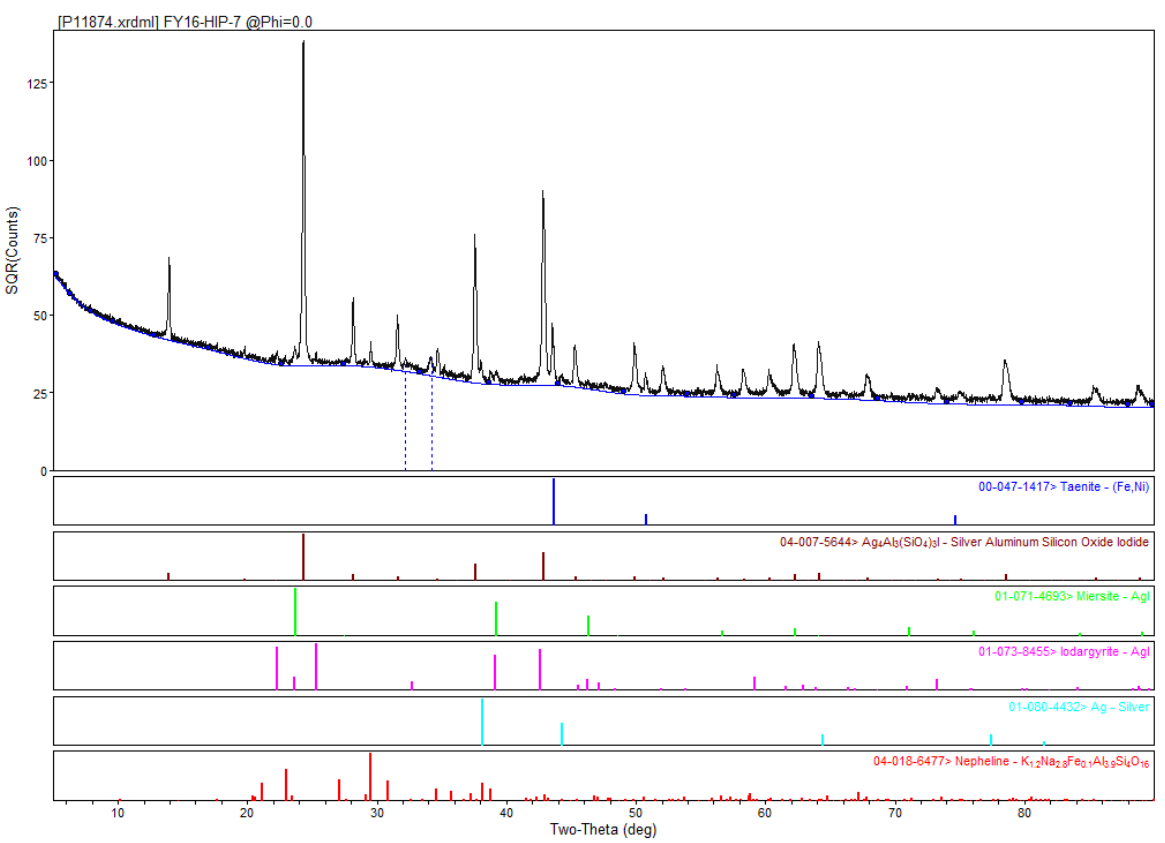

Figure A.7. The XRD pattern obtained from the sample FY16-HIP-7 (AgX| Occluded | 1:14.7 | 300 MPa).

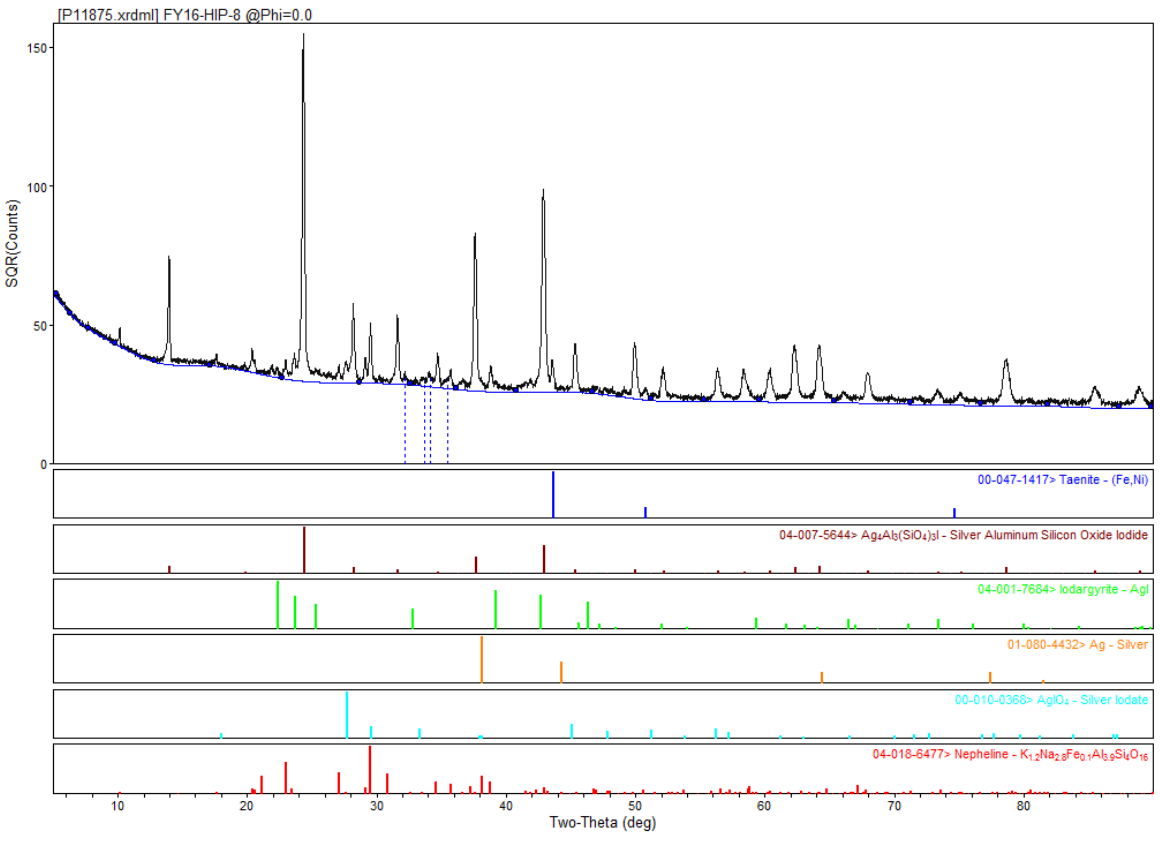

Figure A.8. The XRD pattern obtained from the sample FY16-HIP-8 (AgX | Occluded | 1:14.8 | 300 MPa). 


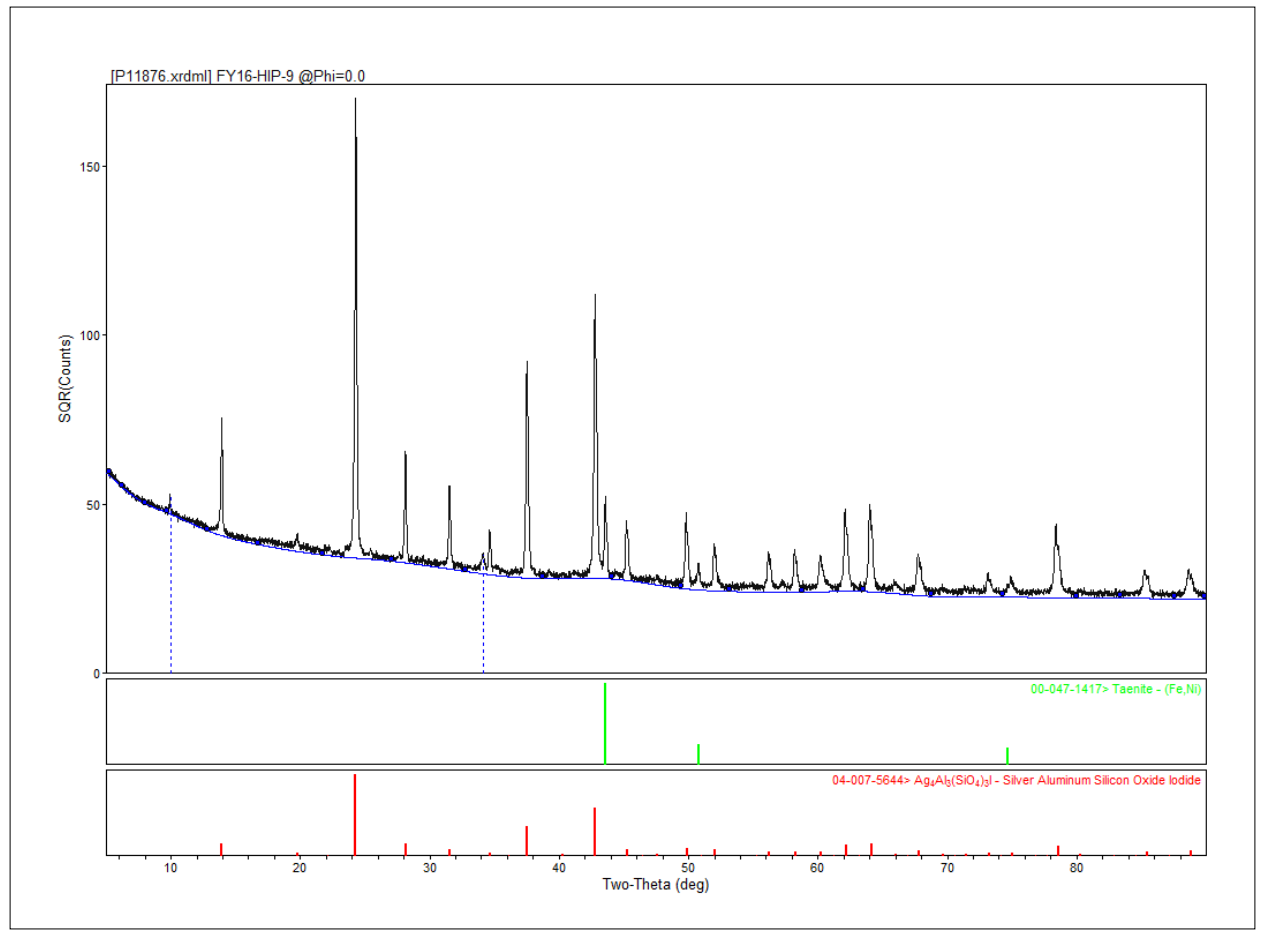

Figure A.9. The XRD pattern obtained from the sample FY16-HIP-9 (AgA | Chemisorbed | 1:0.2 | $175 \mathrm{MPa})$.

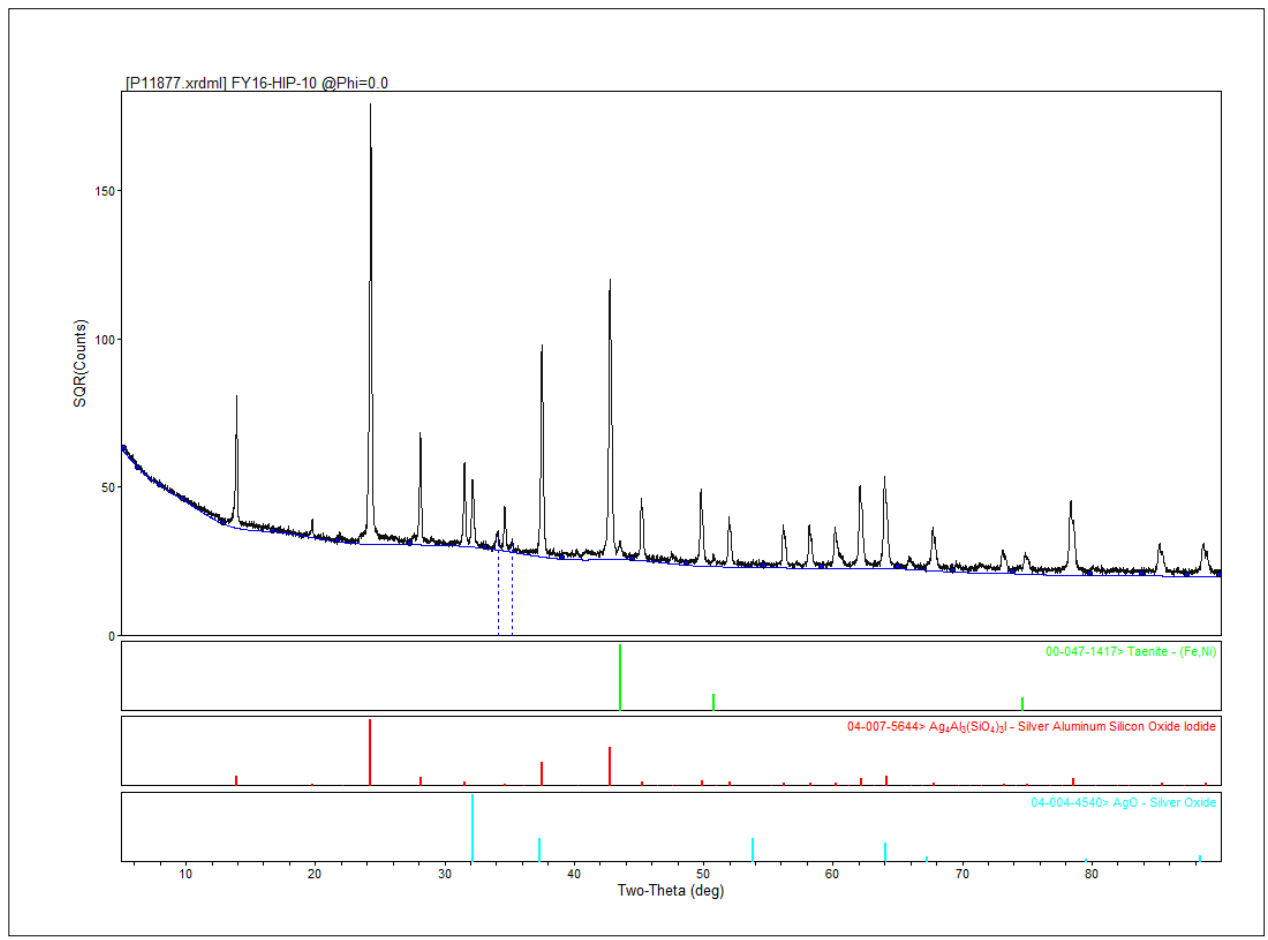

Figure A.10. The XRD pattern obtained from the sample FY16-HIP-10 (AgA | Chemisorbed | 1:0.2 |300 MPa). 


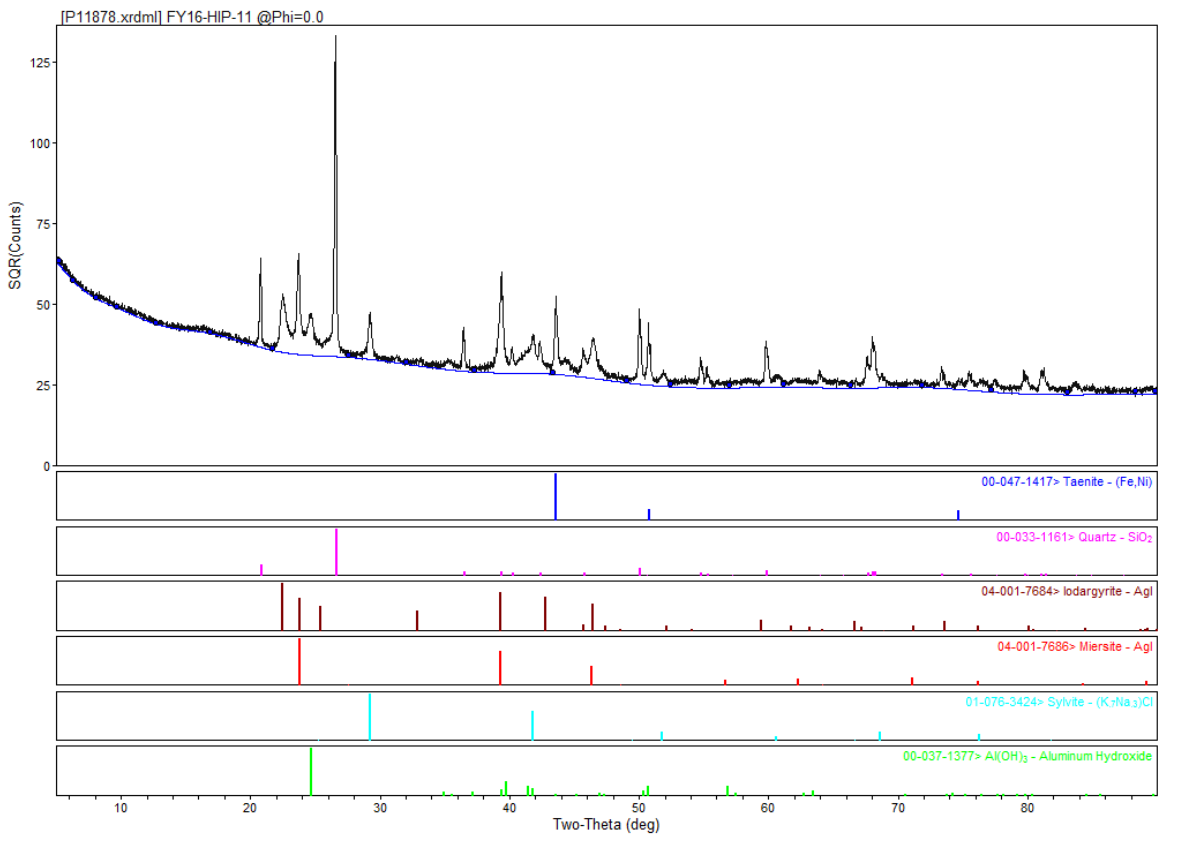

Figure A.11. The XRD pattern obtained from the sample FY16-HIP-11 (AgZ | Chemisorbed | 1:0.2 | $175 \mathrm{MPa})$.

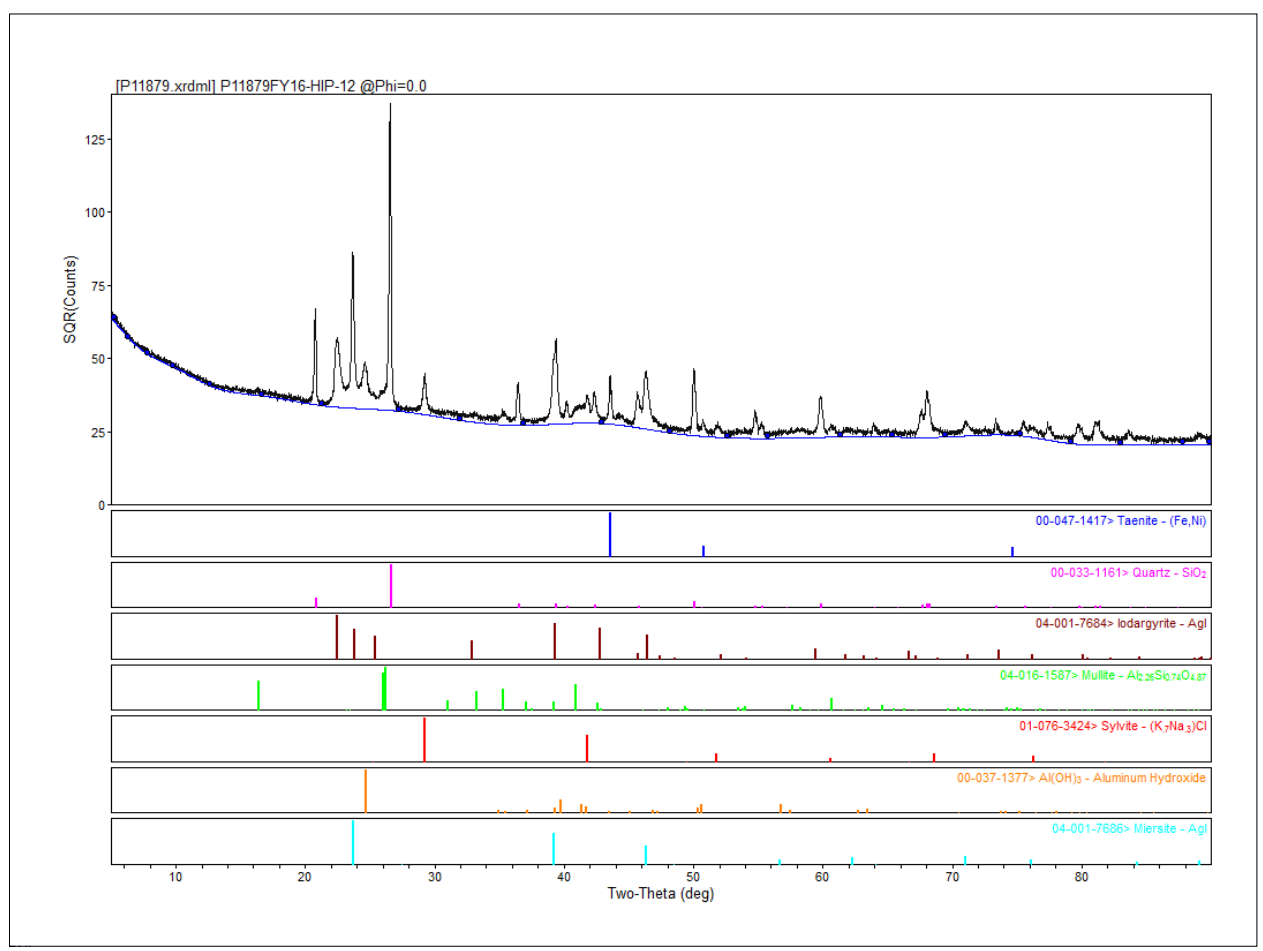

Figure A.12. The XRD pattern obtained from the sample FY16-HIP-12 (AgZ | Chemisorbed | 1:0.2 | 300 MPa). 


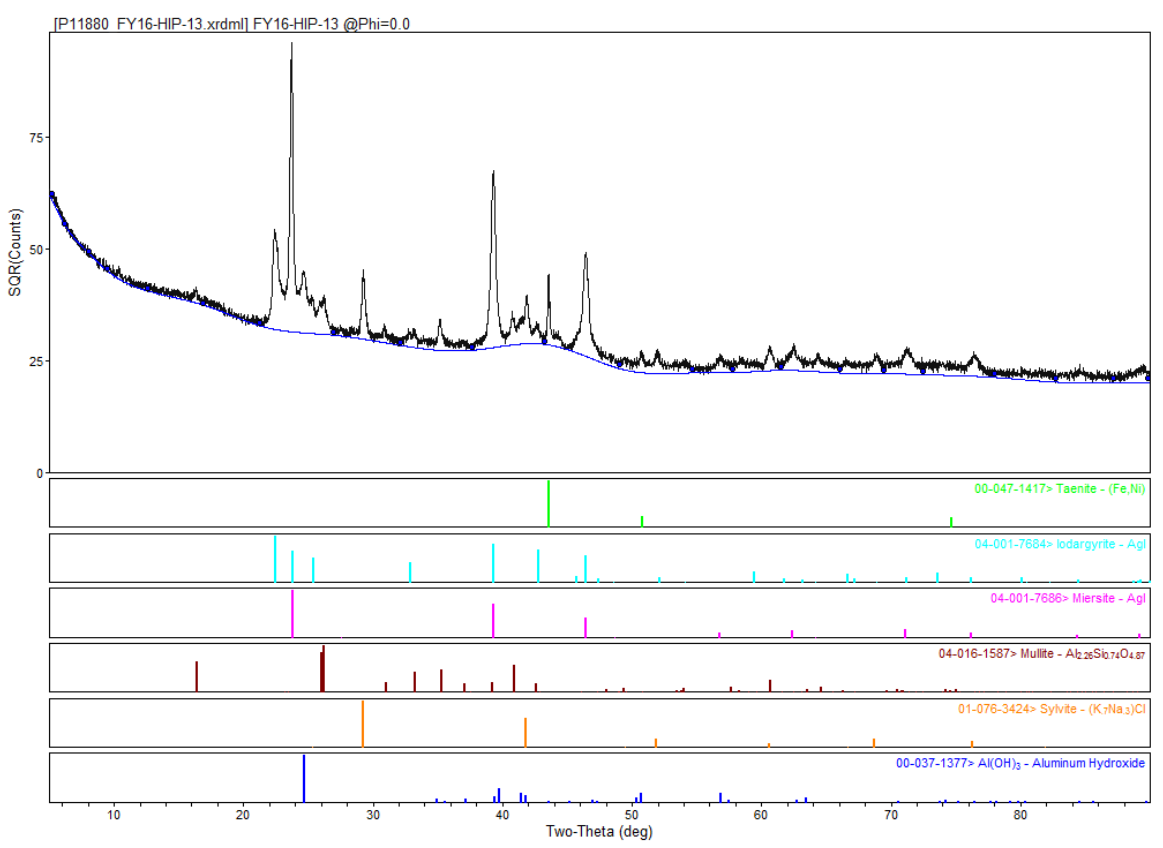

Figure A.13. The XRD pattern obtained from the sample FY16-HIP-13 (AgX | Chemisorbed | 1:2.8 | $175 \mathrm{MPa})$.

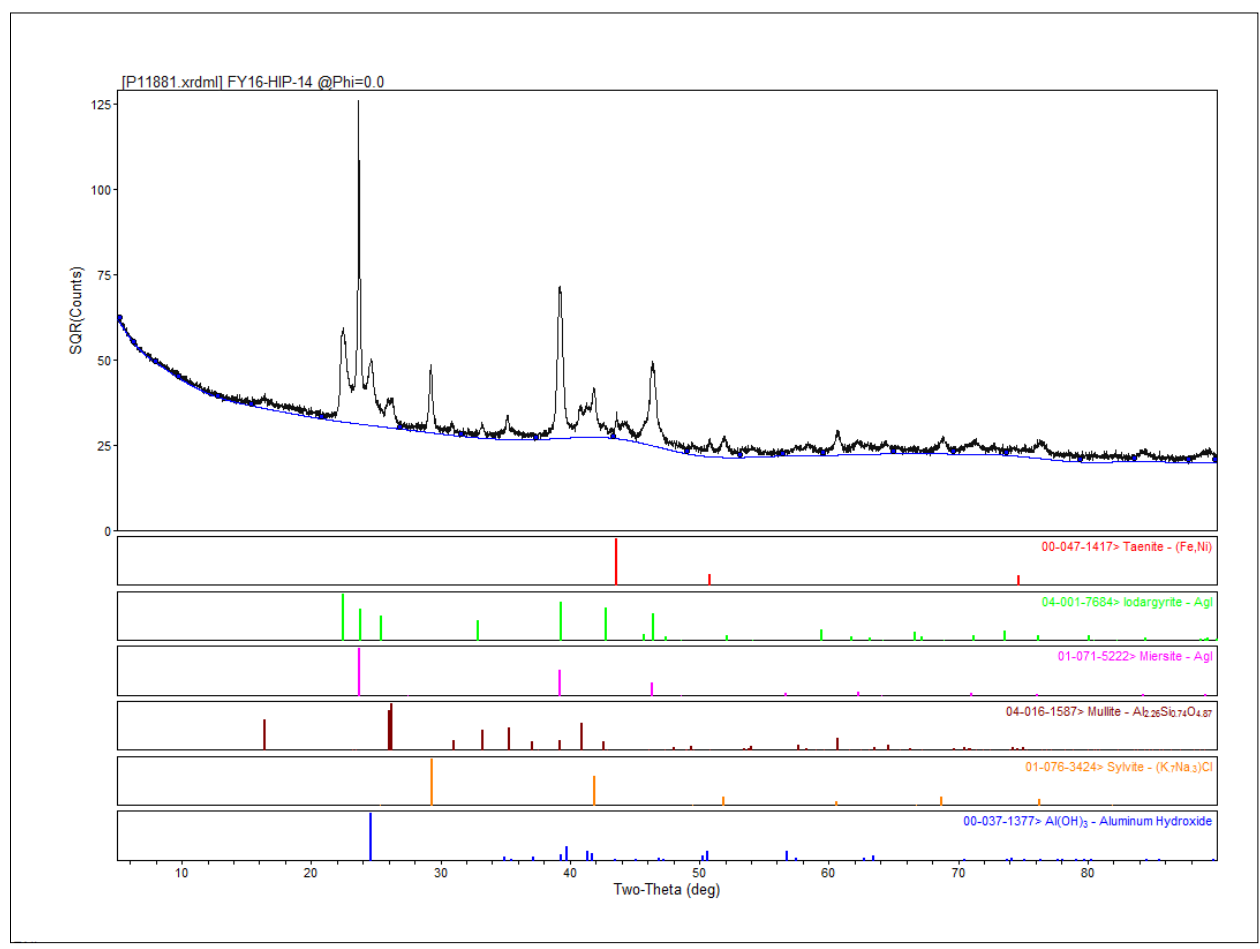

Figure A.14. The XRD pattern obtained from the sample FY16-HIP-14 (AgX | Chemisorbed | 1:2.8 |300 MPa). 
Fundamental Aspects of Zeolite Waste Form Production by Hot Isostatic Pressing A-8

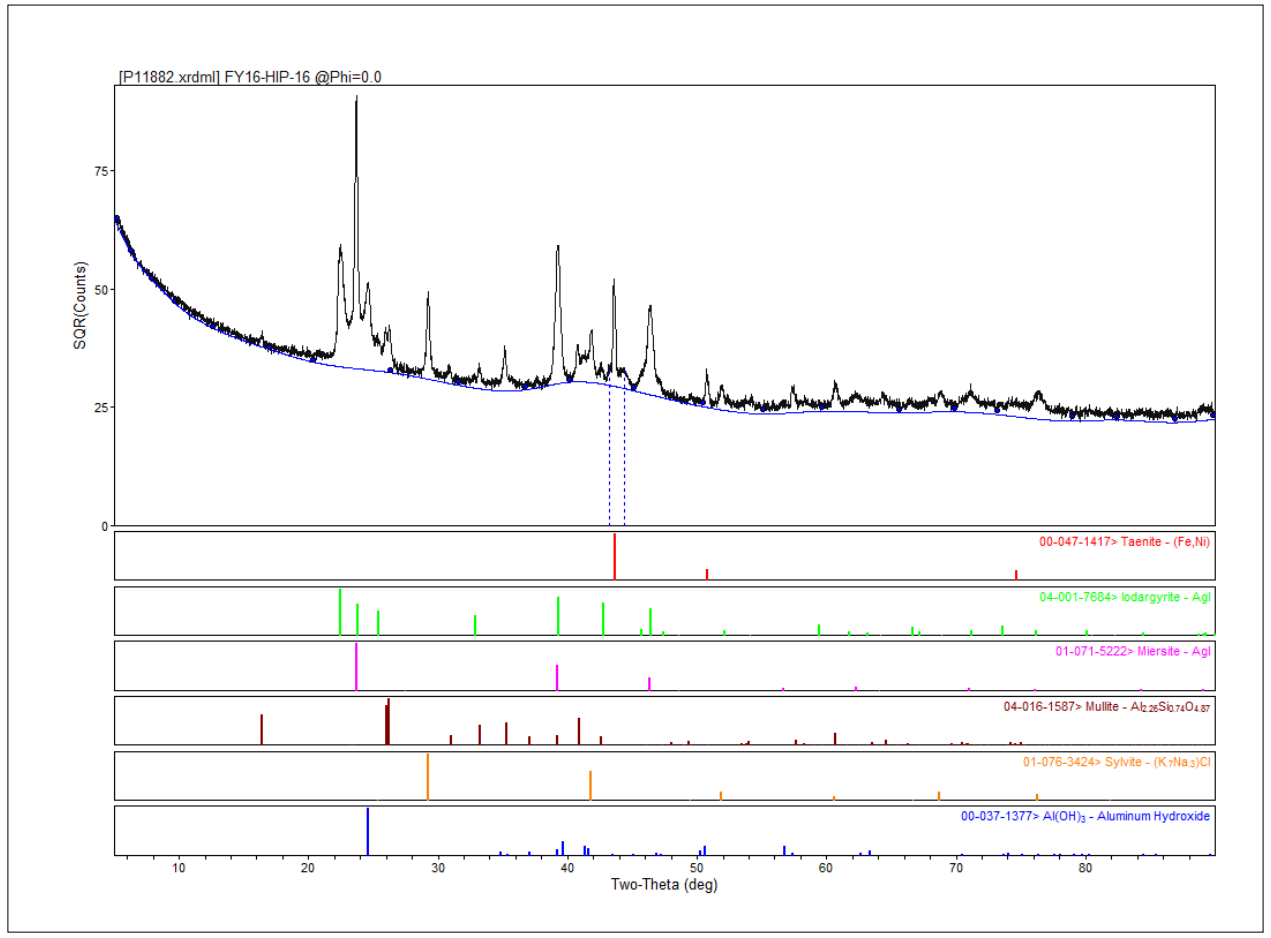

Figure A.15. The XRD pattern obtained from the sample FY16-HIP-16 (AgX | Chemisorbed | 1:2.8 $300 \mathrm{MPa} \mid \mathrm{Al}_{2} \mathrm{O}_{3}$ ). 